\title{
Good Beliefs, Bad Arguments: \\ Pragmatic Reasons in Plato's Dialogues
}

\author{
Edith Gwendolyn Nally \\ Charlottesville, VA
}

M.A. University of Virginia, 2010

B.A. James Madison University, Harrisonburg, VA, 2007

A Dissertation presented to the Graduate Faculty

of the University of Virginia in Candidacy for the Degree of

Doctor of Philosophy

\author{
Department of Philosophy \\ University of Virginia \\ December, 2014
}




\section{INTRODUCTION}

Readers of Plato are often frustrated to find that the dialogues are dotted with strange, unbelievable, and seemingly-invalid arguments. Jonathan Barnes, in his introduction to the Cambridge Companion to Aristotle, goes so far as to take this as a (somewhat tongue-in-cheek) reason to prefer the study of Aristotle. He writes:

Plato's philosophical views are mostly false, and for the most part they are evidently false; his arguments are mostly bad, and for the most part they are evidently bad. Studying Plato will indeed make you realize how difficult philosophy is, and the study has a particular fascination and a particular pleasure. But it can also be a dispiriting business: for the most part, the student of Plato is preoccupied by a peculiar question: How and why did Plato come to entertain such exotic opinions, to advance such outré arguments? ${ }^{1}$

Barnes' problem, although it has not gotten much attention, is central to much of Platonic scholarship. In fact, there is a rather large industry of diagnosing unconvincing arguments in the dialogues - some of the most notable scholarly debates concern the validity of the Third Man Argument in the Parmenides, the Powers Argument in Republic IV, the Slave Boy Demonstration in the Meno, and the so-called "Exquisite" Argument in the Theaetetus (which appears anything but exquisite). Commentators have pointed to a host of false premises or puzzling deductive steps in these and many other of Plato's most enduring arguments.

The question is, when we encounter an unconvincing argument on the part of Socrates, how ought we to interpret it? Scholars tend to adopt one of the following two strategies. The first strategy is to interpret unsound arguments in the dialogues as an oversight either on the part of Plato or on the part of his readers. Many who take this approach apologize for Plato, developing an interpretation which explains the circumstances under which he might have overlooked what would seem otherwise to be a conspicuous puzzle or egregious flaw. ${ }^{2}$ Plato was, after all, only human, wrote in a language very different from our own, and lived nearly 2500 years ago. Others have sometimes preferred to restore a problematic passage to its "original" state. Scholars who

\footnotetext{
${ }^{1}$ Barnes (2007) ix.

${ }^{2}$ Crombie (1962) 26 gives a general statement of this principle, claiming that where we encounter a flawed argument on the part of Socrates we ought to "find an interpretation of it which renders it valid, or at least to reconstruct the valid train of thought the presence of which in Plato's mind allowed the fallacy to pass undetected."
} 
take this tack attempt to draw out implicit premises or other misunderstood details, the goal of which is to produce an interpretation according to which the argument in question turns out to be both valid, sound, and presented as such in the original text. ${ }^{3}$ Of course, this approach has many variants and most end up reconstructing the argument as it "ought" to have been presented, rather than focusing exclusively on how it is actually presented in the original text.

A second (and far less popular) strategy has been to treat Plato's seemingly bad arguments as intentionally bad arguments, meant to confuse and confound. Those who have defended this view think that Socrates sometimes tricks his interlocutors into believing false claims, either as a matter of expediency or as a means of showing his own rhetorical prowess. ${ }^{4}$ Roslyn Weiss interprets the the Slave Boy Demonstration as such, arguing that Socrates advances many of his ill-founded questions to confuse and, thereby, pacify Meno. ${ }^{5}$ George Klosko and Rosamund Sprague have each made a case of this sort for the Euthydemus, claiming that Socrates frequently employs recognized fallacies and false statements in his interaction with the Sophists. ${ }^{6}$

However, in general, scholars have been quite suspicious of this strategy, thinking it improbable that Socrates, a man who gave his life to the pursuit of truth, would avail himself of anything resembling deceptive or misleading rhetoric. ${ }^{7}$ Instead, scholars have tended toward the

\footnotetext{
${ }^{3}$ This approach is so widespread that to quote even a fraction of those who have taken it would be absurd. For a particularly clear example of the extent to which interpreters strive to make Socrates' arguments valid, see the extended debate over the third man argument in the Parmenides (132a1-b2): Vlastos' (1954), Sellars (1955), Strang (1963), Vlastos (1969), Cohen (1971), Cohen and Keyt (1992). For a statement of this very principle in a dialogue that will be of great interest see Scott (2006) 4.

${ }^{4}$ It is worth adding that Leo Strauss (1964) champions an interpretive approach, according to which a careful reader of the dialogues is supposed to pay attention to the "silence and action of Socrates which is not identical with his speech" (60). Strauss was an advocate of a style of interpretation, which took as a fundamental assumption the fact that the dialogues themselves contained important exclusions and deliberate falsehoods. Accordingly, he held that it was the job of the careful and initiated reader to employ his understanding of those deliberately excluded views-about characters, history, political strife, etc.- - in order to discern Plato's own undisclosed views, which could, at times, be radically different from the views expressed in the dialogues. A great deal has been written in disparagement of Strauss' approach (see especially Burnyeat [1985]).

${ }^{5}$ Weiss (2001) 94-107.

${ }^{6}$ Klosko (1987) and Sprague (1962). Guthrie (1975) 246 and Dodds (1959) 242 have noticed that Socrates does from time to time resort to a "wickedly sophistical use of ambiguity", tending to "repay the Sophists in their own coin." Others who have diagnosed Socrates' sophistic tendencies include: Woodbridge (1929): 269-70; Robinson (1942): 101-2; Friedlander (1964) II: 19, 181, 254; Sinaiko (1965) 14-15; Ryle (1966) 119; Gulley (1968) 24, 45; Kahn (1983) 93 and 1996: 110-16, 189, 237; McTighe (1984) 226; Stokes (1986) 34; Teloh (1986) 1-2, 16-18; Klosko (1987); Graham (1992) 152-4; and Beverluis (2000).

${ }^{7}$ See Vlastos (1991) 155, who issues a challenge to insincere interpretations of the dialogues. "None of the scholars who have seriously believed that Socrates employed insincere beliefs or consciously fallacious inferences in these or
} 
first approach, preferring a more "patient" reading of these passages. ${ }^{8}$

Suppose, however, that we could point to instances in which Plato himself seems to be aware of having presented a bad, unconvincing, or unsound argument. Further suppose that, from time to time, Plato pens an admission on the part of Socrates that one of his arguments has been tenuous, unbelievable, or even downright misleading. And, suppose that these cases, although they are not overly-abundant, occur with some frequency in the dialogues. Such evidence would bring about a host of new interpretive problems. Chiefly, what could be the function of these bad arguments? Why include admittedly tenuous, unbelievable, or misleading claims on the part of Socrates?

\section{Unconvincing arguments}

This dissertation shows that such evidence exists - that Socrates is sometimes aware of having presented an unconvincing argument (an argument that is tenuous, unbelievable, or even downright misleading) in defense of his own view. In each of the cases I examine, from the Meno, Phaedo, and Phaedrus, Socrates delivers an argument for his view followed by a "disclaimer" of sorts. In each of these disclaimers, I argue, Socrates hesitates about the preceding line of argument, unwilling to endorse something in what he has just said. For instance, in the Meno (this is the topic of Chapter 1), after having delivered the slave boy demonstration in support of the theory of recollection, Socrates claims (86b6-c2):

On the one hand, at least, I would not put my trust in the other things on behalf of my view; on the other hand, I would contend at all costs in both word and deed as far as I could that we will be better men, braver and less idle, if we believe that one must search for the things one does not know, rather than if we believe that it is not possible to find out what we do not know and that we must not look for it. ${ }^{9}$

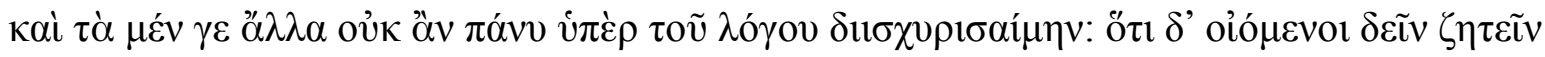

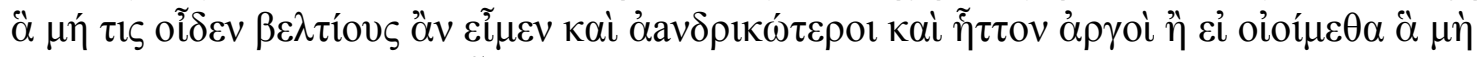

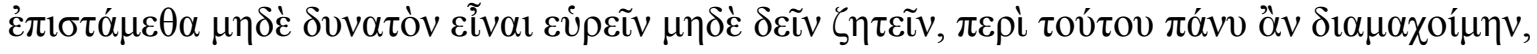

other arguments has ever tried to explain how such infidelity to the quest for truth could be reconciled with Plato's concept of Socratic philosophizing." He adds, if Socrates cheats in his arguments, especially in those that are meant to establish the foundations for deeply important moral truths, it will be difficult to understand Plato's fond remembrance of him as "a man who was of all those we have known the best, and also the wisest and most upright" (Phd. 118a).

${ }^{8} \operatorname{Scott}(2006) 5$.

${ }^{9}$ I follow Cooper (1997) with some changes. 


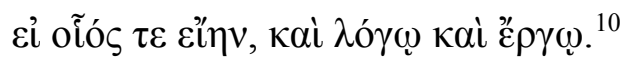

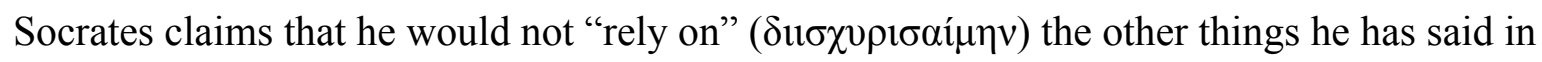
defense of his view. At this point in the dialogue, he has just finished telling Meno about the theory of recollection, and providing him, via the slave boy demonstration, with a proof that recollection can and does occur. So what exactly is it that Socrates is not willing to endorse? What is it about what has been said that Socrates does not find convincing? Similarly, in the Phaedo (this is the topic of Chapter 2), following on the heels of the myth at the end of the dialogue, in which Socrates has just finished describing the hierarchical system of rewards in the afterlife, he again claims that a reasonable person will be unwilling to "rely on" what he has just said (Phaedo 114d). What is it about this passage which a reasonable person will find unconvincing? Finally, in the Phaedrus (this is the topic of Chapter 3), Socrates goes as far as to claim that his preceding speeches contain an example of "misleading" discourse (Phaedrus 262d). This is surprising given that one of these speeches, the palinode, is often heralded as a paragon of middle-Platonic doctrines. What might Plato be disclaiming in a speech that is generally taken to be representative of his own developed philosophical views?

\section{Disambiguating the disclaimers}

Each of these disclaimers presented in the following chapters contains a fair amount of ambiguity. For this reason, one primary focus of this project will be to properly disambiguate each passage. The first task of disambiguation concerns the sentiment expressed in these disclaimers. What exactly is the nature of Socrates' hesitancy about his preceding arguments? Does he think that he has made a mistake? Does he perceive some other kind of weakness? Or is his hesitancy of a more general sort? Perhaps Socrates' disclaimers are simply an act of modesty on the part of Plato? Consider, for instance, the problem often known as the preface paradox. Raised in the mid-century by David Makinson, the preface paradox claims that academic authors (of which Plato was, arguably, the first) tend to preface their works with disclaimers, like "any errors that you find herein are solely my responsibility." " Such statements are often thought to be problematic in that the author has presumably written (and checked) each of the statements in

${ }^{10}$ Ed. John Burnet (1903).

${ }^{11}$ Makinson (1965) 205-7. 
his book and believes each to be true. Simultaneously, however, he has reason to believe that, despite his efforts to rid the book of errors, it is very likely that his book, being of a reasonable breadth and length, will inevitably contain some mistakes. This is paradoxical in that the author appears to have reasons to believe both that his book is free of errors and that it contains some. Although the paradox itself will not be of any interest to us in what follows, it is worth noticing that this problem nevertheless raises a significant interpretive challenge in this context: although Socrates appears to doubt or disclaim something in each of the dialogues in question, he might be no more committed to the presence of any particular, nameable errors in each, than the author who issues such a statement in the preface of his book is committed to the presence of any particular, nameable errors in his work as a whole. The preface paradox, or more precisely, the fact that authors often issue general disclaimers without being committed to there being any nameable flaws in their work, is therefore a constant concern in what follows.

In response to this worry, I shall argue that we have reason to believe that each of Socrates' disclaimers are not a simple act of modesty. In each case, he appears to be looking back to some specific part of the preceding exchange, claiming that he is not willing to fully

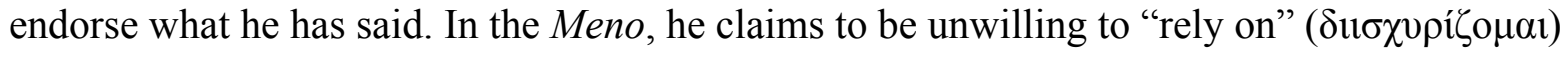
what he has just said. This follows on the heels of the slave boy demonstration. In the Phaedo, he makes a very similar disclaimer (he even uses the same verb) just after delivering the myth about good souls and the rewards that await them in the afterlife. And, in the Phaedrus, we find a disclaimer of an even stronger sort; Socrates claims that portions of his preceding speeches were downright misleading.

The fact that, in each of the disclaimers, Socrates appears to be picking out some portion of the dialogue which he finds unconvincing (or downright misleading) gives rise to a second task of disambiguation. What is it about each of these exchanges that Socrates is unwilling to endorse? What exactly is it that he finds unconvincing? Sometimes the best answer to this question is not as fine-grained as we would hope. At times, the best we can do is point to certain bits of the dialogue to which Socrates is likely referring. Where it is possible, where there is some evidence to go on, I shall try to give a more fine-grained answer, showing what exactly — which premise or deductive step — Socrates finds tenuous or misleading in the 
preceding line of argument.

Ultimately, I take this body of evidence to show that Plato is sometimes himself aware of having given an unconvincing argument on the part of Socrates. Of course, if I am correct in my assessment of these cases, if there are in fact instances in which Socrates is aware of having presented a bad argument in favor of his own views, then a host of other very pressing questions arises. Chief among these is the question of purpose: what purpose do these unconvincing arguments serve in the dialogues as a whole? Why should Socrates present an argument which he does not find convincing only to disclaim it shortly thereafter? And how are we to reconcile the presence of such arguments with the general spirit of Platonic philosophy, known both for its rigor and commitment to truth and honesty?

\section{Non-veridical reasons}

I take the answer to these questions to be closely related to another, rather surprising feature of the passages in question. In each of the cases I have identified, having failed to give a convincing, deductive argument in favor of his view, Socrates seems to invoke a purely pragmatic reason for belief. Despite having failed to give a good argument, one that shows the view in question is likely to be true, Socrates claims instead that the view is good to believe - that believing it will make us better, wiser, or less idle — and that this is grounds enough for believing it. Looking again at the Meno, Socrates claims that, despite the fact that he is unwilling to "confidently assert" the argument he has given, despite being unwilling to stand behind the slave boy demonstration and the argument predicated on it, Meno should nevertheless believe in the theory of recollection (86b-c). Socrates urges Meno to believe his view, not because he has given him a sound argument that recollection actually occurs, but because believing in the theory will make him a better, wiser, and less idle person (86c1-2). Meno should believe Socrates, even in the absence of a convincing argument, insofar as believing it will be good for him. ${ }^{12}$

This is not an isolated incident. A statement of the same form appears in the Phaedo

\footnotetext{
${ }^{12}$ Believing in recollection will make him abandon the eristic paradox, and convince him, once and for all, that he can inquire into what he does not already know. For more on why this is good for Meno, see Chapter 1.
} 
disclaimer: despite the fact that Socrates has delivered an unconvincing argument against the fear of death, he encourages his interlocutors to believe him. Why? Because believing that good souls have nothing to fear in death will be beneficial (114d1-6). Presumably, although Socrates has not proven that good souls fare well in the afterlife, believing as much will encourage his followers to do philosophy and care for their souls, so that they too, when they pass into the next world, might fare well. Similarly, I argue, Socrates' argument in the Phaedrus, which he himself disclaims at $262 \mathrm{~d}$ as "misleading", appears to be driven, at its root, by pragmatic considerations. He delivers the palinode both in order to purge himself of any earlier impiety (which would have been incurred by mimicking Lysias' speech about Love), and, more importantly, as a means of persuading Phaedrus to give up his affiliations with the rhetoricians and to study philosophy instead. In each of these cases, I conclude, despite having given an unconvincing argument, Socrates urges his interlocutors to believe him, because believing him will be of some benefit to them in the long run, making them better, braver, wiser, and fundamentally more sympathetic to a life of philosophy.

It is quite surprising - perhaps even more surprising than the fact that Socrates is aware of his unconvincing arguments - to find Socrates endorsing pragmatic reasons for belief. Simply put, pragmatic reasons do not seem to provide a "veridical basis" for belief. A "veridical basis" is just some reason, argument, explanation, or proof that a given claim is true. Pragmatic reasons are non-veridical (or extra-veridical) reasons, in that they make a claim about what it is good to believe, rather than about the the truth of the claim in question. Generally, we would not expect Plato to give any credence to non-veridical reasons for belief; in the dialogues, it often seems that a person ought to abstain from believing a claim, unless she has veridical basis, a reason, argument, proof, or explanation as to why the claim in question is likely to be true. In what follows, I call this the "veridicity principle", the view that, for Plato, a person ought to believe a claim, $\mathrm{x}$, only insofar as he has a reason for thinking that $\mathrm{x}$ is, in fact, true.

The veridicity principle is highly-motivated. Throughout the dialogues, it often appears that a person ought to believe something only insofar as he has a veridical basis for believing it, only insofar as he has some reason, proof, or explanation for thinking that the claim in question is true or accurate. To give an example, it is this principle, which seems to motivate the elenchus. 
Socrates often subjects an interlocutor's beliefs to careful scrutiny, demanding reasons for thinking a given belief is true and weeding out any inconsistencies. This practice implies that one should only venture to believe a claim if he has a reason to think that it is true or accurate.

Otherwise, if a person has no veridical basis for his belief, he ought to do his best to abstain from believing it. In the Euthyphro, for instance, where Socrates is examining Euthyphro about the nature of piety, he chides him thus (9a1-b3):

Come now, my dear Euthyphro, tell me, too, that I may become wiser, what proof

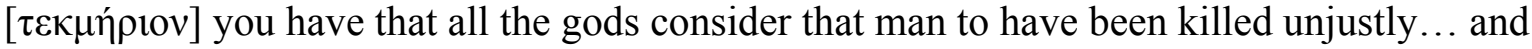
that it is right for a son to denounce and to prosecute his father on behalf of such a man. Come, try to show me a clear sign that all the gods definitely believe this action to be right. If you can give me adequate proof of this, I shall never cease to extol your wisdom. ${ }^{13}$

In this passage, as in many others in the early dialogues, Socrates seems to be pressing his interlocutor for some proof as to why he thinks his belief is correct-in this case, Socrates asks Euthyphro to prove that it is pious to prosecute his own father. Because Euthyphro fails to provide any reasonable defense of his view, because he fails to show that his view is likely to be true, it is implied that he is unjustified in holding his belief.

The veridicity principle is further supported by Socrates' explicit views about false belief. In the Gorgias, Socrates claims that it is better to be refuted than to refute others, because being refuted prevents one from the worst possible fate, harbouring false beliefs (458a3). Again, it looks like, if a belief is unfounded or shown to be false, a person should abstain from believing it. Similarly, in the Phaedo, Socrates goes so far as to say that harbouring false beliefs is bad because it harms the soul. He warns Crito against believing false things. "For", he says, "dear Crito, you may be sure that such wrong words are not only undesirable in themselves, but they infect the soul with evil" (115e5). Although none of these passages is a direct statement of the veridicity principle - that one ought only to believe those things for which he has a veridical basis - this principle follows from the fact that it is bad to believe false claims. It seems that a person ought to venture to believe only those claims which he has a reason to believe are true.

There is a somewhat more direct statement of the veridicity principle in the Republic. Where Socrates is discussing the mathematicians, he claims that many of them are ultimately unjustified in their beliefs, insofar as they merely assume the truth of the axioms of mathematics,

\footnotetext{
${ }^{13}$ This and all other translations are from Cooper (1997), unless otherwise noted.
} 
without articulating any proof or explanation of them $(510 \mathrm{c} 2-\mathrm{d} 1)$ :

I think you know that the students of geometry, calculation, and the like hypothesize the odd and even, the various figures, three kinds of angles, and other things akin to these in each of their investigations, as if they knew them. They make these their hypotheses and don't think it necessary to give any account of them, either to themselves or to others, as if they were clear to everyone.

Plato's disapproval of the mathematicians method is rooted in the fact that they do not investigate the axioms of mathematics themselves. Mathematicians, he claims, merely assume that these principles are true and go about their business conducting proofs. As a result, he later claims the mathematicians are not justified in their beliefs (533b8-c2):

[The Mathematicians], while they do dream about what is, they are unable to command a waking view of it as long as they make use of hypotheses that they leave untouched and that they cannot give any account of.

It looks as if the mathematicians of the Republic are ultimately unjustified in their beliefs in that they leave the first principles of mathematics "untouched". They cannot defend the truth of the first principles from which they conduct proofs and draw conclusions. Here again, we find a statement of something like the veridicity principle. Because the mathematicians cannot give an account of the principles of mathematics, because they cannot show that these principles are true, it seems that they are unjustified in their beliefs.

In each of these passages, then, it looks like a person ought only to believe a claim insofar as she has a veridical basis - some proof, explanation, or account as to why this claim is, in fact, true. To put this principle in a slightly different way, we would expect Plato to think that a reasonable person ought only to form beliefs based on the strength of his conviction that the belief in question is true. If a person has no veridical basis for a belief, if she has no reason to think that it is in fact true, then, presumably, she ought to abstain from believing it.

If I am correct, however, if the arguments of Chapters 1 to 3 are correct, then there are cases in which Plato gives credence to purely pragmatic reasons for belief. There are cases in which Plato endorses reasoning of the form: "It is good to believe $\mathrm{x}$, therefore you ought to believe x." This is a rationale which seems to give little thought to truth and accuracy. It follows 
that the veridicity principle, no matter how well it is supported in other parts of the dialogues, is not universally operative.

These results give rise to as many pressing questions as the disclaimers themselves raise. How does this sort of rationale fit with Plato's commitment to the discovery of truth? Why, for Plato, if we are ultimately interested in discovering the true nature of things, ought we sometimes believe what it is good for us to believe? And why, if pragmatic reasons are sufficient for belief, does he ever go to the trouble of presenting arguments for the truth of the conclusion in question? Why not simply give pragmatic reasons, insist that this is sufficient justification for belief, and move on? Each of the following chapters takes up these questions in addition to the above questions about the function of unconvincing arguments in the context of Plato's overall philosophical project. What, indeed, are these pragmatic reasons, preceded by unsound arguments, doing in the dialogues? And how are we to reconcile this body of evidence with the explicit methods and goals of Platonic philosophy - the pursuit of truth through careful argumentation?

\section{Thesis}

To anticipate, I shall argue that, in each of the above cases, from the Meno, Phaedo, and Phaedrus, Socrates maintains his views without a veridical basis for doing so. In each, Socrates issues an argument or claim for his view, which he recognizes as weak, unconvincing, or even false. He then disclaims his argument and endorses his view on seemingly pragmatic grounds: one ought to believe him, because believing him will be good or beneficial to believe. We have seen, however, that this is quite perplexing - for Plato, one ought to accept only those claims which he has some reason to think are true. In addition to presenting the above body of evidence, this study will advanced an argument in response to this problem, as to why Socrates might be justified in employing such non-veridical reasons. There are, I will argue, a certain limited class of false claims, which, insofar as they justify and motivate philosophical inquiry, will be good or appropriate to believe, even if they turn out to be false or inaccurate. Claims of this sort, insofar as they are beneficial to believe even if they are false, will not be harmful to the soul in the way of other falsehoods. For this reason, I argue, it is appropriate to believe such claims on 
non-veridical grounds: they motivate a person to study philosophy, and, therefore, do not harm the soul in the way that other falsehoods might. 


\section{WORKS CITED}

Barnes, A. 1997. Seeing Through Self-Deception. Cambridge: Cambridge UP 4-17. 2007. The Cambridge companion to Aristotle. Cambridge: Cambridge UP.

Beversluis, J. 2000. Cross-examining Socrates a defense of the interlocutors in Plato's early dialogues. Cambridge UP, [Online].

Crombie, I. M. 1962. An Examination of Plato's Doctrines. New York: Humanities Press.

Cohen, S. M. 1971. The Logic of the Third Man. The Philosophical Review, 80(4), pp. 448-475.

Cohen, S. M. and Keyt, D. 1992. Analyzing Plato's Arguments: Plato and Platonism. In J.

Klagge \& N. Smith (eds.).

Dodds, E. R. 1959. Gorgias. Oxford: Clarendon Press.

Friedlander, P. 1964. Plato. 2, The dialogues, first period. London: Routledge \& Kegan Paul.

Graham, D. W. 1992. Socrates and Plato. Phronesis, 37: 141-165.

Gulley, N. 1968. The philosophy of Socrates. London: St. Martin's P.

Gutherie, W. K. C. 1975. A History of Greek Philosophy: Plato, the Man and His Dialogues, Earlier Period. Cambridge: Cambridge UP.

Kahn, C. H. 1983. Drama and Dialectic in Plato's Gorgias. Oxford Studies in Ancient Philosophy, 1996. Plato and the Socratic dialogue: the philosophical use of a literary form. Cambridge; New York: Cambridge UP.

Klosko, G. 1987. Plato and the Morality of Fallacy. The American Journal of Philology, 108: $612-626$.

Makinson, D. C. 1965. The Paradox of the Preface. Analysis 25:205-207.

McTighe, K. 1984. Socrates on Desire for the Good and the Involuntariness of Wrongdoing:

"Gorgias" 466a-468e. Phronesis, 29(3), 193-236.

Plato. 2007. In J. COOPER M. and D.S. HUTCHINSON, eds, Plato: Complete Works.

Indianapolis, Ind: Hackett Pub.

Plato. 1903. Platonis Opera, ed. John Burnet. Oxford: Oxford UP.

Robinson, R. 1942. Plato's Consciousness of Fallacy. Mind, 51(202), 97-114.

Ryle, G. 1966. Plato's progress. Cambridge: Cambridge UP

Scott, D. 2011. Philosophy and Madness in the Phaedrus. Oxford Studies in Ancient Philosophy. 
2006. Plato's Meno. Cambridge: Cambridge UP

Schofield, M. 2006. Plato: political philosophy. Oxford; New York: Oxford UP.

Sellars, W. 1955. Vlastos and "The Third Man". The Philosophical Review, 64(3), 405-437.

Sinaiko, H. L. 1965. Love, knowledge, and discourse in Plato; dialogue and dialectic in

Phaedrus, Republic, Parmenides. Chicago: University of Chicago Press.

Sprague, R.K. 1962. Plato's use of fallacy; a study of the Euthydemus and some other dialogues.

London: Routledge and K. Paul.

Stokes, M.C. 1986. Plato's Socratic conversations: drama and dialectic in three dialogues.

Baltimore: Johns Hopkins UP.

Strauss, L. 1964. The city and man. Chicago: Rand McNally.

Teloh, H. 1986. Socratic education in Plato's early dialogues. Notre Dame: University of Notre Dame Press.

Vlastos, G. 1954. The Third Man Argument in the Parmenides. The Philosophical Review, 63(3), 319-349.

1969. Plato's "Third Man" Argument (PARM. 132A1-B2): Text and Logic. The

Philosophical Quarterly, 19(77), 289-301.

1981. Platonic Studies. Princeton: Princeton UP, 3-42.

-1991. Socrates, ironist and moral philosopher. Ithaca, N.Y.: Cornell UP.

Weiss, R. 2001. Virtue in the Cave: Moral Inquiry in Plato's Meno. New York: Oxford University Press.

Woodbridge, F. J. E. 1929. The son of Apollo; themes of Plato. Boston; New York: Houghton Mifflin Company. 


\section{CHAPTER ONE: THE MENO}

\section{The puzzle: Meno 86b6-c2}

This chapter concerns a puzzling passage at the end of the slave boy demonstration. Because this passage occurs in the middle of the dialogue, I begin with a summary of the exchange preceding it. Midway through the Meno, having given three failing definitions, Meno starts to question whether an inquiry into the nature of virtue is even possible. In his frustration, he introduces a pair of paradoxes. The first of these, referred to as "the paradox of inquiry", asks how one can begin to inquire after an entity which he does not already know (80d5-6). ${ }^{14}$ The worry is that a person who is not familiar with something cannot begin to investigate it. For, if one is unfamiliar with the nature of the thing in question, he is not able to set about investigating what it is. ${ }^{15}$ If this paradox holds, then Meno's failure to meet Socrates' demand for a definition of virtue is understandable. It would be impossible for Meno to produce a definition of something that he does not already know. His second paradox, "the paradox of discovery", concerns the way in which discoveries are verified. It asks how one can know that, once he has discovered a potential answer to the question at hand, it is the very thing for which he began to search in the first place (80d6-7). This second paradox shows that even if Meno were to stumble upon a correct definition of virtue, he and Socrates may not have the wherewithal to recognize it.

In the lines that follow, Socrates takes up these paradoxes, reformulating Meno's challenge as follows (80e1-5):

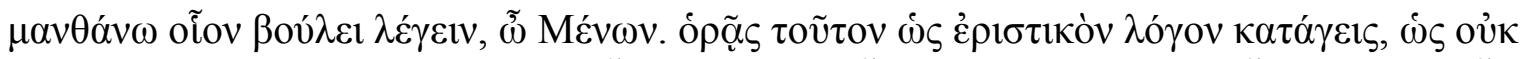

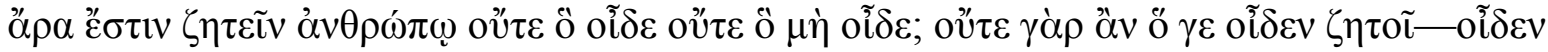

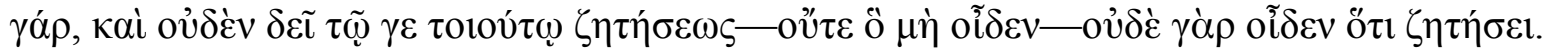

I know what you want to say, Meno. Do you realize what an eristic argument you are bringing up, that a man cannot search either for what he knows or what he does not know? He cannot search for what he knows - since he knows it, there is no need to search-nor for what he does know, for he does not know what to look for. ${ }^{16}{ }^{17}$

Acerding to Seras introduced an "eristic argument", a common mode of

${ }^{14}$ Dominic Scott (2006) 76 notices that what is generally referred to as "Meno's paradox" is in fact a pair of paradoxes.

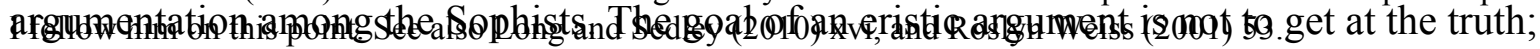

${ }^{15}$ Scott (2006) 76-77 notes the extreme nature of the paradox: one cannot begin to investigate something that he does not know at all. It should be noted that Fine (2014) 32-4 carefully reconstructs this challenge in a different way: one cannot know anything about $\mathrm{x}$, if he does not know what $\mathrm{x}$ is. 
rather it is to dominate a conversation and bring prestige to the speaker. ${ }^{18}$ Arguments of this sort generally turn on a confusion, equivocation, or subtle error. The bite of this particular argument lies in the assumption that one either knows completely the topic at hand, or else not at all. If a person already has complete knowledge of the topic, he will not need to inquire into its nature. And if he knows nothing at all of the topic, he will be unable to begin to investigate it. This creates a stalemate of sorts. Because a person either knows completely or not at all, it is supposed to follow that all inquiry is impossible.

Meno wonders whether Socrates thinks the eristic argument is a good one (81a1). Socrates replies that it is not, and introduces the theory of recollection, claiming to have heard from wise priests and priestesses that the soul is immortal and that it has knowledge of everything while in the afterlife (81a-b). Once a soul is reincarnated, he claims, it is capable of recollecting what it does not know at present $(81 \mathrm{~b})$. Socrates further claims that believing the eristic argument, that we cannot know what we do not already know, will make us idle (81d). Believing in the theory of recollection, by contrast, will make us more energetic and inquiring (81e). Here, at the end of his exposition of the theory of recollection, Socrates seems to gives a pragmatic reason to believe it; whereas believing the eristic argument will make a person lazy, convincing him of the impossibility of intellectual inquiry, believing in the theory of recollection will set him on a better path, encouraging him to inquire after and discover what he does not already know.

Meno is skeptical of recollection, however. He asks Socrates to prove that what he has said is true, that the theory of recollection is in fact an account of how we come to know (81e3-82a4). In response, Socrates undertakes the slave boy demonstration. As he questions the boy, he constructs the following dilemma: Either the boy has been taught the answers to the questions Socrates asks (whether it be by someone in Meno's household or by Socrates at present) or else the boy must be calling back to mind something that he already knows (82e4,

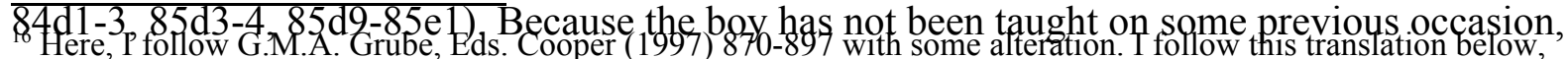

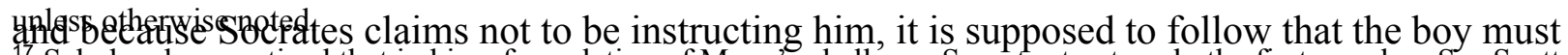
"Scholars have noticed that in his reformulation of Meno's challenge Socrates treats only the first paradox. See Scott

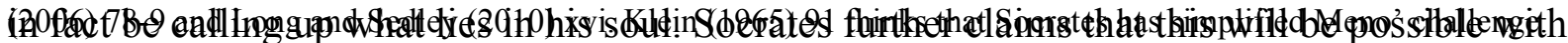
John Thomas (1980) 123 and Nehamas (1994) 228 observe that Socrates leaves out "to parapan" in his formulation of nespatit all kinds of knowledge. Whatever a person does not know at present, he can endeavor ${ }^{18}$ Irwin (1995) 585 is helpful on the nature of eristic. See also Klosko (1987) 616, who speaks of agonistic debates in which Socrates would not have felt the need to uphold the mandates of philosophical dialogue. 
to recollect (85d2-86b3). It follows that we ought not to give in to the eristic argument (86b1-3). We ought to endeavor instead to recollect all that we do not already know.

This brings us to the puzzle which will be the focus of this paper. At the end of the slave boy demonstration, Meno agrees that what we call learning is really just recollection, and that we ought, therefore, to endeavor to inquire into that which we do not presently know. Yet his assent is tinged with uncertainty: "To say this seems right to me, Socrates, I don't know why" (عṽ $\mu$ or

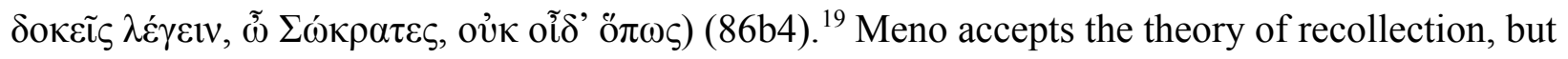
does not quite understand why. What happens next is very surprising: Socrates responds in a somewhat hesitant way. Where we would expect Socrates to reassure Meno, standing behind his argument for the theory of recollection, he gives the following disclaimer instead (86b6-c2):

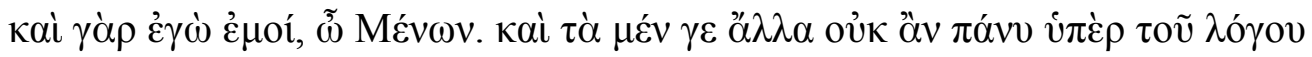

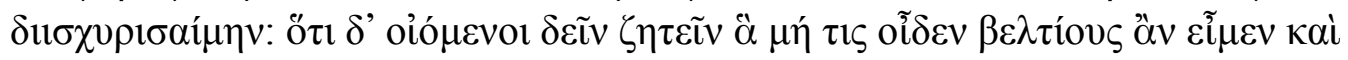

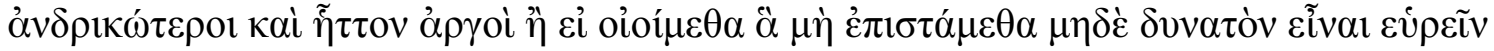

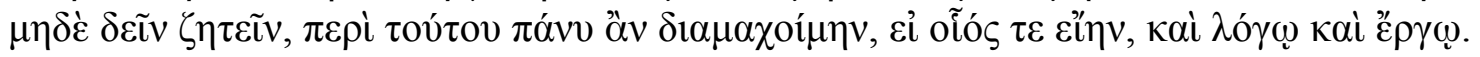

And so it seems to me, Meno. On the one hand, at least, I would not altogether confidently affirm the other things on behalf of my argument; on the other hand, I would fight at all costs in both word and deed as far as I could that we will be better men, braver and less idle, if we believe that one must search for the things one does not know, rather than if we believe that it is not possible to find out what we do not know and that we must not look for it. $^{20}$

In the first line of this passage, which I refer to throughout as "the disclaimer", Socrates sympathizes with Meno's belief that what has been said seems true, saying "And so it seems to me, Meno." In the lines that follow, however, he sets up a somewhat surprising opposition. On

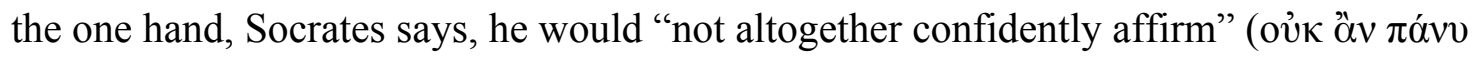
$\delta ı \sigma \chi v \rho ı \alpha \alpha i \mu \eta v)$ the "other things" ( $\left.\tau \dot{\alpha} \alpha \alpha^{\prime} \lambda \lambda \alpha\right)$ which have been put forward "on behalf of the

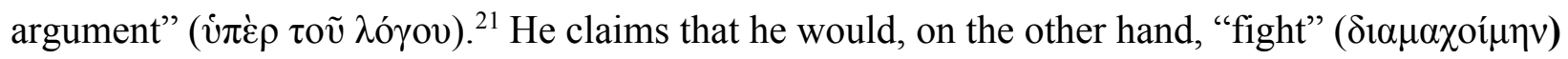
in both word and deed for the pragmatic claim that we will be better and braver if we believe that we can search for what we do not already know. ${ }^{22 \mid 23}$ What are we to make of this opposition and Socrates' hesitancy? What does he mean when he says that he would "not altogether confidently

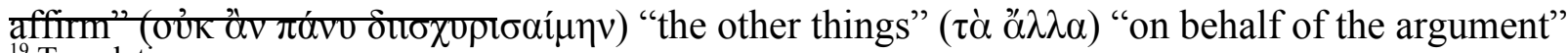
${ }_{19}$ Translation my own.

${ }^{20}$ Here I follow Grube (1997) with a number of substantial changes. 


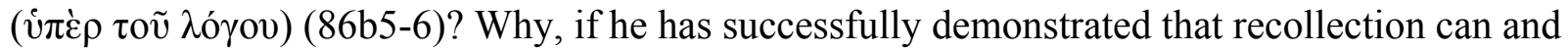
does occur, does Socrates only seem willing to stand behind the pragmatic reason he has given?

In what follows, I explore the ambiguities of the disclaimer at 86b6-c2 in more detail. My argument proceeds in four parts. In the first part, I discuss what has been said about the disclaimer passage in the literature. Scholars have assumed, largely in passing, that the disclaimer must refer to the esoteric, religious and metaphysical details included alongside Socrates' initial exposition of the theory of recollection. ${ }^{24}$ They think Socrates must be uncomfortable asserting firmly that the soul is immortal, reincarnated or that it can quite literally recollect what it does not already know. This interpretation seems, I shall argue, to be motivated by a contemporary bias against such a strange and outmoded metaphysics. In the second part, I argue for an alternative interpretation. Socrates is not disclaiming the esoteric metaphysical details of the theory of recollection, so much as expressing a lack of confidence in the proof of his theory. By examining the logical structure of the disclaimer passage, I show that what Socrates is unwilling to "altogether confidently affirm" must in fact be the demonstration argument- he is unwilling to stake his case for the theory of recollection on the argument which arises out of his exchange with the slave boy. In the third part, I discuss a number of possibilities as to why Socrates is not willing to "confidently affirm" this argument. And, finally, in the fourth part, I discuss the pragmatic reason, that believing in the theory of recollection is a good thing to do. It is surprising, I will argue, given Socrates' unwillingness to stake his case for recollection on the demonstration argument, an argument which purports to show that recollection is the true account of how we come to know, that Socrates should nevertheless encourage Meno to believe the theory on purely pragmatic grounds.

\section{Disambiguating the disclaimer: common approaches to 86b5-6}

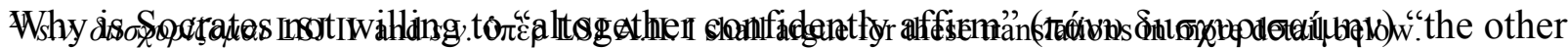

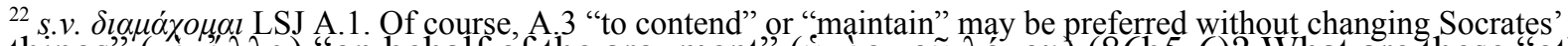

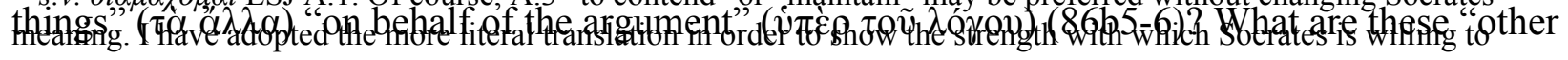

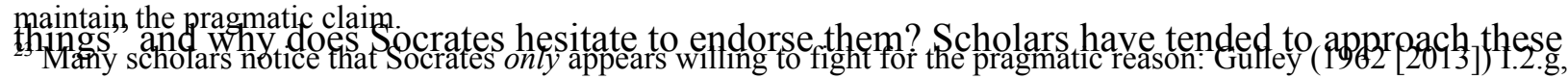

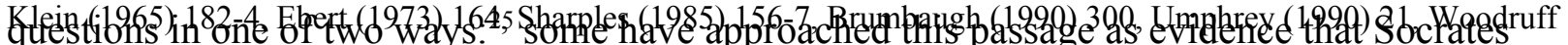
(1990) 82; Fine (1992) 214; Scott (2006) 121-2; Weiss (2001) 122-6; Ionescu (2007) 24, 48; and Bluck (1961 [2010]) elbes not believe anything of the theory of recollection or the slave boy demonstration. ${ }^{26}$ In what ${ }^{24}$ Below I discuss Bluck (1961 [2010]) 318, Fine (1992) 214, and Sharples (1985) 156-7. See also: Scott (2006) 121-2 (and n.12 below) and Ionescu (2007) 24, 48. 
follows, I refer to this as "the red herring view". However, the majority of scholars take a second tack, treating the disclaimer passage as a relatively minor admission on the part of Socrates that the theory of recollection rests on a number of bizarre and cursory metaphysical claims, about the soul and its reincarnation. Scholars in this camp do not take the theory of recollection literally; rather, they treat it as a hypothetical account or as a bare-bones metaphysical scenario, intended to show that we can in fact inquire after and discover what we do not already know. ${ }^{27}$ This section examines each of these views in detail. I conclude that both views are ultimately unsatisfying and ill-fitted to the text of this part of the dialogue, and, in the next section, I present an alternative.

\section{The Red-Herring View}

Roslyn Weiss has taken the disclaimer at 86b5-6 as support for the view that Socrates' response to the eristic argument - from the introduction of the theory of recollection to the end of the slave boy demonstration - is largely insincere. It is her view that Socrates introduces the theory of recollection in order to convince Meno to drop the eristic argument. This whole part of the dialogue is, on her view, little more than an argumentative expedient, a series of red herrings thrown in Meno's path so that he will return his focus to the question of virtue. Weiss summarizes her treatment of this part of the dialogue as follows:

$[\mathrm{N}]$ either the recollection thesis, as a general account of how knowledge is acquired, nor the metaphysical notions that undergird it are Socrates' own beliefs. ...[H]is development of, first, the myth and, then, the slave-boy-demonstration constitutes his fight "in word and deed" $(M .86 \mathrm{c} 2-3)$ for the value of moral inquiry. As Socrates makes clear, what recommends the view that all knowledge comes by recollection is that it makes good men of its adherents, whereas the alternative view, Meno's paradox, makes bad men of those who

${ }^{25}$ Therthisctibestople ther interpretation I do not discuss here. Gulley (1962 [2013]) I.2.g claims that this passage ought to be read as expressing Plato's own doubts, not Socrates', about the theory of recollection, which he has only just begun to explore as proof of his theory of knowledge.

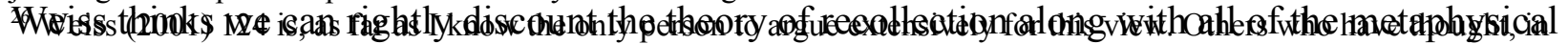
passing, that Socrates means to disclaim the theory of recollection in some capacity include: Gulley (1962) [2013]) n.2.jo,

${ }^{27}$ Bluck (1961 [2010]) 318-9, Fine, (1992) 214 and Sharples. (1985) 156 7. Scott (2006) 121 -5 does not fit as neatly

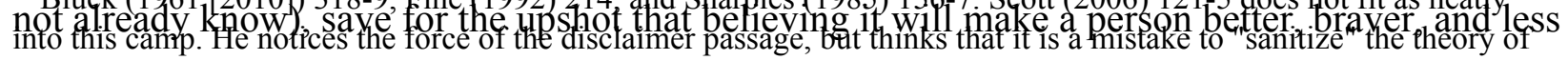

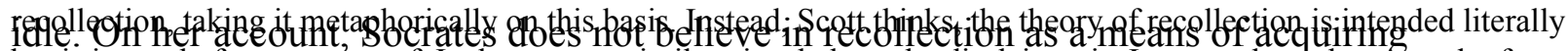
but is in need of stronger proof. I adopt a very similar view below: the disclaimer is, I argue, about the strength of proof

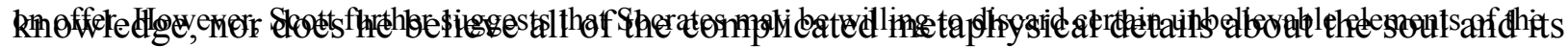
theory of recollection, i.e. reincarnation, while maintaining that recollection and immortality ought to be taken seriously. With regards to this suggestion - that what Socrates means to disclaim are certain features presented 
journey into the afterlife. All he is willing to maintain of this section of the dialogue is the underlying "moral" that we will be better off if we reject the eristic argument.

Weiss bases her view on a number of details, which, she claims, show that Socrates should not be taken seriously in this part of the dialogue. Among these she includes the fact that Socrates presents recollection, a very complex view, in a myth without any further explanation; ${ }^{29}$ that he "puts his trust in" the view for its practical value, not because it is true; ${ }^{30}$ and that the story he tells clearly appeals to Meno's vanity and interests. ${ }^{31}$ In particular, she claims that the myth ought not to be taken seriously insofar as it resembles Pythagorean doctrine. ${ }^{32}$ Yet none of her arguments offers substantive proof that Socrates (or Plato) does not take the theory of recollection seriously. Plato often has Socrates introduce complex metaphysical claims in myths. ${ }^{33}$ It would be unwise to discount anything on this basis alone. It would be equally unwise to discount any claim that Socrates makes without further explanation. He sometimes sets out elliptical summaries of views that we can only assume would have been recognizable philosophical theses. ${ }^{34}$ That a view is introduced quickly and without much explanation is, at least on its face, not a reason to suspect that Socrates is being disingenuous; rather, it seems to be a good reason to assume that those participating in the conversation, whether it be the named interlocutors or Plato's larger audience, are expected to have some familiarity with the view in question. Furthermore, that Socrates endorses the theory of recollection for its practical benefit but not for its truth is correct only if we limit our focus to the discussion following the myth. As we shall see below, at the start of the recollection myth, Socrates commends recollection both for its truth and provenance. Finally, that the myth appeals to Meno's interests and vanity does little to show that Socrates does not take recollection seriously. In the Phaedrus, Socrates reports that a practitioner of artful dialectic will know how to tailor his arguments to the soul of his interlocutor. ${ }^{35} \mathrm{~A}$ skilled speaker will be adept at appealing to the interests of his audience. It seems misguided, therefore, to assume that an argument that is tailored to Meno's interests must be a devious or unserious one. It may simply be one that is delivered by an adept speaker, Socrates.

By contrast, there are a number of features of this part of the dialogue, which suggest that 
possibility of inquiry and discovery. ${ }^{36}$ Consider, first, the context in which Socrates introduces the theory. He brings up recollection as a view that is at odds with the eristic argument. Just after he reformulates Meno's challenge- either one knows something completely and does not need to inquire or else he does not know it at all and cannot even begin to inquire-Meno asks whether Socrates thinks this is a good argument (81a1). ${ }^{37}$ Socrates replies that it is not (81a2) and immediately proceeds to introduce the myth (81a4). It is natural to read this exchange as proof that Socrates introduces recollection in order to expose some weakness in Meno's challenge.

In addition, the exposition of the theory contains a number of indications that Socrates views recollection, at the very least, as a plausible view. He claims that the doctrine he is about

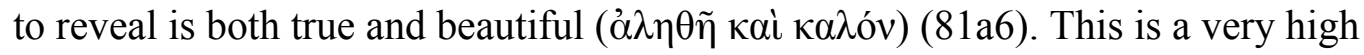
recommendation, one that is hard to make sense of if Socrates has introduced recollection as a red-herring or argumentative expedient intended to get Meno back to the question of virtue. Weiss, on her reading, is forced to take Socrates' recommendation of the view as "true and beautiful" to apply only to "the moral lesson that follows from the immortality and rebirth of the soul", that we will be better, braver, and less idle if we believe it. ${ }^{38}$ This is quite a stretch. Socrates seems to praise the doctrine that he is about to reveal, not merely the moral lesson that follows from it.

It is also notable that, in the first line of the myth, Socrates claims to have heard about recollection from a number of wise priests and priestesses, who studied so as to be able to defend

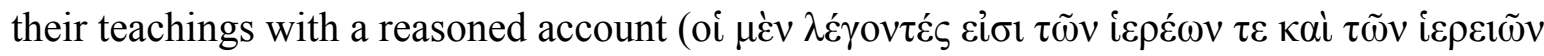

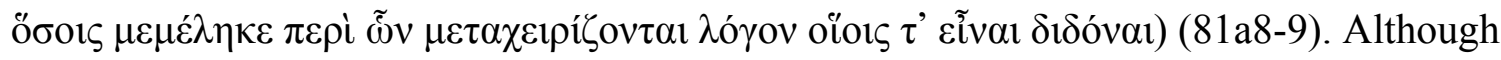
Socrates is reporting the doctrine secondhand, as hearsay, the fact that those from whom he learned were able to give a logos of their teachings is, it seems, a way of suggesting that what follows is a defensible view. This is especially suggestive in that, in the Meno, the difference between true opinion and knowledge consists in whether or not a person has a logos, a reasoned account of what that which he claims to know (98a). ${ }^{39}$ That those who defend the theory of recollection had a logos supporting their view may, therefore, suggest that Socrates sees them as wise, possessing a reasoned account of how we come to have knowledge. Indeed, these details in

${ }^{29}$ Ibid. 64. She cites others (n.36) who have thought this suspicious: Ebert (1973) 177; Rohatyn (1980) 71; Ryle (1976) 9; and Brumbaugh (1990) 300. See also Weiss (2001) 69-71, where she discusses the "slipshod presentation of the myth". 
the presentation of the theory of recollection weigh heavily in favor of the view that Plato regards it, at the very least, as a plausible account.

Perhaps the most telling evidence for this view is the reappearance of recollection later in the dialogue. At 98a, Socrates claims that true opinion, although it is less secure than knowledge, is just as good for guiding action. One who has true opinion, so long as he is in possession of it, will choose to act just as well as a person with knowledge. In this later passage, Socrates appeals to recollection once more (97e2-98a6):

[T]rue opinions, as long as they remain, are a fine thing and all they do is good, but they are not willing to remain long, and they escape from a man's mind, so that they are not worth much until one ties them down by (giving) an account of the reason why. And that, Meno my friend, is recollection, as we previously agreed. After they are tied down, in the first place they become knowledge, and then they remain in place. ${ }^{40}$

At the end of the Meno, it looks like the difference between true opinion and knowledge is that, in the the case of the latter, one has fastened his belief down with something roughly like a causal account. It is remarkable that this, the fastening down of true opinions, happens by the process of recollection. It seems therefore that Socrates regards recollection, however we flesh out its details, as the process by which true opinion becomes knowledge. If this is correct, then it is very unlikely that he should introduce the theory of recollection earlier in the dialogue merely as an expedient. ${ }^{41}$ Because recollection ultimately plays a key role in this later account-it is what converts true opinion into knowledge - it seems rather unlikely that Plato would introduce it as a red herring earlier in the conversation.

\section{The prevailing view: the metaphysics are strange}

Of course, most scholars have taken a somewhat less extreme view of the disclaimer. Whereas Weiss thinks Socrates' disclaimer refers to the theory of recollection, that he is disclaiming this part of the dialogue wholesale, most interpreters have argued that Socrates' hesitancy at 86b5-6 is very likely a reference to the otherworldly details which appear in his exposition of the theory. ${ }^{42}$ For example, Bluck puts forward the view that "the other things" at 86b5-6 must refer to the exotic details included in the exposition of the theory, which have yet to be proved with any 
certainty. ${ }^{43}$ Bluck thinks Socrates hedges at the end of the discussion as an acknowledgement that these complicated religious-cum-metaphysical claims, the immortality of the soul, reincarnation, and recollection have not been proven in the present conversation. For this reason, Bluck argues that the theory of recollection should be regarded as hypothetical. If it turns out to be true, this view constitute a counterexample to the eristic argument. According to Bluck, the structure of the dialogue from 81a-86d might be summarized as follows: If what he has said about the afterlife is true, if we have immortal souls that are reincarnated and recollect what we already know, then we need not be troubled by Meno's paradoxes. Socrates hedges at the end of the discussion, Bluck thinks, because he regards the theory of recollection as a hypothesis in need of further proof.

Sharples makes a similar argument, claiming that Socrates' disclaimer very likely refers to the otherworldly details of the recollection myth, especially the view the soul is immortal. ${ }^{44}$ Sharples thinks that Socrates would not be willing to endorse the immortality of the soul, as this is a claim that he does not take up fully until the Phaedo. He sees this as a relatively minor point, however, in that the immortality of the soul has little influence on the more relevant claim which follows from the theory of recollection, that we are able to inquire into the nature of what we do not already know. Sharples (like Weiss) distinguishes between the metaphysical details of the theory of recollection and its overall "lesson" or "moral". Although Socrates hesitates about the details, the theory of recollection entails an important lesson to which Socrates would certainly assent: We can endeavor to search out and discover what we do not already know. In short, Sharples believes we can regard the theory of recollection as offering a plausible alternative to the eristic argument if we understand that Socrates would not confidently endorse the metaphysical details which undergird it.

Fine also takes the disclaimer to refer to certain of the "unbelievable" underpinnings of the theory of recollection. It is her view that Plato puts less stock in the exposition of the view than he does in the elenchus that follows. The exchange with the slave boy, she argues, offers more definitive proof of our capacity to inquire into the nature of what we do not already know. Fine summarizes her view of this part of the dialogue thus: 
However one spells out the details of the theory of recollection, few nowadays are likely to believe it. The elenctic reply, however, remains convincing, and it can be accepted even by one who rejects the theory of recollection; one can accept Plato's claim that one can inquire in the absence of knowledge, because of one's capacity for reflection and because of one's true beliefs, without accepting his account of what explains the capacity and the beliefs. It is thus pleasing to see that Plato himself seems to place less weight on the theory of recollection than on the elenchus... Socrates says he would not like to take an oath on all that he has said (86b); but later he says that if he were to claim to know anything, one of the few things he would claim to know is that knowledge differs from true belief (95b1-5). ${ }^{45}$

Fine takes Socrates' unwillingness to affirm these "other things" as referring to those features of the theory of recollection that "few nowadays are likely to believe". She thinks that the disclaimer refers to the exposition of the theory, in particular, to the exotic religious and metaphysical details of the explanation, which most of us would likely regard as untenable (i.e. that we are immortal souls, which are reincarnated and can quite literally recollect all of what we once knew). This result is pleasing, Fine argues, in that Plato seems to give more credence to a version of the view which is stripped of these suspect metaphysical details. All he would be willing to defend is the core view that we possess a capacity to inquire after and discover what we do not already know, with true opinion as our guide. ${ }^{46}$ This core view is privileged, Fine argues, in the elenchus between Socrates and the slave boy. In the demonstration, Socrates shows that however the boy comes to have true opinions, whether it be by recollection or some other reflective process, he has the capacity to do so.

In summary, the prevailing view of the disclaimer at $86 \mathrm{~b}$ is that Socrates is in some way uncomfortable with the exotic-sounding religious and metaphysical details included in the exposition of the theory of recollection. In particular, commentators take Socrates to be unwilling to endorse the view that the soul is immortal and reincarnated (and perhaps even the claim that it can quite literally recollect anything from within). This camp maintains, however, that Plato would be willing to affirm the philosophically redeeming implications of the theory, attributing to him a metaphysically-bare version of the theory of recollection, according to which we have the capacity to reflect, inquire, and discover what we do not know at present-by taking true opinion as our guide. 
It is worth noticing, however, that the prevailing view is motivated, at its root, by a bias against strange or unexpected metaphysical claims about the soul and its afterlife. Fine observes that modern audiences will find the initial exposition of the theory of recollection unbelievable; "few nowadays are likely to believe" the seemingly-outlandish claims which undergird Socrates initial exposition of the theory of recollection. ${ }^{47}$ She goes on to cast the details of the theory of recollection as less important than the elenchus which follows, taking the disclaimer as proof that Socrates (Plato) has reservations about his initial exposition of this view. Similar thinking appears to be what drives both Sharples to cast the details of the view as less philosophically important than the lesson which follows from it and Bluck to view the theory of recollection as but one hypothetical explanation of how we come to to have knowledge through inquiry. Generally speaking, the prevailing wisdom seems to be that the exposition of the theory of recollection is too strange in and of itself to constitute Plato's own fully reasoned view. Because, however, Socrates seems to entertain the view seriously, these commentators conclude, Plato must be willing to entertain recollection as a kind of bare-bones or hypothetical scenario, which, although its details are in need of further proof, seems to express an important lesson- that we are endowed with the ability to search out and discover what we do not know at present.

I shall argue that the disclaimer ought not to be read in this way, as a confirmation of our own biases against the strange, religious metaphysics upon which the theory of recollection rests. The strangeness of the view is not itself a reason to suspect that Socrates has the details of the theory in mind when he issues a disclaimer at $86 \mathrm{~b}$. Although the portrait of the afterlife that Socrates paints in his exposition of the theory of recollection is strange and unexpected to the modern observer, this is not in and of itself a reason to think that it would have seemed odd to Plato. Furthermore, setting aside worries of anachronism, even if the metaphysics of the theory would have appeared strange to an ancient audience, this is still not itself a very Platonic reason to discount the view. In fact, Plato frequently has Socrates set aside concerns of strangeness or unexpectedness, demanding instead that his interlocutors follow an argument where it leads. ${ }^{48}$ Take, for example, when Crito comes to Socrates in prison with a plan for his escape. Socrates refuses him, claiming that it is better to respect the law, even if that means staying and accepting 
his sentence. In his defense of this position, unhappy and bizarre as it may sound to the modern (or ancient) audience, Socrates claims that he will nevertheless follow reason alone (46b1-6):

My dear Crito, your eagerness is worth much if it should have some right aim; if not, then the greater your keenness the more difficult it is to deal with. We must therefore examine whether we should act in this way or not, as not only now but at all times I am the kind of man who listens to nothing within me but the argument that on reflection seems best to me. ${ }^{49}$ | 50

In choosing what to do, Socrates claims that he will follow the argument to its logical conclusion, no matter how unexpected or unhappy the conclusions may be. Similarly, in the Republic, during the discussion of education, the interlocutors take up the question of whether mimetic writing should be admitted into the Just City. Socrates claims here that although he does not know the answer to this question, he knows how to go about searching for the answer: "[W]hatever direction the argument blows us, that's where we must go". ${ }^{51}$ No matter what the conclusion, how strange or unexpected it may appear, Socrates urges Adamanteus to put his trust in reason and proceed. Given Plato's own commitment to suspending judgement with respect to odd or unexpected claims, it would seem rather un-Platonic to argue that the theory of recollection, insofar as it rests on strange or unexpected metaphysical notions, ought to be taken less seriously, sanitized, or assumed to be hypothetical. By Plato's own lights, a strange view, like the one Socrates sets out in response to the eristic argument, may in fact turn out to be an accurate one.

What this shows is, I think, that the prevailing view of the disclaimer is somewhat biased. In what follows, I shall present an alternative reading of this part of the dialogue, which further suggests that the prevailing view is incorrect: whereas most scholars have taken Socrates' disclaimer at 86b5-6 to refer in some way to the exotic religious and metaphysical claims set out in the exposition of the theory of recollection, I will argue that a close reading reveals instead Socrates' reservations about his arguments in the slave boy demonstration. ${ }^{52}$

\section{An alternative reading}


This section is divided into two parts. I begin with an examination of the strength of the

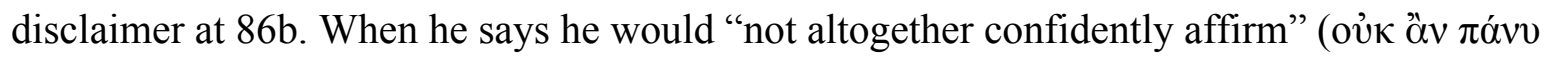

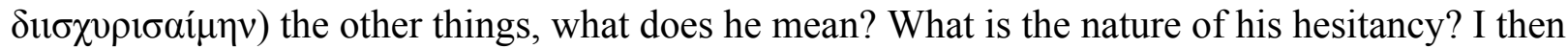
examine the logical structure of the disclaimer passage in order to show that what Socrates doubts is very likely the efficacy of the slave boy demonstration in showing that the theory of recollection is the true account of how we come to know. Simply put, this section shows that Socrates is unwilling to stake his case for the theory of recollection on the demonstration argument.

As a matter of clarifying this view, it will be useful to say a bit more at the outset of this discussion about how the demonstration functions as an argument. It ought to be noted that Socrates is engaged in two parallel conversations during the demonstration. ${ }^{53}$ In the foreground, he asks the slave boy a number of questions about geometrical figures. This exchange fuels another conversation, in the background, in which Socrates asks Meno to observe the boy's progress. The boy's ability to answer, despite not having been taught, is supposed to show that he is recollecting bits of his previous knowledge. Near the end of the demonstration, however, the conversation in the foreground trails off. Socrates presents Meno with a final synopsis of what has just occurred - this argument and the running background exchange are based on a number of observations about how the boy responds to questioning. In what follows, I refer to this, the background exchange, in which Socrates argues that all learning is recollection, as "the demonstration argument". This argument, the one based on the demonstration, and not the demonstration itself, is, I argue, the likely focus of Socrates' disclaimer at 86b5-6.

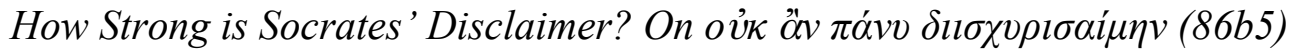

Before we turn to the question of what Socrates seems to be disclaiming, we ought to explore just how strongly he seems to be disclaiming it. There are, of course, a number of ways to understand what Socrates means when he says he would "not altogether confidently affirm" (ov̉k

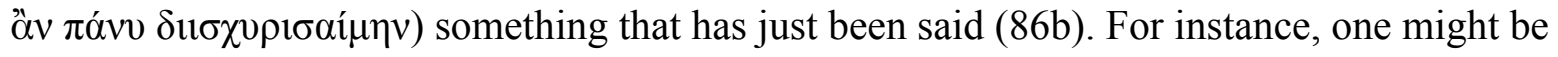
tempted to take this as a statement that Socrates does not believe something in the preceding exchange. In keeping with the red herring view, Roslyn Weiss has argued that, from the 
introduction of the theory of recollection to the conclusion of the slave boy demonstration, Socrates is being insincere. Weiss takes Socrates' unwillingness to "altogether confidently

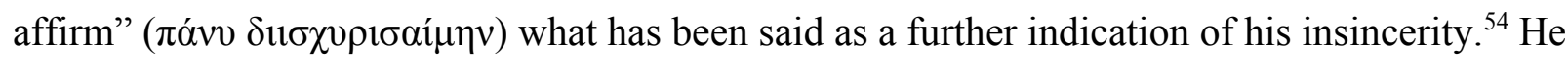
means to hasten Meno back to the discussion of virtue, tailoring his arguments to Meno's interests, while leading the slave boy through a series of "sham" proofs, feeding him information, and encouraging him to parrot back the correct answers. ${ }^{55}$

Dominic Scott rejects all such interpretations outright. ${ }^{56} \mathrm{He}$ argues that any reading that takes a large part of the dialogue to be put forward insincerely runs afoul of Socrates' explicit mandate that the interlocutors are expected to speak the truth (75c-d). Moreover, he claims, in most cases, a better interpretation can be found by dealing more patiently with the passage in question. Following Scott, it seems reasonable to take a closer look at the passage in question, especially the verb $\delta 11 \sigma \chi v \rho i \zeta o \mu \alpha 1$, which I have translated as "to confidently affirm". ${ }^{57}$ Weiss takes Socrates' unwillingness to "confidently affirm" something that has been said, as an expression of his disbelief. But a closer look at this verb will show that $\delta ı \sigma \chi v \rho i \zeta o \mu \alpha t$ is generally an expression, not of simple belief or disbelief, but of the level of confidence one has in a given state of affairs. ${ }^{58}$ The difference here is subtle but important: that Socrates would "not

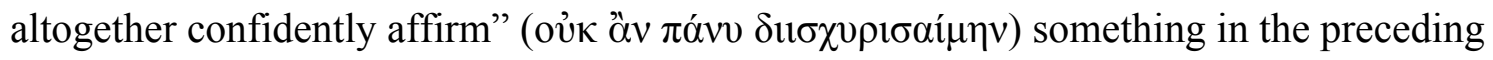
exchange ought not to be taken as a statement of his disbelief about something that has been said. Instead, he ought to be taken as unwilling to 'put his trust in' something that has been said. ${ }^{59}$

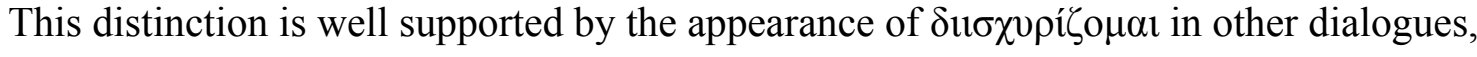
where, in its positive form it frequently carries with it a connotation of 'staking a belief in' something. ${ }^{60}$ Take for example, Euthyphro 5c9, where Socrates asks Euthyphro to tell him about the nature of piety. He says: "So tell me now, [Euthyphro], by Zeus, what you just now

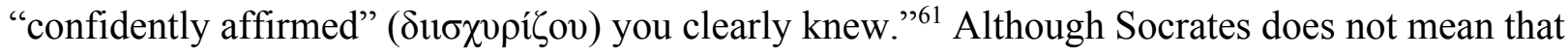
Euthyphro actually knows about the nature of piety, this passage suggests that Euthyphro has made a strong claim to know piety. In fact, Euthyphro has just finished claiming that he knows the nature of piety "exactly" ( $\alpha \kappa \rho 1 \beta \tilde{\omega} \varsigma)$ and better than other men (5a2). The type of statement one makes when he "confidently affirms" ( $\delta 11 \sigma \chi v \rho i \zeta \varepsilon \tau \alpha l)$ something is, it seems, a claim about the strength of one's convictions in a given state of affairs. Euthyphro is so confident in his claim 
to know piety that he stakes himself as knowing it. We find a similar usage at Theaetetus $158 \mathrm{~d} 6$. Here, Theaetetus wonders what proof can be given that one is asleep or awake. Socrates claims that regardless of whether we are awake or asleep we tend to trust that our present experiences are waking. That is, we tend to trust that whatever we are currently experiencing is really happening. Even in dreams we often assume that we are awake. In his explanation of this attitude, Socrates claims that we tend to "confidently affirm" ( $\delta ı \sigma \chi \nu \rho \iota \zeta$ ó $\mu \varepsilon \theta \alpha)$ both states, sleeping and waking, treating them as equally real. Once again, it looks like "confidently affirming" something in this sense is to 'stake' or 'put one's trust in' a state of affairs - assuming a stance of confidence that one is presently awake.

This analysis is compatible with all other uses of this verb in the dialogues. ${ }^{62}$ What these

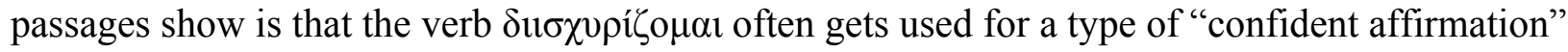
in which one 'stakes oneself on' or 'places one's trust in' a given state of affairs. This type of assent applies both to claims like Euthyphro's, who thinks he has exacting knowledge of piety, in addition to claims like the one a person might make about the realness of her present experience. I conclude that, at Meno 86b5-6, when Socrates claims that he would "not altogether confidently

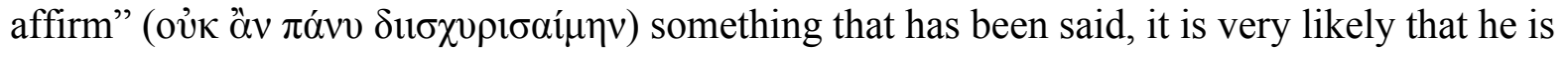
making a claim about his willingness to 'put his trust in' or 'stake a belief on' something in the preceding conversation. In contrast to Weiss's view, it looks like Socrates is not making a simple claim of disbelief, he is not claiming to have put forward a view he does not himself accept, so much as he seems to be making a claim about how confidently he is willing to assert, 'put his trust in' or 'stake a belief on', something in the preceding exchange.

\section{The logic of 86b6-c2}

If I am correct, then, at 86b5-6 Socrates is very likely expressing a lack of confidence or an unwillingness to stake himself on something in the preceding exchange. Of course, this gives rise to a number of questions: chiefly, what exactly has caused Socrates' reservations? In what bit of the preceding exchange is Socrates unwilling to put his trust? In what remains of this section, I argue that Socrates is not willing to rest his case for the theory of recollection on the demonstration argument. 
My reading draws heavily on the structure of this part of the dialogue. Let us, therefore, briefly consider some relevant features of the way this exchange unfolds. To begin, recall that, just after Meno puts forward his pair of paradoxes, Socrates accuses him of making an eristic

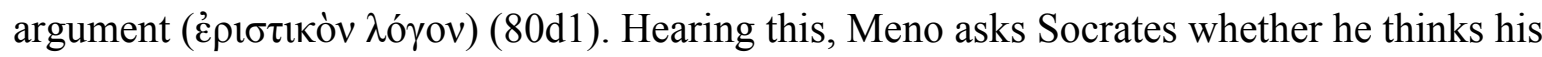
argument ( $\dot{o} \lambda$ ó$_{0} \varsigma$ ) is a good one (81a1). Socrates answers that it is not and begins to explain that he has heard an alternative from a number of wise priests and priestesses. At this point,

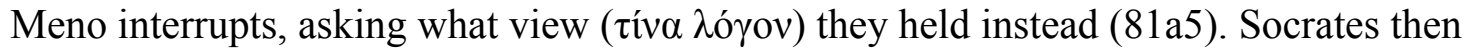
introduces the theory of recollection. This exchange is notable in that it suggests that we are to interpret the eristic argument and the theory of recollection as two competing logoi. Plato appears to be alluding to a style of rhetorical competition, common among Sophists and other Presocratics, in which each speaker would defend one of two competing views, logoi, against an opponent. ${ }^{63}$ In particular, it looks like Meno is the champion of the eristic logos and Socrates is the champion of an opposing logos, the theory of recollection. In the following conversation, in the fashion of these competitions, Socrates fleshes out his logos and attempts to show that it is superior to Meno's.

Also recall that, at the tail end of his initial exposition of the theory of recollection, Socrates presents a pragmatic reason for believing what he has said. Whereas believing in the eristic argument will make us idle, believing in recollection will, by contrast, make us more enterprising and curious (81d4-e2). The eristic argument is damaging to a person's character in that it encourages intellectual laziness. If we believe that we cannot even begin to discover what we do not already know, this will have profoundly bad effects on how we approach life, making us stagnant and unmovable in our beliefs. ${ }^{64}$ By contrast, if we believe in recollection, we will be made more enterprising by believing it. After delivering this pragmatic reason, Socrates says that he is prepared to return to the discussion of virtue. "Trusting in the truth" of what has been said,

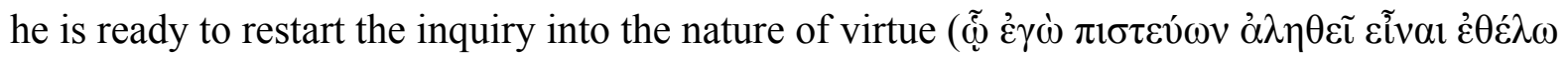

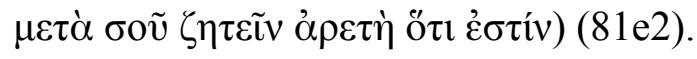

But Meno is not satisfied with Socrates' purely pragmatic reason. He is unwilling to give up his $\log o s$, the eristic argument, so easily. Instead, he demands proof that Socrates' theory actually holds, that when we seem to be learning we are really just recollecting something of 
what the soul once knew (81e3-4, 82a3-4). In this part of the dialogue, Meno seems to be demanding a better reason to believe the theory of recollection. Unsatisfied with the purely pragmatic reason Socrates has given - that one should believe in recollection because believing it will be good for him-Meno seems to be demanding a proof that the theory of recollection is in fact true. In response to Meno's request, Socrates first accuses Meno of trying to trick him. But Meno presses on, asking again for proof of what Socrates has claimed. Socrates eventually relents. He claims that recollection will be no easy matter to prove, but that he will make an effort for Meno's sake (81a5-b2). By examining the slave boy, Socrates will attempt to show that, whenever a person learns something, he is really only recollecting something of what his soul once knew.

To summarize, Plato has here introduced two competing logoi, the eristic argument and the theory of recollection. The former logos holds that we cannot discover what we do not already know. The latter logos holds that, because we recollect, we can inquire and discover what we do not know at present. Following his presentation of the theory of recollection, Socrates gives two reasons to favor this logos over the eristic one. The first reason is pragmatic; accepting recollection will make us better and less lazy than if we accept the alternative. When Meno is not satisfied with Socrates' first reason, however, and asks for proof of the theory's truth, Socrates undertakes the slave boy demonstration. The demonstration will provide a second reason to believe the theory of recollection, illustrating that this is the true way in which all knowledge is acquired. Whereas the pragmatic reason fails to convince Meno, who is unwilling to simply trust in the theory, the arguments of the slave boy demonstration will show that recollection is in fact a true account.

Keeping the structure of this part of the dialogue in mind, let us now turn our attention to the finer details of the disclaimer passage. Here it is again:

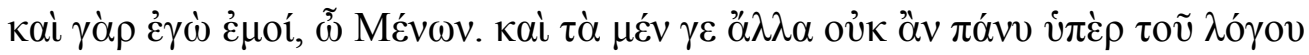

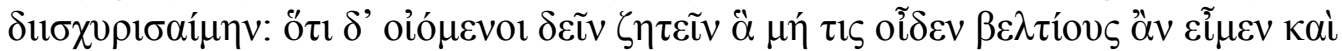

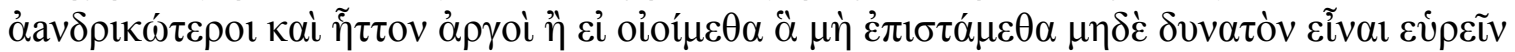

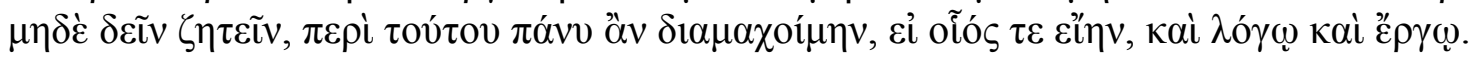

And so it seems to me, Meno. On the one hand, at least, I would not altogether confidently affirm the other things on behalf of my argument; on the other hand, I would fight at all costs 
in both word and deed as far as I could that we will be better men, braver and less idle, if we believe that one must search for the things one does not know, rather than if we believe that it is not possible to find out what we do not know and that we must not look for it.

The disclaimer sets up an opposition between what Socrates "would not altogether confidently affirm" and "what he would altogether fight for". Our primary interest is in what Socrates claims

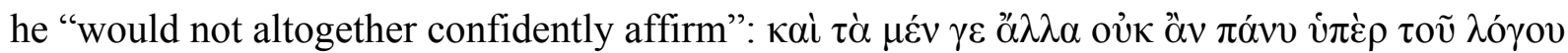

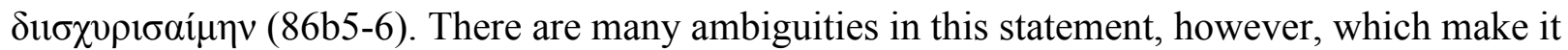
difficult to discern what exactly he has in mind. These ambiguities are as follows:

(1) First and foremost, it is unclear what $\tau \dot{\alpha} \alpha$ ỏ $\lambda \lambda \alpha$ picks out. What are "the other things" in which Socrates is unwilling to put his trust? ${ }^{65}$

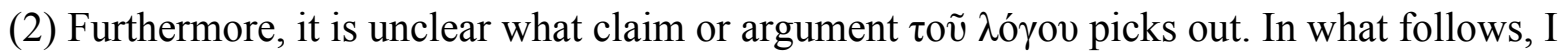
will argue that the logos in question in this passage is very likely the theory of recollection.

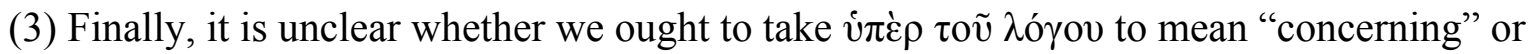
"on behalf of" the claim or argument. ${ }^{66}$ The difference here may seem negligible at first, but it turns out to be quite important. Socrates could be saying either "I would not altogether confidently affirm the other things concerning the claim or argument..." or "I would not altogether confidently affirm the other things on behalf of the claim or argument." If $v \pi \dot{\varepsilon} \rho$ means "concerning", then it looks like Socrates' reservations could refer to just about anything about the claim or argument in question. He might be taken as referring to something as simple as the tenor of the preceding exchange. Such an interpretation might even be taken as loose support for the prevailing view, that what Socrates finds objectionable at 86b5-6 are simply the esoteric metaphysical details which underlie his exposition of theory of recollection. If, however, $v \pi \varepsilon \dot{\varepsilon} \rho$ means “on behalf of" or "in support of", then Socrates would appear to be drawing our attention to something that he has said in defense of the claim or argument in question. In what follows, based on the structure of the disclaimer passage, I will argue for the latter reading of $\dot{v} \pi \varepsilon$ p: Socrates is pointing out something he has said "on behalf of" a given claim or argument. 
Each of these ambiguities can be resolved by looking more closely at the opposition between what Socrates "would not altogether confidently affirm" and what he "would altogether fight for". Notice that Plato puts what Socrates "would not altogether confidently affirm" and what he "would altogether fight for" in a men-de construction. On the one hand, he claims that he would not altogether confidently affirm these other things either "concerning the claim or argument" or

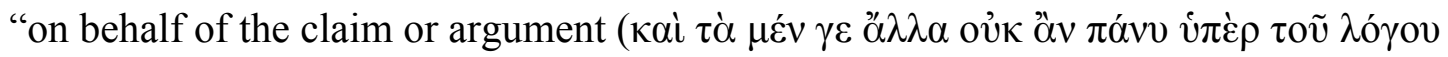

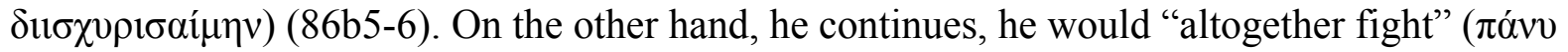

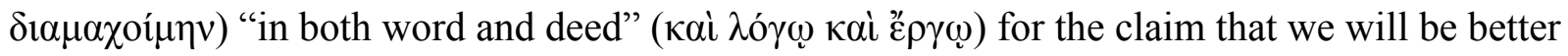
and braver if we believe that we can inquire than if we believe that we cannot discover what we do not already know (86c1-2). The men-de construction suggests a contrast between these two statements, but it also suggests a correlation between them. This is just to say that whatever Socrates "would not altogether confidently affirm" and whatever he "would altogether fight for" must be similar enough to make sense as the two comparanda in an "on the one hand... on the other hand..." construction. A conceptual correlation between the two statements is further supported by the fact that each contains a verb closely related to strength. "To confidently

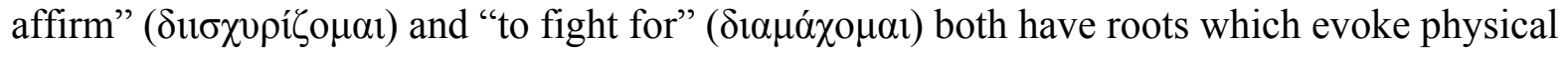
strength, durability, and fortitude ${ }^{67}$ Additionally, it is notable that both statements contain the

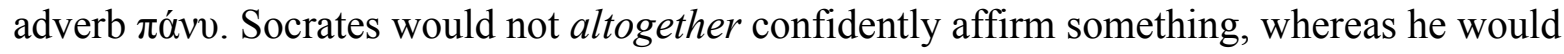
altogether fight for something else. Again, Socrates appears to be contrasting the strength of his commitment to two closely correlated ideas in the previous exchange.

I take these details - the men-de construction, the related verbs of strength, and the mirroring of $\pi \alpha ́ v v$ in both statements - to show is that there is a close conceptual correlation between whatever it is that Socrates "would not altogether confidently affirm" and what he "would altogether altogether fight for". Now, consider that what Socrates says he "would altogether fight for" is a restatement of the pragmatic reason he initially gives in favor of the theory of recollection. He would fight in word and deed for the claim that we will be better and braver if we believe we can discover what we do not already know than if we give into the eristic argument (86b3-c2). This is the very same reason that Socrates gives after the initial exposition of the theory of recollection. There, he claims that we ought to believe in recollection insofar as 
believing it will make us better and less idle than succumbing to the eristic argument (81d4-e2). In the second statement in the disclaimer passage, at 86b3-c3, Socrates appears to be reaffirming this initial reason. Now, because there is such a strong symmetry between what Socrates "would altogether fight for" and what he "would not altogether confidently affirm" (the two statements are set in a men-de construction and both use verbs of strength modified by $\pi$ ávv) and because, in the second statement, he maintains his commitment to the pragmatic reason, which he originally presented in defense of the theory of recollection, it seems reasonable to conclude that the first statement must also concern the theory of recollection. Because, in the second statement, Socrates stands behind one of the two reasons he has given to believe the theory, it seems to follow, given that Socrates is here contrasting the strength of his commitment to two closely

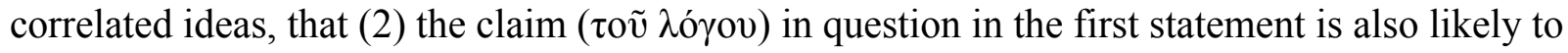
be the theory of recollection.

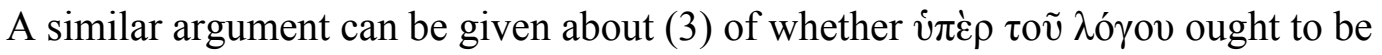
translated "concerning the claim or argument" or "on behalf of the claim or argument. We are now in a position to reformulate this question as follows: ought $i \pi \dot{\varepsilon} \rho \tau$ "concerning the theory of recollection" or "on behalf of the theory of recollection"? Consider again the structure of the disclaimer passage. The second statement, what Socrates "would altogether fight for", is one of two reasons he has given "in support of" the theory of recollection. Meno should believe in recollection, he claims, because believing it will be good for him. Because the two statements in the disclaimer are strongly correlated, it is likely that whatever Socrates "would not altogether confidently affirm" is some other reasons he has given "in support of" the theory of recollection. In short, at 86b5-6, it appears that Socrates must be weighing the strength of two reasons he has given "in support of" his view. While he stands behind the pragmatic reason, he is not willing to stake his case for recollection on the "other things" he has said in its defense.

If I am correct, then the disclaimer passage ought to be paraphrased roughly as follows: on the one hand, Socrates would not altogether confidently affirm the other things on behalf of the theory of recollection; on the other hand, he would fight in both word and deed as far as he could for the pragmatic reason. If this is correct, then we have every reason to believe that (1) 
whatever these "other things" are, they are very likely something else which Socrates has said in support of the theory of recollection. Recall, now, that in this part of the dialogue Socrates has presented two different reasons to believe the theory. He first gives the pragmatic reason, that the theory of recollection makes us better, more intellectually curious people. When Meno is not convinced by this reason, however, Socrates responds with the slave boy demonstration. This is meant to supply Meno with a second reason to believe the theory, proving that it is a true account of how we come to have knowledge. If this is correct, then, it is not unreasonable to conclude that, when Socrates says he is willing to fight for the pragmatic reason, but would not altogether confidently affirm "the other things" he has said in support of the theory of recollection, it is very likely that he is referring to the other of the reasons he has given in support of the theory of recollection. In other words, he must be referring to the demonstration argument.

At this point, someone might object that this reading makes too much of the internal logic of the disclaimer passage. Such a detailed reading, the objection goes, takes what Socrates has said too literally. Although I am inclined to brush this objection off as a concern about the style of my argument rather than its substance, it is perhaps best to give an additional response: the above argument rests on a series of deductions, made after disambiguating (2) what claim or argument $\tau$ oṽ $\lambda$ ó $\gamma o v$ picks out. I have extrapolated from the passage, based on a close correlation between the two statements, that $\tau$ ov $\lambda$ ó yov likely refers to the theory of recollection. Everything else I have said follows from this initial disambiguation. In response to the above objection, then, it is worth noticing that we have another very good reason to think that $\tau$ oṽ $\lambda$ ó yov must refer to the theory of recollection. Recall that Socrates and Meno originally treated the eristic argument and the theory of recollection as two competing logoi. In the way of the Sophists, Meno puts forward one logos, the eristic argument, and Socrates puts forward an alternative, incompatible logos. Because there appears to be a continuous exchange, running from the introduction of the theory of recollection through the end of the slave boy demonstration, we have every reason to believe that the logos to which Socrates refers at $86 \mathrm{~b} 5$ ( $\tau$ o $\tilde{v} \lambda$ ó $\gamma 0 v$ ) is likely to be the very same logos to which he refers on multiple occasions at the outset of the discussion and has been attempting to defend ever since. The casual manner in which Socrates mentions this logos at 
$86 \mathrm{~b} 5$, without any hesitation or disambiguation, further suggests that it is meant to be taken in the context of the preceding exchange.

In short, then, the disclaimer passage ought to be read as follows: Socrates would be willing to fight in word and deed for the claim that we ought to believe in recollection because it will make us better and wiser. By contrast, he is not willing to "altogether confidently affirm" the other reason he has given in support of the theory of recollection - that is, he is wary to put his trust in or stake his case on the arguments of the slave boy demonstration, which are intended to prove to Meno that recollection is the true account of how we come to have knowledge.

Of course, it might be further objected that the grammar of the passage allows for an alternative reading, that (3) what Socrates "would not altogether confidently affirm" ought to be interpreted as something simply "concerning" the theory of recollection. In other words, someone might accept that the structure of the passage shows that Socrates is here concerned with the theory of recollection (my answer to 2), but object to the view that Socrates is weighing two reasons he has given "in support of" the theory (my answer to 3). After all, this objection goes, Socrates could be taken as saying that he is willing to stake his case on the pragmatic argument despite being uncomfortable with "the other things" merely "concerning" the theory of recollection. And, as I mentioned above, this reading might be taken as loosely supporting the prevailing view, which holds that, Socrates is wary of the metaphysical details on which the theory of recollection rests. Whereas my interpretation of the disclaimer shows Socrates unwilling to stand behind the arguments of the slave boy demonstration, this alternative interpretation gives us a route by which to understand the disclaimer as being about the inessential metaphysical details of the theory.

Given that my view casts Socrates as hesitant to endorse the demonstration argument, and this is the more disruptive view, what grounds do we have to prefer it? I have already argued that the logic of this part of the disclaimer strongly supports my reading. However, it is also worth noticing that logic of the disclaimer passage weighs heavily against the prevailing view. The prevailing view would have us read the disclaimer as follows: Socrates "would not altogether confidently affirm" the details of his exposition of the theory of recollection, although he "would 
altogether fight in word and deed for" the pragmatic reason that he gave in support of the theory. On the prevailing view, Socrates would be contrasting certain features of a description of recollection with one of the reasons he has given in support of the theory. It is unclear, however, why Socrates should contrast, in a closely correlated oppositional statement, the details of his exposition of the theory with only one of the reasons he has given in its favor. Indeed, the prevailing view seems somewhat unlikely if we think that Socrates has presented more than one reason to believe the theory of recollection. The prevailing view takes Socrates, having just concluded the demonstration argument, to be pausing to consider his exposition of the theory of recollection, from pages before, in addition to only one of the reasons he gives in its defense, also from pages before. All the while, however, he would neglect to mention the most fundamental and pressing reason he has given in support of this theory - the demonstration argument, which claims to show that we should believe in recollection because it is an accurate account of how we come to have knowledge. It would seem, therefore, that the prevailing view leaves a rather large elephant in the room. It would have us believe that in his retrospective remarks, Socrates considers the strength of everything but the case he has made for the truth of the theory of recollection.

Finally, in response to those who may be reluctant to rely so heavily on the internal structure of the disclaimer passage, it is possible to identify a number of other indications that Socrates is wary to put his trust in the demonstration argument. For example, it is notable that the demonstration is framed on both sides by a statement of uncertainty. Before the demonstration even begins, where Meno asks Socrates for further proof that recollection can and does occur, Socrates responds that to demonstrate this will be no easy matter (81a5-b2). He claims that he will try nevertheless for Meno's sake. The disclaimer might be seen, therefore, as an echo of this earlier hesitancy, forming a frame around the arguments of the demonstration. At the start, Socrates is hesitant to stake the case for recollection on what he is about to say; it is unsurprising then that at the end of the demonstration he feels no differently.

Furthermore, the exchange following the conclusion of the demonstration argument suggests that disclaimer is likely meant as an evaluation of this argument. At 86b1-2, which I take to be the conclusion of the demonstration argument, Socrates claims that whatever a person 
does not know at present he ought to search for and recollect. In the lines that follow, Meno agrees to this conclusion, albeit somewhat hesitantly: "To say this seems right to me, Socrates, I

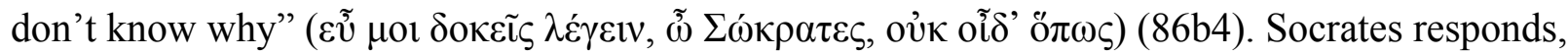

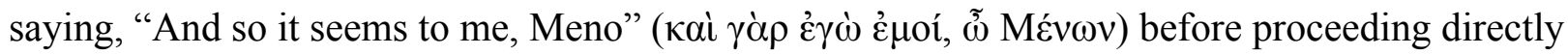
into the disclaimer. The fluidity of this exchange - the conclusion of the demonstration argument, followed by Meno's tenuous assent and Socrates' agreement ${ }^{68}$ — suggests that the disclaimer will adhere to the same topic as what precedes it. It is natural to read Meno as evaluating the argument he has just heard. Likewise, it is natural to read Socrates reply, "And so it seems to me, Meno", as continuing this evaluation; given that the focus of the exchange up to this point has been the convincingness or efficacy of the demonstration argument, it is natural to assume that the disclaimer is also intended as such. Socrates is willing to endorse the theory of recollection, but he is hesitant to rest his case on the argument just presented.

Whereas most have taken the disclaimer at 86b1-c2 to refer to certain of the unbelievable details in the exposition of the theory of recollection, I have argued that Socrates ought to be taken as referring instead to the demonstration argument. This is a surprising result, one that flips the prevailing wisdom on its head. Defenders of the prevailing view (Fine in particular) have thought that Plato privileges the demonstration, and the accompanying background argument, more than he does his initial exposition of the theory of recollection. This view is often thought to be comforting in that we find Plato relying less on an unbelievable metaphysical description of the afterlife and more on what looks like a philosophically redeeming argumentative exchange, one that purports to show that we can search for and discover what we do not already know. My view suggests, by contrast, that what Socrates is unwilling put his trust in at 86b5-6 is not so much the strange metaphysical picture that he has proposed in his description of the theory of recollection, as it is the the proof that he has given that the theory is in fact the correct account of how we come to know. Although this is an unexpected result, and one that is less comforting than the prevailing view, it seems to follow from the above reading of the disclaimer passage. It seems appropriate, therefore, to invoke the Crito: strange and unsatisfying as this result may seem, this is where reason has ultimately led us. 


\section{Diagnosing the demonstration argument}

The above reading is a great deal less radical than the interpretation put forward by commentators like Weiss, who think Socrates undertakes the demonstration entirely in bad faith. Nevertheless, it ought to give us pause. If I am correct, the disclaimer passage invites readers of the dialogues to do a double-take of sorts, revisiting the demonstration argument in order to look for causes of Socrates' hesitation. ${ }^{69}$ Why is he unwilling to "confidently affirm" this argument as a reason to believe in recollection? What is it that makes this argument inadequate or unconvincing in Socrates' eyes?

In what follows, I discuss a number of possible answers to these questions. It will be good to recognize, however, that there is little evidence to recommend any one of these suggestions in particular. Moreover, it is worth noting that such a lack of specificity might be taken to be problematic. In the introduction to this project, I discussed the preface problem, the worry that Socrates may not have any particular errors in mind in his disclaimers. Instead, his lack of confidence might be likened to that of an author who claims that "any of the errors found herein are my fault alone." Such an author is ultimately not committed to there being any particular, nameable errors in what he has written. This worry might be taken as especially relevant in the present context, if we cannot pinpoint the exact source of Socrates' unwillingness to put his trust in the demonstration argument.

However, the preface problem has, I think, already been largely put to rest. I have argued that Socrates is unwilling to 'put his trust in' the demonstration argument as support for the theory of recollection. Presumably, therefore, Socrates' hesitation is not of a piece with the hesitation expressed by the author of the preface, who seems to be admitting a free-floating, general worry about his ability to foresee unnameable errors in a work of such length. In contrast, Socrates appears to be admitting something quite specific: the demonstration argument has made an unconvincing defense of the theory of recollection. Whatever the deficiency in the demonstration argument, it is both specific enough and severe enough that Socrates is unwilling to cite the argument as support for the theory of recollection, resting his case instead on the pragmatic reason that believing the theory will make us better and more curious. 
In response to the preface problem, it is also worth mentioning that Socrates uses a similar construction to the one just discussed, even using the same verb ( $\left.\delta 1 \_\chi \cup \rho i \zeta o \mu \alpha \imath\right)$, to express his reservations in a passage in the Phaedo (114d). In chapter 2, I address this other disclaimer, which occurs after the myth and the conclusion of Socrates' argument against the fear of death. Because Socrates uses a very similar construction there, and because that disclaimer more clearly refers to an identifiable bit of the dialogue, it is not unreasonable to think that the present disclaimer might also signal something more than a general hesitation or show of modesty.

It is nevertheless problematic, from an interpretive point of view, that Socrates expresses his unwillingness to put his trust in the demonstration argument at a very general level. We should not, however, assume that all possible problems in the part of the dialogue are equally viable sources of Socrates' reservations. For instance, a number of scholars have taken issue with the legitimacy of the mathematical proofs which Socrates uses as examples in this part of the dialogue. ${ }^{70}$ But we can, it seems, rule out problems in the foreground exchange between Socrates and the slave boy as likely sources. As we have seen, Socrates is hesitant to put his trust in the demonstration qua support for the theory of recollection. He is unwilling to stake his case for recollection on the demonstration argument. Yet, problems in the foreground exchange, like the mathematical proofs themselves, are inessential to the argument that recollection occurs. Assuming that Socrates could have chosen another example - at one point he says as much, claiming that all other types of knowledge can also be recollected in this way (85e2) - problems in the mathematical proofs themselves seem less likely to be the focus of Socrates' hesitation than flaws in the background exchange. Because the foreground arguments are inessential to a defense of recollection, and because Socrates' hesitates to endorse the demonstration argument qua plausible defense of this theory, it follows that such problems are unlikely candidates in our present search. Socrates must be worried instead about some feature of the argument which bears on its efficacy in showing that recollection is the true account of how we come to know.

But there are also many possible problems in the demonstration argument. As we shall see below, Socrates puts forward a number of contentious premises and at least one hasty 
generalization. It is very difficult to say, therefore, which of these is the flaw to which he could be referring at $86 \mathrm{~b}$. Nevertheless, I shall argue that there is one, very deep flaw in the demonstration argument. Plato appears to object to the very idea of a demonstration: he considers the proof Socrates offers Meno an unconvincing method of showing that something imperceptible, like recollection, actually occurs. What is more, I argue, this particular flaw seems to indicated in the text itself: at the start of the demonstration, Socrates expresses uncertainty about demonstrating the theory of recollection. This would seem, therefore, a very likely candidate for what causes Socrates to issue the disclaimer at 86b5-6; he does not think that recollection can be effectively demonstrated. Moreover, I shall argue that this hesitation-Socrates' mistrust of using a perceptible method of proof-seems to account for the other problems I identify in the argument; Socrates' uneasiness with proving demonstratively that recollection occurs explains most if not all of the other mistakes in this part of the dialogue.

Let us now turn to a careful analysis of this argument. For ease, we might formalize the background exchange as follows:

1. The slave boy is able to answer questions about geometrical figures (84d3-85b8).

2. Socrates is not teaching the boy the answers $(85 \mathrm{~b} 8)$.

3. The slave boy has not been taught the answers on any previous occasion (85e6).

4. The boy must, therefore, be retrieving the answers "out of himself" (85d3-4).

5. Retrieving the answers "by himself and in himself" = recollecting (85d5-6).

6. It is possible to recollect all other forms of knowledge (85e2).

7. Because we can recollect all forms of knowledge, we should feel confident that inquiry into unknown topics is possible (85e1-4).

The question is: Why is Socrates be unwilling to "confidently affirm" this argument in defense of recollection? What is it that makes this argument inadequate or unconvincing in his eyes? I turn now to a number of possible deficiencies.

An overly-narrow definition of teaching 
Scholars have noticed that the demonstration argument shows a certain sensitivity to issues of teaching and instruction. For example, Dan Devereux wonders why Socrates attempts to show that all learning is recollection. ${ }^{71}$ In order to show that we can learn what we do not already know, he needs only to show that we can learn some things via recollection. Devereux further notices that, in his asides to Meno, Socrates frequently asks him to observe that he is not "teaching" the slave boy, only asking him questions (i.e. 81e4-5). ${ }^{72}$ In an attempt to solve both of these puzzles, Devereux proposes that the demonstration argument does not offer a sincere definition of "teaching". The point of the demonstration is, instead, to bring out the differences between Meno's very narrow conception of teaching, as dictation, and Plato's competing conception of teaching, as guiding the soul through the process of recollection.

In order to better understand this suggestion, let us turn for a moment to the strict definition of "teaching" in this part of the dialogue. ${ }^{73}$ Socrates frequently takes pains to maintain the distinction between his interrogation of the slave boy and "teaching", by defining "teaching" solely as the transmission of information (84cd1). For example (84c-d):

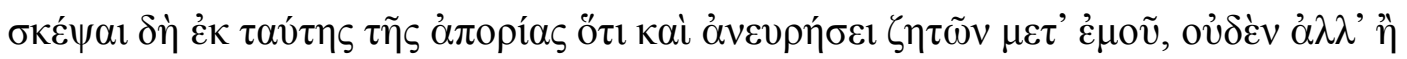

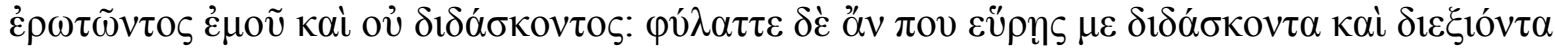

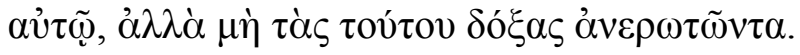

Look then how he will come out of his perplexity while searching along with me. I shall do nothing more than ask questions and not teach him. Watch whether you find me teaching and dictating things to him instead of asking for his opinion. ${ }^{74}$

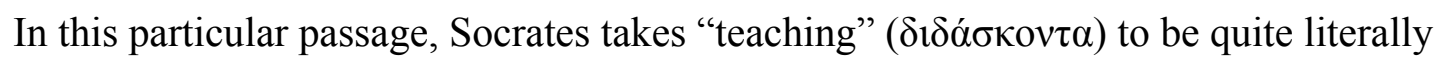
synonymous with "dictation" ( $\delta 1 \varepsilon \xi$ lóv $\tau \alpha)$. Devereux rightly notices that this definition is elsewhere attributed to the Sophists; for them, "teaching" is nothing other than "dictation". ${ }^{75}$ Of course, this is an extremely narrow concept, insofar as "dictation" seems to involve nothing other than the positive assertion of information. "Interrogation" does not count as "teaching" on the Sophistic definition, in that, when asking a question, a person does not assert anything definitively.

By maintaining this narrow, Sophistic definition of teaching, Socrates secures the necessary claim that, despite asking the boy questions, he is not in fact "teaching" him anything. Since the boy has not learned geometry on any other occasion, it is supposed to follow that he 
must be recollecting something of what he once knew. There is, however, according to Devereux, an alternative definition of teaching supplied in the demonstration itself. Throughout, Socrates guides the slave boy to form true opinions. ${ }^{76}$ He would appear to guide his soul through the early stages of recollection. This is, Devereux concludes, the very purpose of the demonstration - to create a contrast between these two conceptions of what it means to teach.

We are now in a position to see that Socrates' treatment of teaching creates a problem in the demonstration argument. In particular, the argument turns on a narrow, Sophistic definition of teaching as "dictation". At best, all that Socrates can claim in this part of the dialogue is that he is not dictating information to the slave boy-but this is not enough to show that he is not in fact "teaching" him in a much more general sense of the word. Additionally, it seems possible, if Devereux is correct, that Plato recognizes this flaw: he creates a tension between the two conceptions of teaching in the demonstration itself. Plato shows Socrates leading the boy through the early stages of recollection, and thereby, puts forward an alternative account of what it means to teach. The overly narrow definition of teaching is, I conclude, a plausible cause of Socrates' unwillingness to put his trust in the demonstration argument at 86b5-6. This may be what Socrates has in mind when he later claims to be unwilling to endorse the demonstration argument as sufficient proof for the theory of recollection.

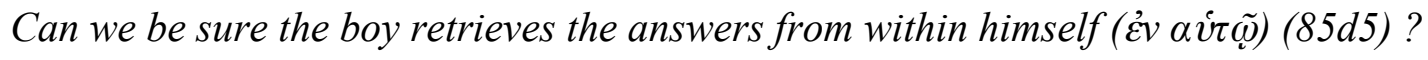
Setting aside whether Socrates thinks he is "teaching" the boy, and granting that the boy has not learned geometry before, it still does not follow from what has been shown that the boy must be retrieving his responses "out of himself". In other words, it may be that premise 4- "the boy must, therefore, be retrieving the answers “out of himself” ( $\dot{\varepsilon} \xi \alpha \dot{v} \tau o \tilde{v})(85 \mathrm{~d} 3-4)$ "- is false. This is, I shall argue, another possible source of Socrates' reservations in the disclaimer passage.

To better grasp this problem, let us turn for a moment to Socrates' final synopsis of the argument. Here, he sets out what I have labeled 'Premise 4' above, that the boy must, (insofar as he has not be taught now or on some other occasion), be retrieving the answers "himself, out of

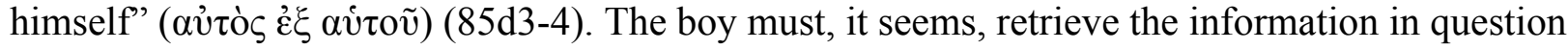
A) himself and B) from himself. Following directly on the heels of this premise, Socrates asks 
(this is labeled 'Premise 5' above): And is not this recovery of information "by himself and in

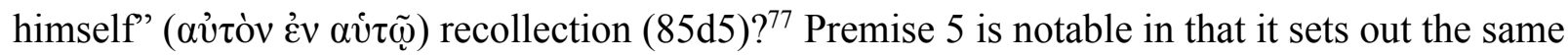
two conditions for what Socrates thinks makes for successful recollection. It is the retrieval of

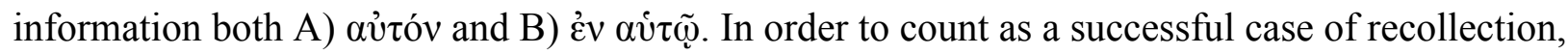
it seems, some bit of information must be retrieved both A) "by himself" and B) "out of/in himself". ${ }^{78}$

Conditions A and B account for why Socrates is so keen to show that he is only questioning the slave boy: if Socrates were dictating information to him, then it would become unclear whether the boy's answers are in fact something that he retrieves by himself and out of himself. However, many scholars have noticed that it is problematic that, even if Socrates does not think he is dictating information to the boy, he does nevertheless ask extremely leading questions ${ }^{79} \mathrm{He}$ even goes so far as to introduce many of the correct answers interrogatively. For example, when considering a four-foot by four-foot square, he asks: "Roughly, there are four smaller two-foot by two-foot squares, each with an area of four-square feet, are there not?" (83b). At the end of this line of questioning, the boy arrives at the correct answer. It is apparent, however, that Socrates has done all the heavy-lifting. What this shows, rather uncontroversially, is that, despite denying that he teaches the boy, Socrates is nevertheless supplying him with a great deal of correct information. Observations of this sort have led a number of commentators to defended what is sometimes called the "parrot" interpretation. ${ }^{80}$ The parrot interpretation holds that the boy is not recollecting anything, only repeating what Socrates says. If this is correct, then, even if Socrates is not dictating information to the boy, he may be still be supplying him with enough information that the boy takes his answers from the questions themselves. And, this is problematic with respect to Premises 4 and 5 in that, if the boy parrots the answers, it is no longer clear that the boy meets either of Conditions A and B. In other words, if the parrot interpretation is correct, then Socrates has failed to show that the boy is recollecting anything by himself or in himself. ${ }^{81}$

Gregory Vlastos has, however, rejected the parrot interpretation on two counts. First, he has argued that it is inconsistent with the fact that the boy has been told to answer according to his conscience (83d2). ${ }^{82}$ Second, and more importantly, Vlastos notices that Socrates introduces 
a number of false answers alongside the correct ones (82e, 83d). It appears, therefore, that the boy, even if he has garnered some information from Socrates' questions, must be discerning the correct answers for himself. ${ }^{83}$ If Vlastos is correct, then, the parrot interpretation is not viable; the boy appears, at the very least, to be weighing the answers in order to determine which are the correct ones.

I am in agreement with Vlastos that the parrot interpretation does not hold; the boy must, it seems, be weighing the answers in order to determine which are the correct ones. However, it is worth noticing that a version of the same problem still exists. Vlastos' view, call it "the deliberation view", shows that the boy is, at the very least, deciding between the answers supplied to him by Socrates. However, this view shows only that Condition A holds; the boy appears to be deciding the correct answers by himself. The deliberation interpretation does nothing, however, to show that Condition B holds - even if the boy deliberates about the correct answers by himself, this does not prove that he has retrieved anything from within himself. In other words, even if Condition A holds, even if the boy is doing the work of deciding the answers by himself, it is nevertheless possible that he is not retrieving any information from inside his own soul. Instead, his (limited) success in arriving at the correct answers may be entirely the result of his ability to analyze the information supplied to him in Socrates' questions. In short, the deliberation view leaves open the possibility that, by paying careful attention to Socrates' questions, the boy is able to infer the correct solutions.

What we have seen in this section is that recollection is the retrieval of information by a person from within his own soul. It follows that, even if the boy can be seen weighing the different answers Socrates supplies him, this is insufficient to show that recollection has occurred. Because recollection requires that knowledge must be retrieved both A) "by himself" and B) "out of/in himself", Socrates cannot simply show that the slave boy has come to have the correct answers by weighing them. All this shows is that he has done something "by himself'; in order to show, beyond the shadow of a doubt that the boy is beginning to recollect, Socrates must also show also that the boy has actually retrieved some bit of information from within himself. This is, I conclude, another likely cause of Socrates' disclaimer at $86 \mathrm{~b}$. He is aware of having 
supplied the boy with so much information that it is unclear whether he has begun to retrieve anything from within his own soul.

\section{Recollection is not the only explanation}

Premise 5 states that what it means for a person to retrieve answers "by himself and in himself" is just to recollect (85d5-6). Let us suppose, for the sake of argument, that Socrates has shown that the boy retrieves some of the answers "by himself and in himself" (which I argued above he has not). It still does not follow that the boy must have recollected the answers. Just because the boy is able to reason about an unfamiliar mathematical problem, seeming to produce the answers from within, Socrates is not entitled to conclude that a robust metaphysical thesis, like recollection, is true. To put this another way, recollection is not the only explanation as to how the boy comes to have the answers seemingly from "within himself". In fact, there are a number of other explanations as to why the boy might be able to discern the correct answers to these unfamiliar questions by turning inward.

Let us consider an alternative. Take, for example, Augustine's theory of divine illumination. ${ }^{84}$ In De Magistro, Augustine proposes that teaching and learning are made possible by divine illumination. He claims that people are not taught, nor do they learn from others (pace Socrates in the demonstration), but that things in themselves are made manifest to us by the light of God. ${ }^{85}$ Without lingering on the many interpretive difficulties often associated with this view (there is a longstanding debate as to whether God acts as an extrinsic force, imparting specific content to the soul, or merely gives one the inspiration to inquire for himself ${ }^{86}$ ), we are nevertheless in a position to see that divine illumination is another metaphysical/epistemological description of what occurs seemingly "within" the soul of the inquirer. According to this view, when a person inquires, God reveals certain truths to him. What I take this to show is that there are other possible metaphysical and epistemological accounts of the way in which someone might retrieve information by turning inward. If this is the case, however, then Socrates is not entitled to conclude, from the mere fact that the boy appears to turn inward for the answers, that he has in fact recollected something of what he once knew. 
Of course, this suggestion may not be completely fair to Socrates (Plato?). It will be good, before moving on, to say a bit more about the kind of knowledge, which Socrates thinks a person has "within himself". The theory of recollection holds that a person is born with access to a certain amount of information which can be called up by remembering. Scholars are split, however, as to whether this means the soul has innate knowledge, wholly present within it, or merely the innate disposition or capacity to reason about information and form true beliefs. ${ }^{87}$ Although I do not mean to argue definitively in such a short space for the latent knowledge view, there are, I think, a number of reasons to prefer it going forward. First, we have already seen that, at $85 \mathrm{~d} 3-6$, Plato writes about the fact that recollection consists in knowledge being retrieved "from within" the soul. This is hard to understand if what Plato really means is that we have the innate ability to make inferences and form true beliefs based on empirical observation. In what sense would knowledge gained by making inferences about gathered information be aptly described as "within" the soul? Moreover, it is worth noticing that at $85 \mathrm{~d} 9$, Socrates asks whether the slave boy must have either acquired or always had "the knowledge that he has now". ${ }^{88}$ Because the boy is not a very knowledgeable interlocutor, it seems reasonable to conclude that "the knowledge he has now" refers to whatever lies latent in the boy's soul.

Given this reading of the theory of recollection, that Plato very likely believes in some form of latent knowledge, we are now in a position to see that the theory of divine illumination is not, in fact, a viable alternative description of what happens when the boy turns inward. Divine illumination, although it may show the boy retrieving the answers seemingly from within, is not an account of how the boy comes to have latent knowledge. The theory of divine illumination takes the content of what is learned to be supplied either by God, acting as an extrinsic force, or by empirical discovery, inspired by God - either way the content of what is learned is supplied to the learner extrinsically. For this reason, because it is very likely that the demonstration argument is meant to show that the boy begins to access his latent knowledge, it would be unfair to hold that an alternative, like divine illumination, might explain how the boy comes to have the correct answers.

Nevertheless, the problem in Premise 5 remains. We have been assuming, for the sake of argument, that the slave boy does, in fact, retrieve some of the answers from "within himself”. In 
keeping with the above analysis, we might further grant that the boy has latent knowledge and that, during the demonstration, he has begun to access some of it (none of this has, in fact, been shown). It is still problematic, however, to conclude, from the fact that the boy begins to do this, that he has actually recollected anything. The theory of recollection seems to involve much more than a claim about the retrieval of latent knowledge; it is a claim about the soul and its experiences in a pre-natal state. For this reason, even if Socrates can show that the boy has retrieved some bit of latent knowledge, this is insufficient in showing that the theory of recollection holds. There could, after all, be a completely different metaphysical and epistemological account of how this knowledge came to be present in his soul.

Recollection is hardly the only explanation as to why the boy has information lying latent in his soul. Consider, for instance, Leibniz's theory of innate ideas ${ }^{89}$ In response to his empiricist contemporaries, who take the mind to be a tabula rasa that is slowly filled in by empirical investigation, ${ }^{90}$ Leibniz argues that we are able to know necessary truths, which can only be explained by a theory of innatism. Our access to necessary truths, i.e. the necessary truths of mathematics, Leibniz thinks, cannot be explained in terms of empirical investigation. It must be instead that we are born with these already present in the mind. These truths are, for Leibniz, in the mind from the time of birth. ${ }^{91}$ It would appear that, for him, our access to these innate truths is a simple fact about humans. We have access to certain innate truths as a result of our nature.

What I take this analysis to show is that there are other perfectly viable accounts of how the boy comes to have certain truths within his soul - it may be a simple fact of his birth. It follows that, even if Socrates has shown the slave boy retrieving some of his latent knowledge (which I do not think he has), it still does not follow that the boy has necessarily recollected it. Recollection is, it seems, not the only explanation of how the boy arrives at the correct answers to Socrates' questions. Even if we grant Socrates that the boy has begun to access his latent knowledge, it does not follow that he must have recollected anything (premise 5). Instead, there appear to be a number of distinct epistemological and metaphysical descriptions of how his latent knowledge got there. In order to defend premise 5, Socrates would need to further argue that 
recollection is the only explanation, or at least the best explanation, of what occurs when the boy turns inward.

Because Premise 5 is another poorly defended premise, this too seems to be a possible source of Socrates' reservations at 86b5-6. Given that recollection is but one possible explanation of how the boy comes to have latent knowledge, it is no wonder that Socrates would be unwilling to stake his case for the theory on such an argument.

\section{A hasty generalization}

The following problem is quite simple by contrast to the others. Notice that, in Premise 6, Socrates generalizes from the fact that the boy can recollect mathematical truths, to the universal statement that we can do this with any kind of knowledge $(85 \mathrm{e} 2)$. However, this premise seems to have been left largely undefended in the present discussion. It comes seemingly out of nowhere and leaves us with a number of serious puzzles: Can we recollect every piece of information in the same way? ${ }^{92}$ What if the subject of our inquiry is some ethical claim? ${ }^{93}$ Can we recollect truths about matters of skill, like writing and composition, which would seem to take years of practice?

In short, it is simply not clear from what has been shown that Premise 6 is true. Nor does this premise seem to be a valid inference, following from anything Socrates has shown. It does not follow from the fact that we can recall information about one subject, like geometry, seemingly "from within" that we can recall information about every subject in a similar manner. In fact, it seems somewhat unlikely that we can recall all types of knowledge, i.e. scientific facts or technai, "from within" the depths of our own souls. ${ }^{94}$

Because of the haste with which Socrates makes this generalization, it seems reasonable to conclude that this, the universalizing step in the demonstration argument, might be what is at issue, at 86b5-6. Socrates may be aware that he was not entitled to deduce from a single example of recollection, a universal statement that all knowledge can be acquired in the same manner. At the very least, he may be aware that such a generalization is in need of further argumentation. 


\section{The demonstration argument is inappropropriate}

I have now outlined a number of problems in the demonstration argument, many of which have been noticed by others. In this section, I present a new possibility. It is very likely, I argue, that what troubles Socrates at $86 \mathrm{~b}$ is the mere fact that he has given a demonstration in an attempt to prove an unobservable phenomenon, like recollection. This problem, I argue, acts as a sort of uber-explanation of the other problems I have identified: that Socrates does not think recollection can be demonstrated is the root-cause of most, if not all, of the other problems I have outlined. I conclude this is a very likely candidate, the best of all those we have seen, for what causes Socrates' hesitation in the disclaimer passage.

To begin, it would be good to say a bit more about why Plato would be uncomfortable with a demonstration. There are two reasons. First, given what we know about Plato's method of doing philosophy, it seems likely that he (and Socrates) would be unhappy with the very notion of a demonstrative proof. A demonstrative proof draws conclusions on the basis of our perceptions about what is happening before us. Plato, however, is famously suspicious of appearances and sense perceptions. For him, what appears to us to be the case and what actually is the case are often at odds. Consider, for example, Plato's treatment of mathematics in the Republic. In his explanation of the divided line, Plato places the geometer, who spends his time considering figures and constructing mathematical proofs, at level three, falling somewhat short of true understanding. One of the reasons Plato places the mathematicians lower on the divided line, below the fourth level, is that the mathematicians tend to think in terms of images (510d2-511a1):

[A]lthough they use visible figures and make claims about them, their thought isn't directed to them but to those other things that they are like. They make their claims for the sake of the square itself and the diagonal itself, not the diagonal they draw, and similarly with the others. These figures that they make and draw, of which shadows and reflections in water are images, they now in turn use as images, in seeking to see those others themselves that one cannot see except by means of thought.

The mathematicians, although they appear to grasp at the forms themselves, use images and diagrams, of the sort Socrates appeals to in the slave boy demonstration, to ground their arguments. In this way, they make a mistake: the mathematicians rely on images when reasoning 
about the kinds of things, the forms, which "one cannot see except by means of thought".

Dialecticians, those who are at the fourth level of the divided line, are able to inquire in this way, without any appeal to images (511b2-c2):

[By] the other subsection of the intelligible, I mean that which the reason itself grasps by the power of dialectic. It does not consider these hypotheses as first principles but truly as hypotheses - but as stepping stones to take off from, enabling it to reach the unhypothetical first principle of everything. Having grasped this principle, it reverses itself and, keeping hold of what follows from it, comes down to a conclusion without making use of anything visible at all, but only forms themselves, moving on from forms to forms, and ending in forms.

The philosopher, it seems, is one who does not use images - he does not rely on any objects of sense perception - in his search for truth. The philosopher relies, instead, on forms themselves. It would seem, based on this evidence, that Plato would be naturally disposed not to offer visual demonstrations. It is reasonable to assume that he would be suspicious of any task which relies on the objects of sense experience, rather than the objects of reason itself. It is for this reason that we might begin to doubt how strongly Plato would be willing to endorse an argument which relies entirely on what appears to be the case, as is demonstrated before our very eyes. Of course, the demonstration relies on what appears to be the case in at least two ways. First, in the foreground exchange, Socrates quite literally acts as a mathematician would, drawing figures in the sand. Furthermore, in the background exchange, Socrates claims to show, on the basis of having asked the boy a series of questions, that the boy is in fact recollecting. The boy is, it seems, himself an observable example: Meno is encouraged to take what he perceives about the boy's answers as support for the claim that recollection can and does occur. This is, I conclude, not a very Platonic way of proving the theory of recollection.

Second, it will be good to say a bit more about Plato's views on the accessibility of the inner workings of the soul. Consider, for example, in Republic Book II, where Socrates proposes that they look at the city as an analogy for the individual soul (368c-d). Here, Socrates claims that the question at hand — what makes an individual just — will be difficult to determine (368c9-d8):

The inquiry we are undertaking is not an easy one but requires keen eyesight. Therefore, since we aren't clever people, we should adopt the method of investigation that we'd use if, 
lacking keen eyesight, we were told to read small letters from a distance and then noticed that the same letters existed elsewhere in a larger size and on a larger surface. We'd consider it a godsend, I think, to be allowed to read the larger one first and then to examine the smaller ones to see whether they really are the same.

In this passage, Socrates claims that they do not have a very clear picture of what they hope to investigate, which is, of course, the nature of justice in the soul. He further compares their investigation to looking at something at a distance. I take this to mean that Socrates does not think it is easy to observe what justice amounts to in the individual. They cannot, at a glance, simply observe what the inner workings of a just soul are like. Socrates chooses to use the metaphor of the city, therefore, in order to consider justice on a larger scale as it operates on a societal level.

Similarly, in the Phaedrus, Socrates claims that it is very difficult to speak about the inner workings of the soul. Just before he introduces the image of the tripartite chariot team, Socrates claims that to give a full account of the true nature of the soul would be a "superhuman" task (246a4). It is only "within the power of a human", he claims, "to describe the soul briefly in a figure" (246a5). Socrates once again chooses to discuss the soul metaphorically, because he thinks it is difficult, if not impossible, to know its inner workings.

If this is the case, however, if Plato thinks that we cannot easily know about the interior life of the soul then it should strike us as very strange indeed that, in the demonstration argument, Socrates proposes to draw a conclusion about what is happening in the slave boy's soul, purely on the basis of how he answers questions. Socrates takes the boy's answers to be indicative of a phenomenon, which, if it does ever occur, is completely imperceptible - recollection is, after all, the retrieval of knowledge by a person from within his own soul (85d3-6). It is baffling, therefore, that Socrates delivers, of all things, a demonstrative proof of this theory. An argument, based on observation alone, would appear especially ill-fitted to showing that the boy has in fact begun to recollect something of what he once knew.

The other possible sources of Socrates' hesitation have been very speculative. This particular point is different, however, in that it garners some, albeit limited, support from the text. At the outset of the demonstration, Socrates shows a certain suspicion of the method of argument that Meno requests. Meno asks Socrates to prove to him that recollection is, in fact, a 
true account of how we come to know: "But if you can somehow prove to me that this is as you

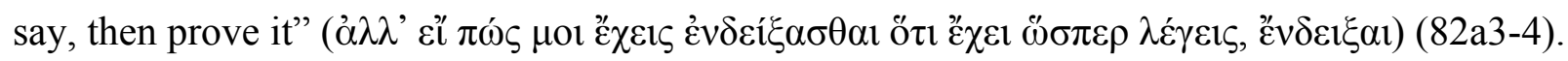
Socrates responds that this will be no easy matter, but that he will try for Meno's sake ( $\alpha \lambda \lambda^{\prime}$ ' $\varepsilon \sigma \tau \imath$

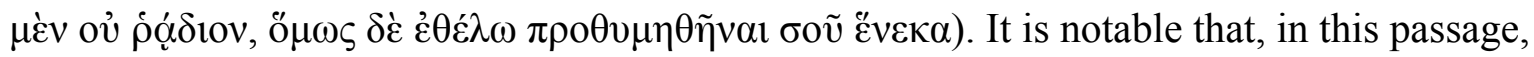
Meno asks Socrates if it is possible to prove ( $\dot{\varepsilon} v \delta \varepsilon i \xi \alpha \sigma \theta \alpha$ l) the theory of recollection. Although it may appear that Meno is simply demanding an additional argument for the theory of recollection, the verb he uses often connotes a very specific sort of argument, a demonstration or display. ${ }^{95}$ It would appear, therefore, that Meno is asking for a particular kind of argument-a demonstration or display which proves that recollection occurs and is the sole means by which we come to know. Socrates responds to this request with some hesitation, however. He claims that such a proof will not be easy (ov̉ $\rho \alpha \underline{\alpha} \delta 10 v$ ) to produce, but that he is nevertheless willing to try for Meno's sake (82a5-6). Although Socrates does not say that it is impossible to prove recollection in this way, it is telling that he hesitates, seemingly on the basis of the kind of proof Meno has demanded. And, when he says that he will try to give such a proof, he claims to do so, purely for Meno's sake.

What I take this exchange to show is that Socrates has reservations, here at the start of the demonstration, about his ability to offer a demonstrative proof of the theory. Given this evidence, and, given what we know about Plato's own hesitancy to put any stock in what only appears to be the case, especially (as we shall see below) in matters of the inner workings of the soul, it seems very likely that this feature may be what ultimately causes Socrates to claim to be unwilling to 'put his trust in' the demonstration argument. In short, it is very likely that Socrates does not think that a demonstration is a powerful enough tool to draw conclusions about a purely imperceptible phenomenon like recollection.

There is, I shall argue, one other reason to think that this particular flaw is what Socrates has in mind at $86 \mathrm{~b}$. This view, that what Socrates objects to in the demonstration argument is its use of a perceptible method of proof for an imperceptible phenomenon, helps to explain most of the other flaws I have identified here. To put this another way, many of the above flaws are, in some way, caused by the fact that recollection cannot be observed. Consider the first problem: 
Socrates seems to adopt an overly narrow definition of teaching. If I am correct that Socrates is suspicious of using a demonstrative proof for imperceptible phenomena, then this might explain why he adopts such a narrow definition of teaching. The narrow definition of teaching, as dictation, is something that we can rightly perceive. If Socrates is dictating information to the boy, this is something that we can know on the basis of what we have observed. Plato's own definition of teaching — guiding the soul through the early stages of recollection — would be, by contrast, much harder to perceive. Because recollection is imperceptible, it is impossible to know, on the basis of a demonstration, whether or not a person has begun to recollect anything. It is no wonder, therefore, that Socrates should feel the need to restrict his concept of teaching to dictation, which is clearly demonstrable.

The view that recollection is indemonstrable helps to explain the second problem, as well. I argued above that we cannot be sure on the basis of what has been shown that the slave boy is, in fact, getting any of his answers from "within himself". Socrates supplies him with too much information for us to be sure. Once again, this problem seems to be explained in terms of the fact that recollection cannot be perceived - it seems impossible to determine, based on what we have seen in the demonstration, whether the boy is in fact recollecting the answers from within his own soul. It is no wonder, then, that Socrates must force this premise; in order to make the demonstration argument go through, Socrates must state outright that the boy is retrieving the answers from "within himself". This view also helps to explain the third problem above. Even if we could determine that the boy is turning inward for the answers, this is not enough to show that he has recollected anything. Once again, the reason for this seems to be that recollection is an imperceptible phenomenon. And once again, it appears that in order to make the demonstration argument go through, Socrates must force this unwarranted result; he must insist that his turning inward for the answers is sufficient proof that the slave boy has, in fact, recollected some of what he once knew. In reality, however, we have observed nothing to this effect.

If the above analysis is correct, then what Socrates would not endorse at $86 \mathrm{~b}$ is the type of proof that he has offered Meno. He would not be willing to put his trust in the demonstration argument insofar as it is insufficient proof that recollection, an imperceptible phenomenon, 
actually occurs. My reasons for thinking that this is what Socrates has in mind are, first, that he seems to hesitate on the same basis at the outset of the demonstration, and, second, that this view helps to explain most of the other flaws I have identified in the demonstration argument. Because a demonstration is not powerful enough to show, definitively, what happens within a person's soul, Socrates is forced to ram through a number of unwarranted conclusions about what happens within the boy's soul.

At the end of this section, I want to emphasize, however, that the above solution is just one of many possibilities. Although this is the best solution we have seen, it is nevertheless impossible to conclude that this must be exactly what he has in mind at $86 \mathrm{~b}$. For this reason, I am inclined to treat this entire exercise as speculation. I am also inclined to admit that there are likely to be many other possible deficiencies in the demonstration argument. Of course, this uncertainty should not cause us to forego any of the conclusions of our previous analysis: whatever the cause of Socrates' reservations, whatever the deficiency in the demonstration argument, it is both specific enough and severe enough to warrant his unwillingness to confidently endorse this argument as support for the theory of recollection. Instead, Socrates seems to rest his case for recollection on the pragmatic reason that we will be better and braver if we believe the theory of recollection, than if we believe the eristic argument.

\section{$I V$. The pragmatic reason}

If I am correct in my assessment of the Meno, Socrates (or should I say Plato) is aware of having presented a weak argument in favor of the theory of recollection. However, if Plato is aware of having given an unconvincing argument on the part of Socrates, then a host of pressing questions arises. In particular, why should Socrates give an argument which he does not find convincing if only to disclaim it shortly thereafter? And, moreover, how are we to reconcile this with the spirit of Platonic philosophy more generally, known both for its rigor and commitment to truth and honesty? As I mentioned in the introduction to this study, I take the answer to these question to be closely related to another, rather surprising feature of the passage in question. Having failed to give a convincing argument for the theory of recollection, Socrates goes on to invoke a pragmatic reason in its defense. Although he is not willing to stake his case for 
recollection on the demonstration argument, he endorses the view because believing it will be a good thing to do. He claims (86c12):

...we will be better men, braver and less idle, if we believe that one must search for the things one does not know, rather than if we believe that it is not possible to find out what we do not know and that we must not look for it.

Socrates encourages Meno to believe in the theory of recollection, even in the absence of proof that the theory is true, insofar as believing it will make him better, braver and less idle.

But why does Socrates rest his defense of recollection on a pragmatic reason? In the introduction to this study, I argued that it is surprising to find any pragmatic reasoning on the part of Socrates. Plato seems elsewhere to maintain "the veridicity principle", which states that a person ought to believe a claim, $\mathrm{x}$, only insofar as he has a reason for thinking that $\mathrm{x}$ is, in fact, true. In fact, the dialogues often show that a person ought to abstain from believing a claim, unless she has veridical basis - a reason, argument, proof, or explanation - as to why the claim in question is likely to be true. We would expect Plato to think, therefore, that a reasonable person ought only to form beliefs based on the strength of her conviction that the belief in question is true. If a person has no veridical basis for a belief, if she has no reason to think that it is accurate, then, presumably, she ought to abstain from believing it. Pragmatic reasons, however, insofar as they do not seem to offer a veridical basis for belief, do not seem fully consistent with the veridicity principle. They make a claim about what it is good to believe, rather than about what is true or accurate. It is surprising, then, that we should find Socrates endorsing reasoning of the form: "It is good to believe x, so you ought to believe x."

So why does this happen? Does Plato actually think that pragmatic reasoning is sufficient justification for believing in the theory of recollection? And if so, why does Socrates go to the trouble of presenting an argument, albeit an unconvincing one, for the truth of the theory? Indeed, why should Socrates ever give any arguments as to the truth of any view? If pragmatic reasons are sufficient justification for belief, why not simply set about to decipher what it is most beneficial for us to believe and set other considerations aside? And, finally, how are we to reconcile these pragmatic reasons with the explicit methods and goals of Platonic philosophy - the pursuit of truth through careful argumentation? In the present context, we might 
begin to address these questions by asking: Why does Socrates give Meno an unconvincing argument if only to disclaim it a few pages later? And why does he rest his case for recollection on the fact that the theory will be good to believe?

I am inclined to read Socrates' exchange with Meno as an honest record of what it is like to do and teach philosophy in the real world: His interlocutor is relatively dense, but he is nevertheless armed with a potent objection, one that cuts to the heart of philosophical inquiry. Moreover, Socrates seems to struggle, in a such a limited space, to fulfill Meno's demands, proving demonstratively that recollection actually occurs. Ultimately, he fails to offer a defense of recollection on veridical terms. Plato seems, therefore, to be reflecting on what happens when the philosopher has his back up against the wall, when his tools fail him, or when he follows reason down an unproductive path. Plato's depiction of this situation is, I have argued, a somewhat unexpected one. He shows Socrates maintaining a view without a veridical basis for doing so. However, there may be a good reason for this.

Consider what is at stake in this part of the dialogue. If we were to accept the conclusion of the eristic dilemma, we would be forced into intellectual stagnation. Believing that one cannot inquire into the nature of anything unknown would ultimately lead us to believe that the search for truth is pointless and that we ought not to waste our time. This result has thoroughgoing implications, both for individuals and for society at large. If it is futile to inquire, then one need not worry about or try to escape his own ignorance. Not only will such a person's mental life cease, but, because most pursuits involve the discovery and perfection of some kind of knowledge, there will be almost no career or pastime available to him. His only outlet will be to convince others to join him in his pitiful state. And, if society at large operates in this way, if people do not believe it is possible to discover anything, they will have no reason to question themselves or their actions, left to act instinctively, harshly, and literally without thinking. This is, I take it, what makes the eristic argument so insidious: It appears to crush one's mental life, while justifying careless action.

Once we begin to recognize the thoroughgoing implications of the eristic dilemma, it becomes clear that this is not merely a playful argument, thrown in the path of Socrates as an obstacle to the present discussion. Instead, it is a direct assault on the importance of considered 
action. We might even go so far as to say that the eristic dilemma threatens the very foundations of philosophical inquiry - it assaults the belief that we can and should search for what we do not already know. It is no wonder, then, that Socrates attempts to argue against this view. It is also no wonder that he should attempt to argue on grounds of truth, even if his argument turns out to be an imperfect one. Socrates is, here, defending the philosophical way of life, showing that philosophical inquiry, even when it fails to yield convincing results is the far more beneficial way of life.

Consequently, while Plato does show Socrates endorsing a view without sufficient proof that the view is correct, something that a philosopher ought not to do in an ideal situation, he seems to do so because the alternative is so bleak. The eristic argument threatens the motivations central to philosophical progress. It threatens the very idea that we can inquire after and discover what we do not already know. Because Socrates is unwilling to give up on philosophical inquiry, he must do something to combat the eristic argument. So what does he do? He first attempts a veridical defense of his view, supporting recollection with the demonstration argument. Because, however, this argument is ultimately unconvincing, because a proof by demonstration is insufficient evidence of an imperceptible phenomenon, Socrates must do something else to defend his view and fight off the view that we cannot inquire into that which we do not already know. His final line of defense seems to be the pragmatic argument.

The pragmatic argument "props-up" Socrates' defense of the theory of recollection, clearing the way for future investigation. Even if the pragmatic argument is not itself sufficient justification for a belief in the theory of recollection, it might at the very least provide us with sufficient motivation to revisit the discussion. Because it will be better for us to believe in the possibility of inquiry, we have every reason to revisit the questions of this part of the dialogue in the future, determining definitively how we come to have knowledge and whether the theory of recollection holds. If, however, Socrates could provide no defense of inquiry whatsoever, the game would be up. The eristic argument would prevail, and with it we would lose all motivation for any kind of philosophical inquiry. I conclude that the pragmatic reason is by and large intended as a motivational argument. It is intended to dispel the eristic argument, so that we might revisit the topics under discussion. Similarly, this line of thinking can, I think, explain why 
Socrates presents an unconvincing argument for the theory's truth, only to disclaim it in the lines that follow. The demonstration argument is, ultimately, a stop-gap of sorts. Socrates recognizes that he ought to argue for the truth of his view, but that such an argument will be very difficult to deliver. Although it would have been better to present a deductively-valid, convincing argument for the truth of recollection, such a task would have been impractical, especially given Meno's request for a demonstrative proof. It is difficult to imagine what a proper demonstration of recollection would actually look like. It is even more difficult to imagine what it would look like in such a short space. Socrates cannot simply, by drawing lines in the sand, the approach which Meno himself suggests, show beyond the shadow of doubt that the slave boy has retrieved something "from within" his soul, let alone that all of what we call "learning" is recollection. A demonstrative proof of recollection seems hard to come by, in that one must show not only that a person has come to have knowledge despite not being taught, but that the knowledge he has come to have originates "from within" his soul and was acquired at a point before he was embodied.

This part of the Meno can, I conclude, be read as a lesson in philosophical commitment. Sometimes the process of developing arguments goes poorly, and some forms of argumentation will be better suited to showing certain kinds of conclusions. Of course, we cannot always know what the limitations of an argument will be until we have pursued it. That being said, the lesson of the Meno seems to be about the proper response to such situations. The proper response is not to give up, like Meno, who, when he had his back up against the wall, begins to question the very project of philosophical inquiry. When our sincere efforts fails, we ought not to abandon the prospect of inquiry altogether. Plato shows Socrates taking a different route; although his defense of recollection is ultimately shaky, he does not turn on the method of argumentation itself. To do so would be to throw the baby out with the bathwater. When the demonstration argument fails him, Socrates does not turn on the philosophical project altogether. Instead, he presents a very good reason to stay motivated: Believing that we can inquire will be a far better way of life for individuals, in their mental lives and as members of society at large. 


\section{WORKS CITED}

Allen, R. E. 1959. “Anamnesis in Plato's Meno and Phaedo.” The Review of Metaphysics 13: $165-174$.

Bluck, R. S. 2010. Plato's Meno. Cambridge: Cambridge University Press.

Brickhouse, T. C. and Smith, N. D. 1994. Plato's Socrates. Oxford: Oxford University Press.

Brumbaugh, Robert S. 1990, “Understanding Plato.” Ancient Philosophy 10: 299-301.

Calvert, B. 1975. "Meno's Paradox Reconsidered." Journal of the History of Philosophy Journal of the History of Philosophy 12: 143-152.

Desjardins, R. 1985. "Knowledge and Virtue: Paradox in Plato's Meno." The Review of Metaphysics 39: 261-281.

Devereux, D. T. 1978. "Nature and Teaching in Plato's Meno." Phronesis 23: 118-26.

Diogenes. 1925. Lives of Eminent Philosophers II. Trans. Hicks, Robert D. Cambridge: Harvard University Press.

Ebert, T. 1973. "Plato's Theory of Recollection Reconsidered an Interpretation of Meno 80a-86c." Man and World Man and World 6: 163-181.

Fine, G. 1992. "Inquiry in the Meno." In The Cambridge Companion to Plato, ed. Richard Kraut. Cambridge: Cambridge University Press, 200-226.

—. 1993. On Ideas: Aristotle's Criticism of Plato's Theory of Forms, Oxford: Oxford University Press. . 2014. The Possibility of Inquiry: Meno's Paradox from Socrates to Sextus. Oxford: Oxford: Oxford University Press.

Fowler, H. N. 1966. Euthyphro, Apology, Crito, Phaedo, Phaedrus. London: Harvard University Press.

Gulley, N. 2013. Plato's Theory of Knowledge (Routledge Revivals). Routledge.

Ionescu, C. 2007. Plato's Meno: An Interpretation. Lanham, MD: Lexington Books.

Irwin, T. 1995. Plato's Ethics. New York: Oxford University Press.

Klein, J. 1965. A Commentary on Plato's Meno. Chapel Hill: University of North Carolina Press.

Klosko, G. 1987. "Plato and the Morality of Fallacy" The American Journal of Philology 108: 612-626. 
Kraut, R. 1984. Socrates and the State. Princeton: Princeton University Press.

Leibniz. 1981. New Essays on Human Understanding. Trans. Remnant, P. and Bennett, J. Cambridge: New York, Cambridge University Press.

Moravcsik, J. 1971. "Learning as Recollection.” In Plato, Vol. 1: Metaphysics and Epistemology, ed. Gregory Vlastos. Garden City, N.Y: Doubleday, 53-69.

Nehamas, A. 1994. “Meno's Paradox and Socrates as a Teacher.” In Plato's Meno in Focus, ed. Jane M. Day. London and New York: Routledge, 221-248.

Popper, K. et. al. 1998. The World of Parmenides: Essays on the Presocratic Enlightenment. New York: Routledge.

Rohatyn, D. A. 1980. “Reflections on Meno's Paradox.” Apeiron 14: 69-73.

Ryle, G. 1976. "Many Things Are Odd about Our Meno.” Paideia 5: 1-9.

Schumacher, L. Divine Illumination: The History and Future of Augustine's Theory of Knowledge. Chichester: Wiley-Blackwell.

Scott, D. 2006. Plato's Meno. Cambridge: Cambridge University Press.

Sedley, D. N. and Long, A. 2010. Meno and Phaedo. New York: Cambridge University Press.

Sharples, R.W. 1985. Meno. Chicago: Aris \& Phillips.

Thomas, J. F. 1980. Musings on the Meno. The Hague: Martinus Nijhoff.

Umphrey, S. 1990. Zetetic Skepticism. Waterfield, N.H.: Longwood Academic

Vlastos, G. 1965. “Anamnesis in the Meno.” Dialogue 4: 143-67.

Weiss, R. 2001. Virtue in the Cave: Moral Inquiry in Plato's Meno. New York: Oxford University Press.

Werner, D. 2007. "Plato's Phaedrus and the Problem of Unity.” Oxford Studies in Ancient Philosophy 32: 91-137.

Woodruff, P. "Plato's Early Theory of Knowledge." In Companions to Ancient Thought, vol. 1, Epistemology, ed. Stephen Everson. Cambridge: Cambridge University Press, 60-84. 


\section{A NOTE ON CHAPTERS ONE AND TWO}

The first chapter addresses a case in which Socrates is aware of having presented a bad argument, one that he himself finds unconvincing. In particular, it appears that Socrates is not willing to endorse the the demonstration argument in favor of the theory of recollection. Near the end of the chapter, we also began to examine the related puzzle as to why Socrates, having provided an unconvincing argument, rests his case instead on a pragmatic reason for belief. Believing in the theory of recollection will be better than believing in the eristic argument, that we cannot inquire after or discover what we do not already know-this is why, Socrates claims, Meno ought to believe him. Such a pragmatic defense is problematic, however, in that Plato seems committed elsewhere to the veridicity principle, the view that we ought only to venture to believe things which we have a basis for thinking are true. Socrates' defense of the theory of recollection is problematic, then, in that he sets aside the truth of the theory, considering instead what benefits will befall those who believe it.

I also began to argue for a solution to this problem. Socrates gives an unconvincing argument, followed by a pragmatic defense of the theory of recollection, because his prime concern in the dialogue is to lead Meno, along with all of Plato's readers, to adopt a better way of life. If Meno comes to believe in the conclusions of the eristic argument, then he will have no reason to pursue the truth, and no reason to do philosophy. If it is impossible to come to know what we do not know, it seems to follow that Meno would be better off not wasting his time in the search. If, however, Socrates can convince him of the opposing theory - the theory of recollection-Meno will come to believe that it is possible to search out and discover what we do not know. As a result, he will be much better off: believing in the theory of recollection will prevent intellectual stagnation. This is why, I have argued, we ought to read Socrates' defense of the theory of recollection, tenuous as it may be, as intended, more generally, as a defense of the philosophical way of life.

This is not, however, a completely sufficient explanation. There is, it seems, still somewhat of a problem: it seems odd that Socrates should, as a matter of defending the philosophical way of life, employ an unconvincing argument, resting his case instead on a 
pragmatic reason. Why indeed should Socrates, of all people, present a bad argument in favor of the philosophical way of life? Why not convince Meno through dialectical argument that the pursuit of truth is the better way of life? This would, after all, seem to be more in line with Plato's thinking about when it is appropriate to form a belief.

The following chapter will, I think, do much to resolve this further problem. I shall explore a very similar case in the Phaedo. To anticipate, the majority of the chapter is devoted to reconstructing the argument of the dialogue as a whole, in order to properly understand the function of the myth at the end. The myth is, I shall argue, a part of the overall argument against the fear of death; in fact, it bolsters the little-discussed but crucial premise (what I call "the otherworldly rewards premise") that when the souls of good men enter the afterlife, they reap the rewards of a life well lived, passing into the company of the gods. At the end of the dialogue, however, following the myth in which Socrates discusses the fate of the souls of good and bad men, we find a disclaimer very much like the one we have just seen. Socrates claims that it would not be appropriate for a reasonable person to confidently affirm what he has just said (114d). Yet, he claims, it is appropriate to venture to believe a story like the one he's told, insofar as such a story is good to believe. It would appear, therefore, that there is a similar puzzle in the Phaedo. Having given an argument against the fear of death-a premise of which Socrates is aware has been poorly defended-he recommends that we believe it nevertheless for purely pragmatic reasons. Believing that good men will go to a good afterlife will, it seems, be beneficial to believe. I shall argue that the reason for this is that Plato thinks the only way to approach death in a state of tranquility, with a clear mind, free of fear, is to believe that the soul goes on to a befitting afterlife.

However, if this is correct, then, once again, it looks like Socrates is violating the veridicity principle, the view that we ought form beliefs on the basis of thinking that the claim in question is likely to be true. Here, he recommends instead that we believe a tale about the afterlife, on the basis of the benefits of believing such a story. Once again, we might wonder why Socrates should think it appropriate to believe something that he has defended poorly, which his interlocutor, and all of Plato's readers, seem to have little or no veridical basis for believing. If Socrates cannot produce a good argument, if he rests a central premise of his argument on a myth 
which he is very much aware is only a tenuous defense, then what reason does he have to recommend his own view?

To anticipate, at the end of this chapter, I shall advance the view that the Phaedo myth is acceptable to believe, because, even if it turns out to be a false and inaccurate account of what happens to the soul on its departure from the body, it is nevertheless the sort of belief which will not harm the soul in the way that other falsehoods do. Believing that the soul goes on to a good and befitting afterlife, in accordance with its life on earth, will be good for a person to believe, encouraging him to be a good person on earth. Even if it turns out to be a false account of what happens to the soul on its departure from the body, even if we face a radically different existence in death, this will be good and beneficial for a person to believe in this life. This is, I shall argue, a promising solution to the problem which stands at the heart of both of these chapters. Socrates violates the veridicity principle in both cases because the beliefs in question are of a special sort. The theory of recollection and the otherworldly rewards premise are special, in that, they do not harm the soul in the way that other falsehoods do. Both will be good for a person to believe-leading him to a life in the pursuit of truth - even if they turn out to be inaccurate accounts of the soul and its otherworldly existence. 


\section{CHAPTER TWO: THE PHAEDO}

The conversation of the Phaedo begins with Cebes, Simmias, and Crito asking how Socrates is bearing his sentence so easily (63a6-7). In response, Socrates puts forward what will be the central claim of the dialogue, that "that a man who has truly spent his life in philosophy is probably right to be of good cheer in the face of death and to be very hopeful that after death he will attain the greatest blessings yonder." (63e4-64a1). ${ }^{96}$ Death, Socrates claims, is nothing other than the separation of the soul from the body (64c4-8). Because philosophers seek wisdom and a life free from bodily concerns (64d-69e), it follows that, when a philosopher dies, he gets what he has been seeking all his life. It would be absurd to wish to be completely free of bodily concerns and yet fear death when it comes (67e2-8). At this point, Cebes interrupts, claiming that Socrates' argument assumes that the soul is immortal and that it possesses some capacity for reasoning in the afterlife (69e3-70b3). Cebes finds this assumption troubling and the interlocutors turn their attention to a discussion of the immortality of the soul (70-107). This lengthy exchange concludes with the interlocutors finally agreeing that the soul must be "deathless and indestructible" (107a1-2).

At the end of the dialogue, Socrates recounts a myth, describing the route which souls take into the afterlife. Each soul, he claims, is led by a guide into different parts of the underworld. The soul that has done philosophy fares well, following its guide easily, whereas the soul that has been accustomed to bodily pleasures fares poorly (108c, 113d-114b). The myth further describes the geography of the underworld, claiming that each soul is sentenced to live in different regions, according to its character in life (113d-114b). Those who have led "an average life" are taken to the Acherusian lake, where they are purified of their wrongdoings and rewarded for their good deeds (113d3-4). The "incurable souls" are sent to Tartarus (113e4-6). The pious are freed from the recesses of the underworld and sent to dwell on earth (114c1-3). The philosophers, a special class of the good souls, are sent to live in "even more beautiful dwelling places", which Socrates describes as being "in the future altogether without a body" (114c3-5).

It is surprising that Socrates presents a myth in the final moments of his life. Why should Socrates, of all people, tell a tale, ripe with religious and scientific-sounding claims about the 
soul and its journey into the next world? We would expect Socrates, a defender of the philosophical life, to prefer a different mode of communication. This puzzle is made even stronger by the fact that, immediately following the myth, Socrates claims that a reasonable man ought not to have confidence in what he has just said, but that he might nevertheless coax himself into believing such a story (114d1-6):

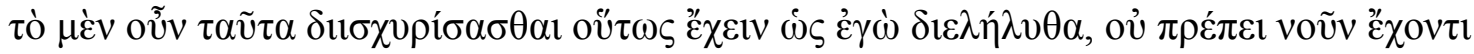

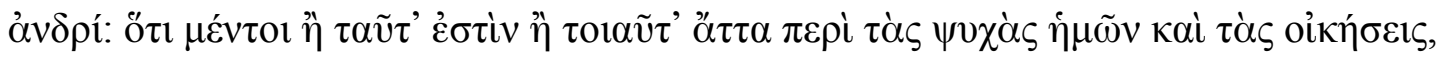

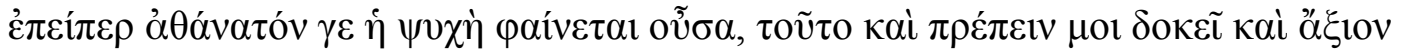

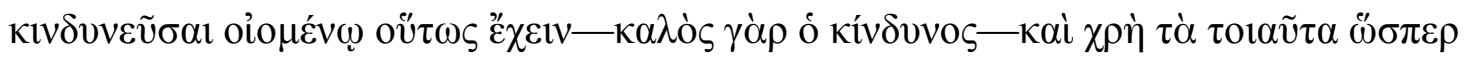

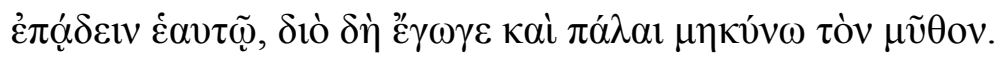

It is not fitting for a man possessing reason to confidently assert these things are just so, as I have described them: but I think it is fitting for a man to risk the belief - for the risk is a noble one - that this, or something like this, is true about our souls and their dwelling places, since the soul is evidently immortal, and a man should repeat this to himself as if it were an incantation, which is why I have been prolonging my tale. ${ }^{97}$

What does it mean that "it is not fitting for a man possessing reason to confidently assert these things are just so, as I have described them"? What exactly has been unconvincing in the preceding tale? Moreover, why does Socrates think it is nevertheless fitting to "risk" a belief in what he has said, repeating it to himself as if it were a charm or incantation? And what does he mean by 'risk' a belief? Are we supposed to stake a belief in a position despite not having any reason to?

In an effort to address these questions, this chapter will present a new reading of the function of the myth at the end of the Phaedo. I argue that Socrates introduces the myth because he is aware of having given short shrift to a key premise in his argument against the fear of death. The myth is, we shall see, the first open discussion of the "otherworldly rewards premise" (ORP). ${ }^{98}$ The ORP claims that the afterlife is arranged in such a way that souls are rewarded, according to their earthly demeanor. Good and philosophical souls fare well, whereas bad and unphilosophical souls fare poorly. The argument against the fear of death turns on the ORP, just as much as it turns on the immortality of the soul. It is only reasonable to not fear death if, in 
fact, the soul is rewarded, going on to a good and favorable existence. But Socrates suspends any examination of this premise until the end of the dialogue. What is more, I argue, when it finally does come, this examination - the myth — is not a sufficient defense. The myth sets out a detailed account of what the afterlife is like. It does not, however, prove that the ORP must be true. This is why Socrates delivers the above disclaimer: at the end of the Phaedo, it is still an open question as to whether the soul of the philosopher-whether his own soul—will embark on a journey that is befitting its earthly merits. For all we know, for all Socrates knows, even the best of souls survive death only to be cast into the depths of Hades. In order to achieve tranquility in the face of death, it is fitting therefore to convince ourselves of such a story about what happens to the soul.

I have divided this chapter into four parts. In the first part, I discuss two common debates about Plato's use of myth. In part two, I argue that the myth is the first open discussion of the ORP - the assumption that the soul of the philosopher, once it is separated from the body, must go to a good and favorable afterlife. In the third part, I turn to the disclaimer at the end of the myth. Why does Socrates think it would be unreasonable to "confidently affirm" what he has said (114d)? And what exactly about the tale that causes this hesitation? In the fourth part, I examine Socrates' prescription that it is fitting, nevertheless, to accept the myth on seemingly pragmatic grounds. We ought to risk believing such a story, because the risk will be worthwhile. But what good will it do to become convinced of an unproven account? Why should a person strive to believe a far-fetched account of the soul's journey into the next world?

\section{The function of the Phaedo myth}

Scholars have tended to take a number of approaches to the general function of Plato's eschatological myths. ${ }^{99}$ They are divided, primarily, over the question of whether or not the myths are intended as sincere accounts. Do Plato's myths express his own philosophical views or are they literary devices of another sort? One approach is to read the eschatological myths as expressing what Plato (or Socrates) actually thought about the soul and its journey into the afterlife. Werner brands this "the dogmatic view" in that scholars in this camp take the myths to 
be expressing Platonic dogma. ${ }^{100}{ }^{101}$ When, for example, Plato says in the Phaedo that incurable souls are hurled into Tartarus (113e), this approach takes it that Plato is giving an unvarnished explanation of what he actually thought happened to bad souls in the afterlife. ${ }^{102}$ Martha Nussbaum is a dogmatist about the Phaedo myth, arguing that it reinforces many of the philosophical points already made. ${ }^{103}$ In particular, she argues that the myth further supports the arguments about immortality of the soul. ${ }^{104}$

Of course, many have understood the truth value of the myths very differently. A second, somewhat extreme, approach treats the myths as entirely resistant to philosophical interpretation or as literary embellishments that are subordinate to the arguments of the dialogues. David Gallop, for example, claims that Plato's afterlife myths tend to resist both philosophical analysis and literal interpretation. ${ }^{105}$ Julia Annas characterizes this as the tendency to treat the myths as "an optional extra for those who like stories." 106 Those who take this approach tend to think that we cannot garner information about Plato's own views from the myths, because he was suspicious of the truth value of myth in general. ${ }^{107}$ This is what leads Werner to brand this "the debunking view", in that scholars who take this tack find nothing of philosophical value in the afterlife myths. Debunkers approach them as, at best, worthy of literary interpretation but not philosophical analysis.

The third approach falls somewhere between the first two. Scholars in this camp treat the myths as complex metaphors, from which we can extract certain philosophical claims or lessons. In what follows, I refer to this approach, generally, as "the symbolic view". The symbolic view takes the details of a given myth, i.e. the complicated cosmic geography in the Phaedo myth, not to be intended as a literal philosophic or scientific account, so much as an allegorical rendering of some philosophically important claim. ${ }^{108}$ In the last chapter, we saw a number of scholars advance this interpretation of the recollection passage in the Meno; Bluck, Fine and Sharples argue that the strange, mythical-sounding details presented alongside the theory of recollection ought not to be interpreted as Plato's actual views about what happens to the soul when it departs from the body. ${ }^{109}$ These details are, they claim, less important than the philosophically important lesson that we are capable of searching out and discovering what we do not already know. In short, this is the view that Plato would accept certain claims that follow from the myths, despite 
not thinking of the myths as scientifically and metaphysically accurate.

As a matter of introduction, it is also worth noting a related debate about rationality and the myths. Scholars have often wondered whether the myths are meant to appeal to reason or the emotions. Should we view them as having the same aim as rational discourse or are they subordinate to the arguments of the dialogues? Many (especially dogmatists) take the myths to be complementary to rational discourse, sharing in the same aims. In what follows, I refer to this as "the rationalist view". Nussbaum, as I mentioned above, takes the Phaedo myth to be an extension of the other arguments of the dialogue about the immortality of the soul. Myths of this sort, according to her, "show forth general philosophical views for which [Socrates] has already argued." ${ }^{110}$ She contrasts the Phaedo myth with others, like the tale in the palinode, which, she thinks, appeals to the non-rational parts of the soul and has purely emotive motivational force. As we shall see, the palinode is highly literary, with many rhetorical flourishes and a number of appeals to images which evoke the passion of love. The Phaedo myth is different, Nussbaum argues, because it is a paradigm case in which Plato appeals to our reason: he uses the myth to "dampen 'mad' passion rather than to arouse it." 111

A second camp has thought that the myths do precisely the opposite; they are meant to excite the non-rational parts of the soul, acting as extra-rational or arational supplements to the arguments of the dialogues. David White has argued that the myth at the end of the Phaedo appeals to Simmias' emotions, who, despite having agreed to a number of arguments about the immortality of the soul, remains unconvinced on rational grounds. ${ }^{12}$ At the end of the discussion, Simmias expresses that, although he has no reason to doubt the preceding arguments, he still has some misgivings about what has been said (107b1-3). Plato includes the myth in order to appeal to his sentiments, White argues, thereby convincing Simmias of the immortality of the soul where rational arguments have failed to do so. White goes on to read this incident as suggestive of the insufficiency of rational arguments in general and attributes to Plato the view that reason alone will sometimes not be able to convince us of certain important philosophical truths. ${ }^{113}$ Werner brands this approach to the "the yogic view", for its similarity to the yogic claim that certain forms of meditation aim to transcend "logical-conceptual thought." 114 The 
yogic view claims that the myths are Plato's method of expressing truths which cannot be expressed through reason and rational argument alone.

To anticipate, my reading of the Phaedo myth will touch on both of these debates. With respect to the second debate - are the myths part of or subordinate to the arguments of the dialogues?-I will offer an interpretation that is squarely within the rationalist camp. We shall see below, in section II, that the Phaedo myth is meant to address the ORP. The myth seems to defend a key assumption in the argument against the fear of death, which Plato has left hanging until the end of the discussion. However, I will also argue that the myth is unsuccessful in this capacity: although we can understand it as having rational aims, the myth does not constitute a proper argument for the ORP. At the end of the dialogue, we are left to wonder what, ultimately, becomes of the souls of good men.

With respect to the other debate-is the Phaedo myth a literal account of what Plato thinks happens when we die?-I will present a somewhat more nuanced position than those I have described above. First, I argue that Socrates himself tells us not to take the myth dogmatically. Following on the heels of the myth, he claims that it is not fitting for a man possessing reason to "confidently affirm" ( $\delta ı \sigma \chi v \rho i \sigma \alpha \sigma \theta \alpha l)$ that the afterlife is just as has described it (114d). ${ }^{115}$ It would appear, therefore, that Plato does not mean the myth to be expressive of his own, well-thought out views about the afterlife. However, at 114d, Socrates further claims that, despite the fact that the myth is not intended as an accurate account, it is nevertheless fitting to convince ourselves of such a story "about our souls and their dwelling places". Socrates seems to think that it is appropriate to believe the myth. This creates a tension. In one breath, Socrates says that the myth is not intended as an accurate account of what happens to the soul when we die. In the next breath, he tells us it is nevertheless fitting to believe it.

In response to this tension, I argue that Plato is not, in this part of the dialogue, putting forward his own well thought out philosophical views. The myth is, however, not purely symbolic. It is not solely an allegory offered in support of some philosophical moral. Instead, the best way to understand the passage is as follows: as truthseekers, we ought to be aware that the myth is not an accurate account of the afterlife, and we ought, as far as we are able, search to 
better understand what happens to the soul on its departure from the body. Nevertheless, as human beings, as mere mortals who will one day face our own deaths, it will be of great benefit to us, in the absence of a better account, to accustom ourselves to believing some such story about the soul and its future dwellings. This is, in many ways a testament to the usefulness of myth: a story such as this has the unique ability to bring us tranquility in the face of death.

I shall take up each of these points in more detail below. The following section argues that the myth is central to the arguments of the dialogue and appears, therefore, to have a rational aim.

\section{The argument against the fear of death and the ORP}

In the sections that follow, in an effort to show the rational function of the Phaedo myth, I outline the basic trajectory of the argument against the fear of death. In particular, I argue that the overarching argument of the dialogue - that the philosopher is justified in not fearing death - turns on the ORP, as much as it turns on the immortality of the soul. I then establish that the ORP is left largely undiscussed until the myth at the end of the dialogue. In focusing on the discussion of the immortality of the soul, Socrates has given short shrift to this other key premise in his argument against the fear of death. It would seem, therefore, that the myth is introduced in order to acknowledge the ORP.

60c-64a: introducing the argument against the fear of death

Let us begin by looking at the way in which the interlocutors frame the conversation of the Phaedo. After gathering at the prison, Simmias and Cebes challenge Socrates, asking why he should bear leaving this life so easily (63a4-8). At this point, Socrates agrees to make a defense against this challenge. He announces that he will make his case, as if he were back in the courtroom, that he is justified in not fearing death (63b1-2). ${ }^{116}$ In particular, he claims to be sure that he will go to wise and good gods and to the company of other men, who are better than men on earth (63b4-6). ${ }^{117}$ Socrates further claims that he is not fearful of death, because (63c3-6):

(1) He has good hope that some future awaits him, and 
(2) This future is much better for good men than it is for the bad. ${ }^{118}$

We shall see in what follows that (1) the immortality of the soul (referred to henceforth as IS) and (2) the view that the afterlife will be favorable for good men (what I have been calling the otherworldly rewards premise, ORP) are key assumptions in Socrates' argument; we are only justified in not fearing death insofar as the soul will go on existing in the afterlife and will experience a favorable fate. ${ }^{119}$

What I take this introductory exchange to show is twofold. First, it is useful to note that Socrates claims that the succeeding arguments are intended to prove that we ought not to fear death. All of what follows, the argument against the fear of death, the four arguments about the immortality of the soul, and the myth about the afterlife, are presumably meant to be taken in this context. Socrates affirms this much as he launches into the discussion, saying "I want to make my argument before you, my judges, as to why I think that a man who has truly spent his life in philosophy is probably right to be of good cheer in the face of death and to be very hopeful that after death he will attain the greatest blessings yonder. I will try to tell you, Simmias and Cebes, how this may be so" (63e6-64a2). ${ }^{120}$ Second, this exchange shows that, at the outset of the discussion, Socrates flags a number of key reasons why he does not fear death. He indicates that (IS) the immortality of the soul and (ORP) the character of the afterlife play a key role in his thinking.

\section{4a-69d: the argument against the fear of death}

Next, Socrates delivers his argument as to why the philosopher ought not to fear death. ${ }^{121} \mathrm{He}$ summarizes his view as follows (63e7-64a7):

[O]ne aim of those who practice philosophy in the proper manner is to practice for dying and death. Now if this is true, it would be strange indeed if they were eager for this all their lives and then resent it when what the have wanted and practiced for a long time comes upon them.

Philosophers spend their lives preparing for death, Socrates argues. They ought not, therefore, fear it when it comes. He further expands upon this argument, giving a detailed analysis of the 
philosopher's relationship to his body and claiming that he wishes to be free from it so that he might better do the work of his soul. We might summarize this argument against the fear of death as follows:

1. In death, the soul is separated from the body $(64 \mathrm{c} 4) .{ }^{122}$

2. The philosopher wishes to be free from his body, because

a) He does not care for its pleasures (64d2-e5), and

b) The body encumbers his search for knowledge (65a7-c8). ${ }^{123}$

3. The philosopher is concerned with matters of the soul instead - he develops his reason in order that he might eventually know reality itself (65e1-66a3).

4. The philosopher ought, therefore, to welcome the separation of the soul from the body (67d6-8).

5. It follows (from 1 and 4) that the philosopher ought to welcome death (67e1-2).

In the first step of the argument, Socrates gives an analysis of death. It is none other than "the state in which the body is separated from the soul and exists alone by itself" (64c5-7). In the second premise, he gives two reasons as to why the philosopher will wish to be free from the body. The first is that the philosopher will care nothing bodily pleasures. He considers a number of different pleasures - food, drink, love, and possessions - in order to show that the philosopher does not care for any of them (64d2-e5). The second reason Socrates gives for the philosopher's lack of care for the body is that the body encumbers his search for knowledge. He goes on about this point at great length, claiming that our corporeal nature deceives us about sense perceptions, distracts us with pains and pleasures, cannot perceive what is real, i.e. the forms themselves, keeps us busy looking for sustenance, distracts us with desire, suffers disease, causes wars, factions, and battles, and desires money (65a-67b). ${ }^{124}$ In the third premise, Socrates claims that the philosopher will care far more for matters having to do with his soul (64de4-5). His soul is the part that, when it is free to do so, reasons about truth and reality (65c-d). But, as we have seen in premise 2, this is difficult to do when embodied. In fact, Socrates even goes so far as to claim that we cannot have knowledge of reality until we are free from the body altogether (66e-67b). In the fourth step, Socrates concludes that, because the philosopher is concerned 
primarily with matters of the soul (premise 3), and because his body encumbers him in these pursuits (premise 2), he ought to welcome the separation of his soul from his body. He reasons that (this is 5) the philosopher ought therefore to welcome death.

At the end of this argument, it is easy to see why Socrates flags IS and the ORP a few pages earlier. In his argument that the philosopher ought not to fear death, Socrates must be assuming both that:

(IS) Some future awaits him after death, and,

(ORP) The future that awaits him is of a certain positive character, i.e. the afterlife is a much better place for good men than it is for the bad.

If Socrates were not assuming these premises, then, even given the above argument, the good and philosophical person would still have every reason to fear death. In particular, the above argument says nothing of the possibility that, when one dies, he simply ceases to exist. Socrates must, therefore, be assuming that the philosopher's soul is immortal and that it will continue to exist after the death of the body. In addition, Socrates must be assuming that, if indeed the soul of the philosopher outlives the body, it will have a favorable fate. For, it is frightening to think that, if one does survive death, he might go on to some grim form of existence. For all we know, however, every soul ends up in a place of punishment or is reincarnated into the body of an unthinking beast. It seems, therefore, that Socrates must also be assuming the ORP, the view that the next world is composed in such a way that the good and philosophical souls await a favorable fate. Otherwise, the philosopher would have every reason to be fearful of his separation from the body.

Of course, we might wonder how aware Plato is of these assumptions. In the case of the first assumption, IS, Plato is almost certainly aware that the argument against the fear of death turns on the immortality of the soul. Upon hearing Socrates' argument, Cebes and Simmias are immediately keen to explore whether or not Socrates is right to assume that the soul outlasts the body. Plato must therefore recognize that this assumption is in need of further exploration. In the case of the second assumption, the ORP, we also have good reason to think that Plato is aware of having assumed it. After all, Socrates seems to make a direct statement of the ORP a few pages 
earlier, at 63c5, giving this as a reason for which he does not fear death. In addition, at the end of the argument against the fear of death, we find what looks like an explicit statement of this premise: Socrates claims that the philosopher is better prepared for death than other men, having practiced the separation of the soul from the body as much as is possible, and that he ought not, therefore, fear his soul's release for reasons having to do with lack of practice (67d). Anyone who does fear death, the argument continues, must either be a lover of the body or a lover of earthly pursuits, like wealth and honor (68c). Souls of this sort, when they enter into the afterlife will, Socrates claims, "wallow in the mire." (69c4). Because they are unaccustomed to the separation of the soul from the body, the unphilosophical souls will be confused by the loss of their senses and will fare poorly as a result. The philosopher, however, having purified himself of bodily concerns, arrives ready to "dwell with the gods" (69c5). This is, I take it, a direct statement of the rewards he awaits in the afterlife (the ORP). Socrates must be assuming that the afterlife is such that, given their familiarity with the separation of the body, the philosophical souls will fare well and unphilosophical souls will become confused and lost. This is why he is justified in claiming that he does not fear death - he assumes that some favorable fate awaits him as a result of his earthly preparations.

\section{9d-107a: testing (IS) the immortality of the soul}

In the exchange that follows, Cebes and Simmias are especially keen to examine IS, taking up the question of whether the soul exists before and after being joined to the body. They press Socrates as to whether the soul survives the death of the body, whether it dissipates or is destroyed, and whether it still possesses the same identity in death (70a-b). The largest part of the dialogue consists of Socrates response to this question (70a-107a). Scholars generally agree that this part of the dialogue contains four arguments in favor of the immortality of the soul. These are "the cyclical argument" (70b-72d), ${ }^{125}$ "the recollection argument" (72e-76e), "the affinity argument" (78b-80d), and "the final argument" (100a-107a). I address each of these arguments below, in order to show that the ORP receives relatively little attention in the dialogue as a whole. Whereas each of the four arguments sets out to explicitly prove some version of IS, none seems intended to prove the ORP. 


\section{The cyclical argument}

Socrates first argument for IS is the "cyclical argument", which holds that if living souls come to

life from having been dead, then they must exist before being embodied (70c-d). ${ }^{126}$ In an effort to show that this is very likely the case, that the soul comes back to life from the dead, Socrates appeals to a number of processes, each of which transforms its object from an opposite state of being. For example, things become smaller from having been larger. Things become slower from having been faster. And the same holds, Socrates claims, of all things, justice, heat, etc. All processes transform their objects, which begin in another, opposite state of being (71a8). To this he adds that living is just such a process, and that dying or death, is the opposite $(71 \mathrm{c} 1,71 \mathrm{~d} 3-4)$. Because these are opposite processes, they must transform their objects, which begin in the opposite state of being: that which comes to life must come to be so from having been dead (70d-e). If this is the case, Socrates claims, the soul must predate the body. If it comes to be from having been dead, then the soul must already exist in a former state. ${ }^{127}$

Although we might doubt the efficacy of the cyclical argument, in showing that the soul must be immortal, all that is important to us at present is that it clearly seems to be intended to show IS. ${ }^{128}$ There is not, however, any mention of the character of the afterlife in this part of the dialogue. The ORP is, it seems, absent from this part of the discussion.

\section{The recollection argument}

Next, Cebes brings up what is sometimes called "the recollection argument". He argues that, if it is true that when we seem to be learning we are in fact just recollecting, then the soul must predate the body (72e). Following this, the interlocutors set about to show that the theory of recollection is very likely to be true, first, by claiming that demonstrations, like the one in the Meno, show that recollection actually occurs (73a), and second, by arguing that we can theorize about the forms. Socrates gives the example of our ability to discern the form of equality, despite only ever having been given imperfect illustrations of what equality is (74b). Although we have only ever had imperfect examples, i.e. sticks which sometimes look equal and sometimes do not, we are able to know the concept of equality itself. From our ability to know equality itself, in 
spite of our imperfect examples, Socrates deduces that we must have encountered these forms in the afterlife. It follows that we must have existed before having been embodied.

Again, the recollection argument seems to provide clear support for IS. In particular, it addresses the claim that the soul pre-exists the body. And again, this argument seems to exclude any arguments for the ORP. It might be objected, however, that there is a sense in which the recollection argument does entail a view about the positive characteristics of the afterlife. If the theory of recollection is true, then the soul must come into contact with perfect entities (like equality, justice, goodness, etc) in its disembodied state. The disembodied soul would seem to have true wisdom, insofar as it has unfettered access to the forms. The recollection argument may seem, therefore, to offer some kind of support for the view that a positive fate awaits souls in the afterlife.

In response to this, however, there are a number of reasons to think that the recollection argument, as it stands, is not intended to address the ORP. First, it is notable that the recollection argument makes no claims about which souls have the ability to recollect. Consider that Cebes introduces the theory thus (72e2-6):

[S] uch is also the case if that theory is true that you are accustomed to mention frequently, that for us learning is no other than recollection. According to this, we must have at some previous time have learned what we now recollect.

Cebes speaks rather generally about recollection, as if it were something that everyone can do. ${ }^{129}$ If, however, all people have the ability to recollect, then it is not clear that only the good, philosophical souls come into contact with these perfect concepts. So, while the recollection argument may seem to make a positive assertion about the quality of the afterlife - it is the place where souls collect information that they will later recollect — this claim differs rather substantially from the ORP in that it says nothing about who is rewarded in the afterlife. Where Socrates has stated the ORP before, he seems to be concerned with the distribution of rewards, with good or philosophical souls faring well $(63 \mathrm{c} 5,67 \mathrm{c}-69 \mathrm{~d})$. The recollection argument, as it stands, says nothing about good souls being rewarded according to their earthly character. At the very least, therefore, the recollection argument seems to be making a more general statement about what the afterlife is like, a claim that does not discriminate between the fate of good and 
bad souls.

Second, and more importantly, the recollection argument, although it may make some claims about the positive character of the afterlife, is in no way intended as a proof of the ORP. Although the recollection argument defends a conclusion that is compatible with the ORP, Plato never puts forward this view — that the soul of the philosopher is rewarded in the afterlife - as a conclusion in this part of the dialogue. Instead, the recollection argument is rather clearly intended as an argument for IS. If the theory of recollection holds, then we have every reason to think that the soul predates the body. For this reason, because this part of the dialogue is clearly intended to address IS, we ought to be wary of taking the recollection argument as a discussion of the ORP. Even if the recollection argument makes some claims that are compatible with the sort of fate Socrates envisions for the philosopher, the argument itself does not purport to show, at least on its face, that the philosopher must in fact await such a fate. I conclude that the recollection argument, even if it makes some claims about the positive character of the afterlife, is not openly discussing the plausibility of the ORP.

\section{The affinity argument}

Next, the interlocutors turn to whether or not the soul exists after the death of the body. In "the affinity argument", Socrates argues that the soul is not likely to be scattered or dispersed after death, insofar as it is an noncomposite entity. He reaches this conclusion by arguing that entities that change are more likely to be composite and disunified, whereas unchanging entities are more likely to be unified and composite (78c-d). Socrates further claims that the Forms, those perfect entities discussed in the recollection argument, are unchanging (78d), whereas sensibles, like men, horses, and cloaks are changeable entities (78e). He also distinguishes between things like the forms and things like men, horses and cloaks, claiming that the former are invisible whereas the latter are visible (79a). The soul, he claims, in virtue of being invisible (79b), when it departs the body must commune with the same kinds of entities, the immortal and unchanging (79d). Because of its likeness to the forms, the soul must also go on existing after the death of the body. The body, by contrast, is more like sensible things and must therefore be divisible (79e). The argument concludes that we ought not to expect the soul to dissipate when the body dies. It 
is more like the forms and must therefore continue to exist. ${ }^{130}$

Once again this argument seems to take IS as its conclusion. We need not fear the dissolution of the soul insofar as it is a divine and, therefore, unchanging thing. The function of this part of the dialogue is clearly to show that the philosopher need not fear the dissolution of his soul. Because he has taken care not to fall into the service of the body, because his soul is more akin to the divine and unchanging, the philosopher need not fear that his soul might disperse. However, the affinity argument is followed by an extended discussion (or by another stage of argument) in which Socrates shows that certain souls will be more like the divine than others. ${ }^{131}$ This part of the dialogue seems to involve some version of the ORP. ${ }^{132}$ I turn now to a closer examination of this discussion in order to determine what role this premise plays in showing that the soul will not dissipate - and whether Socrates might, in this part of the dialogue, be offering proof for this other premise in his argument against the fear of death.

First, this part of the dialogue seems to contain a number of statements of the ORP. ${ }^{133}$ Socrates claims, on a number of occasions, that Souls that have no association with the body in life, those that practice philosophy, when they die, will join the gods in the heavens. For example (81a3-5):

A soul in this state makes its way to the invisible, which is like itself, the divine and immortal and wise, and arriving there it can be happy, having rid itself of confusion, ignorance, fear, violent desires and the other human ills, and, as is said of the initiates, truly spends the rest of time with the gods.

This sounds very much like a statement of the rewards that await the philosopher in the afterlife: the philosopher will, as a result of his earthly merits, pass into the company of the gods. We might, therefore, interpret this passage — and the others like it in this part of the dialogue — as a statement of the ORP.

Moreover, it is worth noticing that the extended discussion of the affinity argument seems to include a rationale for the ORP, which we have not yet seen. The philosopher is better off, Socrates claims, because he has disassociated himself from bodily concerns. This rationale is spelled out in the discussion of what awaits bad souls. Socrates claims that the soul which has enjoyed bodily pleasures (81b1-d4): 
[I]s no doubt permeated by the physical, which constant intercourse and association with the body, as well as considerable practice, has caused to become ingrained in it... We must believe, my friend, that this bodily element is heavy, ponderous, earthy, and visible. Through it, such a soul becomes heavy and is dragged back to the visible region in fear of the unseen and of Hades. It wanders, we are told, around graves and monuments, where shadowy phantoms, images that such souls produce, have been seen, souls that have not been freed and purified but share in the visible, and are therefore seen.

Plato seems to be giving an account of how certain souls become imprisoned in the earthly realm. Because these souls are so accustomed to being embodied, they spend at least part of the afterlife lingering around the earth. This is because they are used to such things. Again, this looks like a description of how one's earthly character affects his journey into the afterlife. A soul that is particularly fond of the body, will not be able to leave the earthly realm. Socrates further claims that these souls are eventually trapped in other bodies, according to the kind of life they led: drunks become asses, and robbers become hawks (81e). The interlocutors muse that those happy and social souls, which were nevertheless inclined to bodily pleasures, must become ants, bees, or humans (82a). Following this line of reasoning, Socrates claims, again, that it is only the philosophers who, are allowed to pass into the company of the gods (82b). Philosophers, because they are completely untaken with the trappings of the body, wealth, pleasure, pain, the senses, do not concern themselves with corporeal things (82c-83). The philosopher is most akin to the true and divine and does not need therefore to fear his soul's dispersal.

This part of the dialogue concludes with the brief argument that, the philosopher, because he has nurtured his soul in this way, by avoiding bodily concerns, is in no danger of his soul dissipating (84a1-b5). The philosopher, because he is less attached to the body will pass into the afterlife unscathed, joining the gods in their divine existence.

I have been arguing that, to this point in the dialogue, Socrates does not include an open discussion of the ORP. Although the ORP may follow from certain claims in the recollection argument, Socrates has yet to offer an open defense of anything other than IS. But the present discussion seems less about IS and more about ORP. In fact, the above analysis poses two rather significant challenges to the view I have been defending. First, it seems plausible that this, the extended discussion of the affinity argument, is intended as an acknowledgement of the view that philosophers await a good afterlife. The afterlife is here described as being arranged so that 
philosophical souls pass into the company of the gods, whereas unphilosophical souls are bound to the earth. Second, and more importantly, it appears that this bit of the dialogue gives something of a rationale as to why some souls fare better than others. The reason that some souls are rewarded and others are not is that some have done better in growing less accustomed to the body. This might, therefore, be taken as a preliminary argument for the plausibility of the ORP.

In response to the first challenge, it is worth noticing that, although the ORP is present in this part of the dialogue, Plato ultimately takes what has been shown here in the service of his conclusion for the affinity argument - as support for IS. At the end of this passage, Socrates concludes:

The soul of the philosopher achieves a calm from such emotions; it follows reason and ever stays with it contemplating the true, the divine, which is not the object of opinion. Nurtured by this, it believes that one should live in this manner as long as one is alive and, after death, arrive at what is akin and of the same kind, and escape from human evils. After such nurture there is no danger, Simmias and Cebes, that one should fear that, on parting from the body, the soul would be scattered and dissipated by the winds and no longer be anything anywhere.

The primary function of this part of the argument seems, once again, to be to support the claim that the soul is unified and therefore unlikely to be scattered upon the death of the body. What I take this to show is that, even if the extended discussion of the affinity argument invokes the ORP, whatever claims it makes are, ultimately, in the service of defending IS. In fact, the ORP seems to be invoked as a premise in this part of the argument. Because the souls of the philosophers are more like the gods, joining in their company in the afterlife and reaping the rewards of a life well lived, it is even more unlikely that their souls will dissipate on the death of the body. When understood in this way, it looks like the ORP, if indeed it appears in the affinity argument, is acknowledged in the service of showing IS (or, at least, IS in the case of the philosopher). ${ }^{134}$ Socrates does not therefore seem to be discussing the ORP itself, as a premise that underlies his argument against the fear of death, which is itself in need of some defense.

Of course, there is another far deeper challenge in the above analysis. It appears that this bit of the dialogue gives a rationale as to why some souls fare better than others. Plato repeatedly claims that philosophical souls fare better in the afterlife, because they know how to function without the body, whereas unphilosophical souls do not. This poses yet a further challenge for 
my interpretation in that Plato might seem to be arguing for the ORP. What makes the philosopher more like the gods is precisely his lack of bodily concern; the other souls are imprisoned on the earth, stuck in a cycle of reincarnation, because they are not accustomed to existing without a bodily form.

It is hard to deny that this part of the dialogue offers a rationale as to why philosophers fare better in the afterlife than other souls. Socrates repeatedly claims that philosophers, those who have done philosophy properly, will feel no affinity to their bodies, and that this lack of bodily concern makes the soul of the philosopher easily freed (80d-e). When the body dies, the philosopher passes easily into the heavens and the company of the gods. In contrast, those who are easily distracted by the body fare much worse. I conclude that, even if this is not taken as an argument in the strict sense, in that Socrates never seems to take the ORP as a conclusion, the extended discussion of the affinity argument does, at the very least, go one step further than the other statements of the ORP that we have seen thus far. Socrates claims that the philosopher, because he is used to being disembodied, is more like the gods. And, because he is more like the gods, he will easily join in their company in the afterlife.

However, we might wonder how strong an argument this really is. It doesn't seem to follow from the mere fact that the philosopher is akin to the gods, in his detachment from the body, that he should necessarily fare better in the afterlife. ${ }^{135}$ After all, it may be, for all Socrates has shown, that the afterlife is a hostile place for everyone, regardless of their earthly merits. This part of the dialogue, although it invokes the ORP in showing that the soul of the philosopher is especially unlikely to dissipate and in doing so provides us with some rationale for the ORP, still seems to assume this premise rather than establishing it. Ultimately, Socrates appears to be making an assumption about what the afterlife must be like. He is assuming that the afterlife is organized in such a way that souls who are used to being without their bodies will fare better than those who are used to giving into their corporeal desires. I conclude that the rationale Socrates has given for the ORP — that the philosopher will be less accustomed to the body — may help to explain why the philosopher is more like the gods; but this does not itself show that the philosopher is guaranteed safe passage into the next world or that he will be rewarded for his 
earthly character.

In conclusion, although this part of the dialogue does seem to involve the ORP - the extended discussion of the affinity argument takes the ORP as a premise in showing that the philosopher's soul is not likely to be dissipated on the death of the body - it is not clear that Socrates means to openly discuss this, as another premise in his argument against the fear of death, which is itself in need of some proof. Rather, he seems to be pulling in a rough statement of the ORP as another means of defending IS. Moreover, although the extended discussion of the affinity argument seems to expand on earlier statements of the OPR by offering a rationale as to why the soul of the philosopher will be more like the gods themselves, this rationale does nothing to prove that the ORP actually holds. Showing that the soul of the philosopher is like the soul of the gods in his lack of affinity for the body does not provide us with a definitive reason to think that the afterlife is organized in such a way that his soul will fare well, whereas other souls will fare poorly. Socrates must, once again, be assuming that the afterlife is favorable to the souls who are least accustomed to being embodied.

In short, this section of the dialogue might invoke the ORP as a premise in showing IS; it might even expand on previous statements, giving a limited rationale for thinking that the philosopher will be more like the gods. However, the extended discussion of the affinity argument seems to include the ORP as a premise of sorts; it does not offer a substantive proof that the ORP is, in fact, the case.

\section{Simmias' Lyre, Cebes' Coat, and the Final Argument}

Following the affinity argument, Simmias and Cebes issue a pair of challenges to Socrates (84c-88b). Simmias worries that the soul, even if it is more akin to the invisible and divine, is like a harmony produced by a lyre. That is, it might exist only insofar as the physical entity which produces it also exists (85e-86d). Cebes worries that the soul, even if has been shown to outlive the body, has not been shown to be immortal. Instead, he suggests that every soul might outlive many bodies, but that it may eventually be worn out. Like a man who outlives his many cloaks, so too might the soul eventually perish (87a-88c). 
As an aside, one that will be useful later, it is worth noticing that the interlocutors take these to be very strong objections. Phaedo even stops the narration of the story to say (88b8-c6):

When we heard what they said we were all depressed, as we told each other afterwards. We had been quite convinced by the previous argument, and they seemed to confuse us again, and to drive us to doubt not only what had already been said but also what was going to be said, lest we be worthless as critics or the subject itself admitted of no certainty.

Phaedo and all those present take the above objections, not just as a challenge to the affinity argument, but as a challenge to the very project of giving arguments. Phaedo claims that he began to mistrust future discussions on this topic, for, he had been so convinced by Socrates until hearing these challenges that he began to feel distrustful of his own judgement. Having seen so clearly both sides of the issue he becomes unsure that any "certainty could be attained in these matters". It is no wonder therefore that Socrates, in his reply, seems to be guarding against such a reaction, beginning with a lengthy statement about how people become misologues (90b5-e4):

[I]t would be a sad thing if a man, because he has met with some of those arguments which seem to be sometimes true and sometimes false, should then not blame himself or his own lack of skill, but should end, in his vexation, by throwing the blame gladly upon the arguments and should hate and revile them all the rest of his life, and be deprived of the truth and knowledge of reality... [L]et us be on our guard against this, and let us not admit into our souls the notion that there is no soundness in arguments at all. Let us far rather assume that we ourselves are not yet in sound condition and that we must strive manfully and eagerly to become so, you and the others for the sake of all your future life.

Socrates begins his reply by claiming that, if it turns out that we put our trust in an argument without sufficient proof, we ought not to blame the arguments themselves. Instead, we ought to realize that it is our own fault for being unable to determine, as of yet, what arguments are best. When we encounter a flawed argument, we ought not to give up on the possibility of argumentation altogether, realizing instead that we must inquire further. Although this particular part of the exchange is completely silent with respect to both IS and the ORP, the fact that Socrates seems to be on guard against misology will be important later in the chapter.

Let us now consider the replies which Socrates offers in response to the challenges raised 
by Simmias and Cebes. Does Socrates' reply to Simmias offer any support for the ORP? Socrates first sets about to show that Simmias cannot hold that the soul is like a harmony, produced by the body, insofar as he believes that the soul can recollect (92a-e). Because it can recollect, it must pre-exist the body and must therefore not be produced by the body. He further argues that a soul cannot be likened to a harmony, in that such an analogy does not admit of any discord or wickedness on the part of the soul (93a-95b). Socrates does not, however, consider any claims about what the afterlife is like.

What about his reply to Cebes? Does this show any traces of the ORP? Here, too, Socrates' focus seems to be entirely on IS. He begins by claiming that Cebes' objection will require a full examination of generation and decay — what causes us to exist and what causes us to die (95e6-7). Socrates then gives a lengthy description of his youthful foray into scientific investigations about life and death (96a5-97b8). ${ }^{136} \mathrm{He}$ describes his first introduction to Anaxagoras' metaphysics and his adverse reaction to physical explanations of cause (97c1-99d2). He then describes the path which led him to believe that there was something more, an underlying reality, which is the cause of all things (99d4-100a8). ${ }^{137}$ Socrates claims, here, that if he is correct in his theory about what ultimately causes everything else, the Forms, then he will be able to show that the soul is immortal (100b1-100c1).

The argument which follows is often called "the final argument". ${ }^{138}$ Here, Socrates begins by arguing that physical things can admit of opposites (102d-103a). Cebes, he claims, is, at once, both taller than Socrates and shorter than Phaedo (102c-d). But this is not the case, Socrates claims, of the forms themselves. ${ }^{139}$ Tallness itself, he says, can never be short; for if Tallness itself were ever to admit of short, it would cease to exist altogether (102d6-103a4).

Next, Socrates asks whether or not his interlocutors agree that the forms, i.e. hot and cold, exist (103c8-9). Socrates then shows that there are certain kinds of entities, like snow and fire, which are like the forms in that they cannot admit of opposite forms. Unlike Cebes, in that he admits of both tallness and shortness, snow and fire admit of only hot and cold, respectively (103d4-8). Socrates further takes up these sorts of entities, which he says are "not the Form but has its character whenever it exists" (103e4). He gives another example, odd numbers, which cannot admit of opposite forms (104a1-b4). Socrates takes this to show that there are certain 
kinds of entities, which are unlike Cebes, in that, whenever they exist, they cannot be of any other character; if something like this begins to admit of its opposite state, it withdraws or ceases to exist (104b5-c3). Fire cannot be fire and be cold. Odd numbers cannot be odd numbers and also be even. In what follows, Socrates repeats the same line of questioning, giving a number of other mathematical examples: the triad (104e1), the number five (105a7), the double (105a8), and fractions (105b1-2).

Finally, Socrates asks what it is, beyond the forms, that causes entities to have their character (105b4-c7). In particular, he wonders what is present in the human body, which makes it living - the answer is, of course, a soul (105c8-9). In what follows, Socrates argues that the soul, whatever it occupies, will bring things to life (105d2). Although there is an opposite state, death, the soul is, it seems, never willing to admit of this state. It looks like Socrates is here identifying the soul as another one of these things that is "not the Form but has its character whenever it exists". The soul, because it is one of these things that admits of only one form-life - does not admit of the opposite, death. Socrates concludes that the soul must be deathless $(105 \mathrm{e} 5)$.

The argument then turns to showing that the soul must, because it is deathless, be indestructible. This follows, Socrates claims, from what has already been shown: "For it follows that it [the soul] will not admit death or be dead, just as three, we said, will not be even nor will the odd; nor will fire be cold, nor the heat that is in the fire." Socrates seems to think that this kind of entity, which is "not the Form but has its character whenever it exists", must be indestructible. Of course, this is followed, immediately, by an objection —other of these entities seem to be destructible. Odd numbered things, for example, frequently become even, by the addition of a member. The same seems to be true of fire; it may be like the form in that it does not admit of its opposite, but it is not indestructible; for, fire often goes out. Socrates response to this seems to be that the soul is an even more special kind of entity. The soul one of these things that is "not the Form but has its character whenever it exists". What it exemplifies is the form of life itself - and nothing should resist destruction, Socrates claims, if the form of life itself cannot (106d5). Because the soul is deathless, Socrates concludes, when death comes to the body, the mortal part dies, but the deathless part — the soul which exemplifies the form of life itself—goes 
on into the afterlife (106e1-107a2).

This detailed description of the final argument shows, conclusively I think, that the final argument does nothing at all to address the ORP. The focus of this part of the dialogue is, without a doubt, to provide support for IS. If the soul can be shown to be deathless, Socrates thinks, he can rightly conclude that the soul will not be destroyed on its departure from the body. Socrates hardly refers to the afterlife anywhere in the argument. At 107a1-2, he claims that the soul "is most certainly deathless and indestructible and our souls will really dwell in the underworld." This is, however, the very first mention of the afterlife anywhere in the argument. Socrates talks about the death of the body throughout, but he never gets into questions about what actually happens to the soul beyond its not being dissipated. Furthermore, this is not itself a statement about the character of the afterlife. Socrates merely says that we will go on existing in the underworld. That the final argument is a proof of IS is confirmed by the fact that, a few lines later, Socrates claims to have shown, somewhat convincingly, that the soul is immortal. In his transition to the myth, he claims: "But now that the soul appears to be immortal..." (107d1-2). The final argument would seem, therefore, according to Socrates' own lights, to have been a proof for IS. It follows that, unless I have left out some important piece of evidence, this part of the dialogue focuses entirely on IS. If I am correct, then we can rightly set aside any further analysis of the final argument: the character of the afterlife has played no significant role in the arguments of this part of the dialogue.

\section{7a-d: from IS to ORP}

To this point, I have argued that Socrates' argument against the fear of death relies on two central assumptions. The first is IS, that the soul is immortal. The second is ORP, that the afterlife is arranged in such a way that the good, philosophical soul's continued existence will be a favorable one. I have also argued that the dialogue vets IS at length, without offering any substantive proof of the ORP. Of course, Socrates does discuss some version of the ORP in the recollection and affinity arguments. At one point, he even seems to provide a rationale for thinking that the philosopher will reap certain rewards in the afterlife. Still, nothing he has said to this point in the dialogue has been offered as explicit or definitive support for this premise. 
Concerned with showing that the soul will continue to exist, Socrates has said little, as of yet, as to why the soul of the philosopher must, in fact, await a favorable fate. If this is correct, however, at the end of the discussion, one of the assumptions underlying the argument against the fear of death has been left largely unaddressed. In what follows, I argue that the myth appears to be Socrates' way of defending this other key premise in the argument against the fear of death - the ORP — which has yet to receive much attention in the dialogue. Just how well the myth does in making a defense is, of course, an open question.

At the end of the discussion of the immortality of the soul, Cebes announces that he is convinced of IS (107a3). Simmias, on the other hand, claims that "he has no remaining grounds for doubt after what has been said" but that, given the importance of the topic and the nature of human weakness, he retains some private misgivings (107a6-b2). Socrates concedes that the principles from which he drew the conclusion that the soul is immortal bear further investigation. He claims that: "[O]ur first hypotheses require clearer examination, even though we find them convincing. And if you analyze them adequately, you [Simmias] will, I think, follow the argument as far as man can, and if the conclusion is clear, you will look no further." (107b3-6). At this point, Socrates shifts his focus. Instead of arguing for IS, instead of further addressing Simmias' uncertainty, he begins to take the immortality of the soul as granted, asking instead about how we ought to live if, indeed, what he has said is true (107c1-d6):

It is right to think then, gentlemen, that if the soul is immortal, it requires our care not only for the time we call our life, but for the sake of all time, and that one is in terrible danger if one does not give it that care. If death were escape from everything, it would be a great boon to the wicked to get rid of the body and of their wickedness together with their soul. But now that the soul appears to be immortal, there is no escape from evil or salvation for it except by becoming as good and as wise as possible, for the soul goes to the underworld possessing nothing but its education and upbringing, which are said to bring the greatest benefit or harm to the dead right at the beginning of their journey yonder.

Once we have established that the soul is immortal, Socrates argues, we can begin to see what danger we are in if we do not care for it properly. We are doing ourselves a disservice not only in life, but also in death (107c3-4). In particular, he claims, the soul, when separated from the body, takes its education and character into the next world, and these preparations benefit or injure it in its journey (107d1-4). It would appear that, at this point in the dialogue, Socrates is prepared to 
set aside the discussion of IS, the immortality of the soul, turning instead to the ORP, the view that the afterlife is organized in such a way that good, philosophically-prepared souls fare well whereas bad, philosophically-ignorant souls do not. And, in the lines immediately following this transitional passage, Socrates begins the myth.

What I take the above exchange to show is that, here, at the end of the dialogue, Socrates will finally set aside IS, addressing instead the other key assumption underlying his argument against the fear of death, which he has, until this point, left largely undefended - this is the ORP. As we saw above, this premise, that the soul is rewarded or punished according to its earthly merits, plays a key role in the argument against the fear of death. Socrates' claim to not fear death is warranted, only insofar as he is assured of a favorable fate in the afterlife. At the end of his discussion of IS, however, it remains an open possibility that the afterlife is radically different than he has imagined it to be. If the soul is immortal, but its fate is uncertain-if, say, souls are not rewarded according to their earthly character - then Socrates would have every reason to fear death. It is no wonder, therefore, that at the end of the dialogue he returns to this key premise (ORP), ushering in the myth as an illustration.

Let us now take a moment to explore the myth in more detail. Whereas some scholars have thought that it further underscores the immortality of the soul, ${ }^{140}$ it will quickly become apparent that the myth takes the immortality of the soul for granted, illustrating instead that the afterlife is ordered in such a way that good and wise souls fare better than the bad and ignorant. ${ }^{141}$ In other words, it will quickly become apparent that the myth does address the ORP.

\section{The myth}

Consider first the way that the myth begins. At 107d-108b, Socrates claims that, in death, the soul is taken into the underworld by a guide. The souls that are accustomed to being free from bodily concerns are less confused and know to trust their guides along the twisting paths, whereas the souls that are accustomed to being embodied are confused and resistant to leaving the earth (108a5-b3). From the very start, Socrates uses the myth to show that the afterlife is such that the souls who are prepared to exist without the body, the philosophers, fare well and those 
that have spent time dwelling on bodily pursuits fare poorly.

This "thesis", the ORP, is continued in the next part of the myth as well. Here, Socrates recounts what occurs when the soul reaches the next world. The impure, those that are truly bad, having committed unforgivable crimes, are abandoned and left to wander (108b). The most pure, who have studied philosophy, are taken by friends or gods to to the upper regions of the earth (108c). This region, the heavens, Socrates adds, stands in the same relation to the face of the earth as the face of the earth stands to the depths of the ocean (108e-111). We can imagine what the heavenly region is like, he reports, by imagining ourselves, having all our lives lived on the ocean floor, emerging to live on the earth. Just as someone in this condition would find the surface of the earth much clearer, so too do the good souls find a clearer perspective in the heavens. Socrates' description of the heavens supports the ORP, in that it details what rewards the good souls reap; they escape from the underworld and achieve clarity in finally knowing things as they really are.

The myth then turns to the sorting that takes place in the underworld, which Socrates describes as a vast chasm filled with rivers and lakes (111c-113a). It is here that souls are first sorted according to how well they have lived. (113a2-114c4). ${ }^{142}$ Here again, this description supports the ORP. The dead are first judged and then sentenced to live in a region according to their earthly merits. "Neutral" souls are sent to the Acheron lake, where they are purified and then reincarnated (113d-e). The worst off, murderers and blasphemers, are sent to Tartarus and never emerge. Souls that have committed lesser crimes are sent into the depths of Tartarus and emerge after a time, at which point they are judged again by those against whom they have wronged. Those souls that have lived a pious life are released from the underworld altogether and sent to live on the earth. The philosophers, Socrates repeats, because they are the most pure, proceed to the heavens, where they live eternally with the gods.

The myth, from start to finish, establishes that the next life is ordered in such a way that the good and reasonable souls will fare better than the bad and ignorant. Socrates achieves this result primarily by describing the geography and terrain of the region to which the soul passes. The winding paths and (Dantean) levels of this universe show that a person who is with his wits, 
accustomed to being without his body, will fare much better than a person who is unprepared. This is why, Socrates concludes, "we ought to do our best to acquire virtue and wisdom in life. For the prize is fair and the hope great" (114c7-8). We ought to pursue a life of philosophy, Socrates concludes, insofar as it will prepare us for a favorable and worthwhile afterlife.

We are finally in a position to re-enter one of the debates, with which I began this chapter. Does the Phaedo myth function as a part of the argument of the dialogue or is it in some way subordinate? If I am correct in the above analysis, then, the myth serves a distinctively rational purpose: Socrates is, here, establishing the ORP by describing in detail what the afterlife must be like. The cosmos is, he claims, arranged in such a way that good people have nothing to fear. What I take this analysis to have shown is just that the myth at the end of the Phaedo plays an important part in the arguments of the dialogue as a whole. ${ }^{143}$ In particular, it provides an account of what the universe is like - an account that through an appeal to cosmic descriptions makes the OPR seem reasonable. I do not, however, take the fact that the myth has a rational aim to show that it actually fulfills that aim. Although the myth appears to have a rational end in the dialogue as a whole - it is the first place that Socrates provides any support for the ORP — it may nevertheless be little more than an acknowledgement of this key premise. Socrates goes on at length about the geography of the universe; this is, however, nothing close to a definitive proof that the ORP is the case. This is why, as we shall see in the next section, despite the fact that the myth addresses the otherworldly rewards premise, Socrates ultimately finds the tale to have been an unpersuasive means of argumentation. One must, it seems, use repetition and force to convince himself that such a tale is actually the case.

\section{Is it fitting to believe the Phaedo myth?}

In part one, I argued that the myth serves a purpose in the overall argument of the dialogue: the myth is an acknowledgment of the ORP, a key assumption in Socrates' argument against the fear of death. It would appear therefore to have a rational aim, fleshing out what the afterlife must be like if indeed the philosopher goes on to a good and favorable existence. In this part, I turn my attention to what comes directly after the myth. When the tale has ended, Socrates concludes that 
we ought to do our best to study philosophy and acquire virtue, because the prize that awaits us is surely a very good one (114c7). If we nurture our souls in the proper manner, doing philosophy and making good decisions, then we will be rewarded in the afterlife and taken to live among the gods. In the lines immediately following, however, he hedges, claiming that $(114 \mathrm{~d} 1-6)$ :

No sensible man would confidently affirm these things being thus, as I have described them, but I think it is fitting for a man to risk the belief - for the risk is a noble one - that this, or something like this, is true about our souls and their dwelling places, since the soul is evidently immortal, and a man should repeat this to himself as if it were an incantation, which is why I have been prolonging my tale.

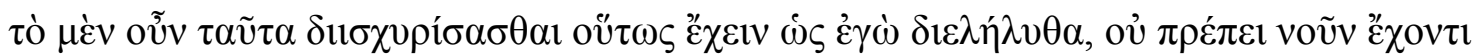

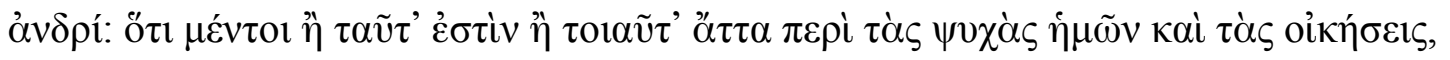

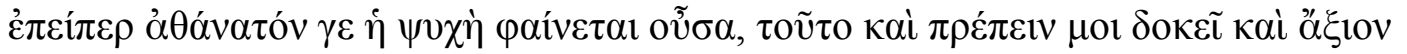

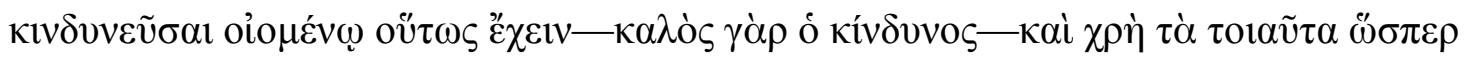

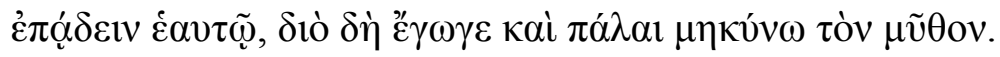

This passage gives rise to a number of questions that are highly relevant to our present discussion. What is it about the myth that it would be unfitting for "a man possessing reason" to "confidently affirm" (114d1)? And just how strong a disclaimer does this amount to? Does Socrates think he has said something false? In what follows, I address the ambiguities in the disclaimer. In the third part, I take up questions about Socrates' endorsement of the view on seemingly pragmatic grounds.

As a matter of clarifying the disclaimer passage, we might first say a bit more about how strong a "disclaimer" this really is. It is notable that Socrates says that a reasonable man will not "confidently affirm ( $\left.\delta 1 \_\chi v \rho i ́ \sigma \alpha \sigma \theta \alpha \imath\right)$ this being thus, as he has recounted it." In the last chapter, I

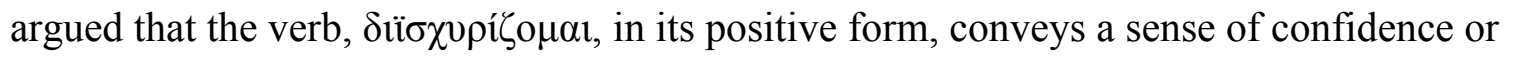
conviction in a given state of affairs. ${ }^{144}$ For example, in the Euthyphro, Plato uses this verb of Euthyphro's insistent claim to know the nature of piety. ${ }^{145}$ Similarly, in the Theaetetus, he uses this verb to indicate the type of assertion one makes when he declares at present that he seems to be awake. ${ }^{146}$ I have also argued extensively that in the Meno, Socrates, uses this verb to express 
his unwillingness to 'put his trust in' the demonstration argument as a proof of the theory of recollection. What this analysis suggests is that when one "confidently asserts" something in this sense, he 'puts his trust in' it or 'stakes a belief' in some state of affairs.

If this analysis holds in the present context, Socrates might be taken as claiming that it is not fitting for a reasonable man to "confidently affirm"-in the sense of putting his trust in or staking himself as knowing - whatever he has just recounted. Of course, this result, that a reasonable man will not be willing to "confidently affirm" whatever has been said, is a far cry from claiming that a man of sense ought to reject something in his previous account. Indeed, Socrates does not seem to be saying that he has expressed some view which he believes to be false. Instead, he seems to be expressing a view about how strongly a person should hold what he has proposed. A reasonable person ought not to regard what has been said with any conviction. He ought not to maintain what has been said with any certainty, lest he be like Euthyphro, who stakes himself as knowing the nature of piety without sufficient proof that what he has claimed is true.

Let us now turn our attention to another of the ambiguities in the disclaimer. If Socrates is in fact making a statement about how confidently a reasonable person ought to be about what he has said, we might wonder: what exactly is it that Socrates thinks a reasonable person ought not to put his trust in? In the first line of the passage in question, he claims that "it is not fitting for a man possessing reason to rely on these things being thus, as I have recounted ( $\tau$ ò $\mu \dot{\varepsilon} v$ oũv

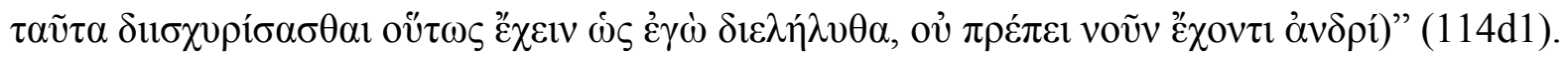
What exactly do these things ( $\tau$ ò $\tau \alpha \tilde{v} \tau \alpha$ ) pick out? I now turn to this question.

In many ways, this passage is the least problematic of all the disclaimers in this study. Whereas other of Socrates' retrospectives (from the Meno and, as we shall see, the Phaedrus) have very ambiguous sources, the passage in question is comparatively easy to figure out. In this case, we can be relatively sure that what Socrates means to address is whatever it is that he has only just finished recounting. After all, he says, "it would not be fitting to rely on these things being thus, as I have recounted ( $\dot{\omega} \varsigma \dot{\varepsilon} \gamma \dot{\omega} \delta 1 \varepsilon \lambda \eta \dot{\lambda} \nu \theta \theta \alpha)$ " (114d1). And, in the preceding line (not quoted above) he takes what "we have recounted" ( $\tilde{\omega} v \delta 1 \varepsilon \lambda \eta \lambda v ́ \theta \alpha \mu \varepsilon v)$ as motivation to acquire 
virtue and wisdom (114c8). Whatever it is that he has recounted is supposed to motivate a person to become good and wise. It seems, therefore, that the previous line is very likely referring to his account of the afterlife; if the afterlife is as he has recounted, then we have all the motivation we need to become good and wise. Now, it is reasonable to assume that what "we have recounted" $(\delta 1 \varepsilon \lambda \eta \lambda v ́ \theta \alpha \mu \varepsilon v)(114 c 8)$ and what "I have recounted" ( $\delta \varepsilon \lambda \eta \dot{\eta} \lambda v \theta \alpha)(114 \mathrm{~d} 1)$, given their proximity (in adjoining lines), are referring back to the same bit of the dialogue. Because the previous line refers to the description of the afterlife set out in the myth, the disclaimer probably does as well. It follows, rather succinctly, that at $114 \mathrm{~d} 1-2$ these things ( $\tau$ ò $\tau \alpha \tilde{v} \tau \alpha$ ) very likely pick out Socrates' preceding description of the afterlife. If this is correct, then Socrates ought to be taken as claiming that "it would not be fitting for a man to confidently affirm the description of the afterlife being thus, as I have recounted."

Of course, this argument provides a very general answer to the question at hand. As we have seen is often the case in these situations, we might be tempted to ask what, more specifically, Socrates means when he says that his description of the afterlife is one a reasonable person would not confidently affirm. Is it possible to pinpoint what gives rise to this hesitation? In the present context, there are at least two approaches we might take to this question. On the one hand, we might assume that Socrates means to attend to some specific claim put forward somewhere in his description of the afterlife. He may, for instance, think that a certain feature of the topographical description of the underworld is incorrect or uncertain. ${ }^{147}$ On this view, Socrates would be claiming that a reasonable man will think one or more of the claims put forward in the myth is poorly defended or incorrect, despite insisting that the rest of the account is an accurate, scientific representation of what happens to the soul on the separation of the body. 148 This is, essentially, the dogmatic reading of the passage in question. On the other hand, Socrates may be claiming that a man of reason will not take any of the claims in the myth as if it were a scientifically accurate description of what happens when the soul separates from the body. On this view, Socrates warns at 114d1-2 that the myth ought not to be taken literally; it is but one account of what happens to us when we die and as such cannot be thought to express a scientifically exacting portrait of the afterlife. It is in this sense that a reasonable person will not 
think the myth reliable.

Which of these is the better approach? There are, I think, a number of reasons to take the myth non-literally. First, it would appear that, given the logic of the disclaimer passage, Socrates is hesitant to endorse the myth qua accurate account of what happens when we die. I noted above that what "we have recounted" (114c8) and what "I have recounted" (114d1) very likely refer back to the same part of the dialogue. Because the previous line is clearly meant to refer to the description of the afterlife, generally — as this is what is supposed to motivate us to be good - we can expect the following line to have a similar scope. It would be odd, after all, if the former line referred to the entirety of the description whereas the latter referred to some specific claim contained therein. If this is correct, then we need not go looking for any specific claims which the reasonable man will not accept. ${ }^{149}$ Socrates must instead be making a claim about how to view the myth as a whole.

Second, it is notable that Socrates himself refers to his description of the afterlife as a "myth" ( $(\grave{o} v \mu \tilde{v} \theta \mathrm{ov})(114 \mathrm{~d} 6)$. He could very well have referred to this description in other terms in order to bolster its credibility. In fact, he could have referred to this description as a logos, as he does for the equally far-fetched and religiously-tinged theory of recollection in the Meno. ${ }^{150}$ But he does not; Socrates calls the description of the afterlife a "myth", thereby signaling that he regards this as a different sort of account as to what fate awaits us on the death of the body. Similarly, as we will see below, he claims that a reasonable person, if he is going to believe such a story, will have to "venture" or "risk" a belief in it (114d5). It would seem, therefore, because one must "venture" to believe it, that the myth itself is not something Socrates finds believable on its own merits. It would be very odd, I conclude, to take the dogmatic view, that his description is intended as a scientifically accurate account of what Plato actually thinks happens in the afterlife. Because Socrates calls his description a "myth" and because he does not regard it as believable in its own right, it makes far more sense that Socrates should be claiming not to take any of the claims in the myth as if it were scientifically accurate descriptions of what happens when the soul separates from the body.

Third, it is also worth noticing that the disclaimer is phrased as a claim about the how literally we ought to take the preceding description of the soul's passage into the next world. 
Socrates claims that a reasonable man "would not rely on these things being thus, as I have

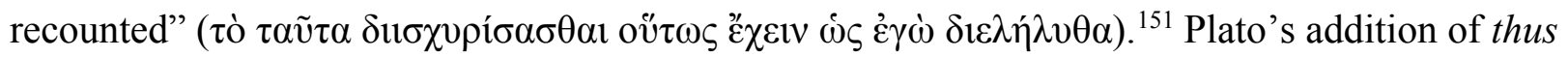

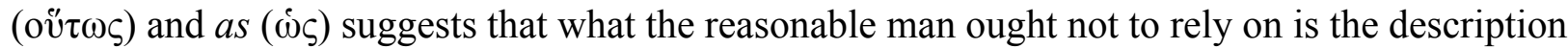
of the afterlife being just as Socrates has described it. ${ }^{152}$ If this is correct, then the disclaimer is not about some particular claim which Socrates thinks is incorrect, so much as it is about how literally a person ought to take the entire description - it would not be reasonable to rely on the afterlife being just so.

If the above analysis is correct, then what Socrates is claiming at $114 \mathrm{~d}$ is that 'a reasonable person will not put his trust in the myth as an accurate account of what happens when we die'. Given this conclusion, we are now in a position to re-enter the other debate with which I began this paper. Are the myths Plato's own views? Does he mean them to express metaphysical, scientific, and philosophical truths? It seems that Socrates himself, in his appraisal of the myth, recommends that we approach it as a non-literal account. ${ }^{153}$ Because a reasonable person would not take the myth to be an accurate account of what happens to the soul when the body dies, it seems likely that Plato is not, here, presenting his own well-thought out views about our passage into the next life. There are, of course, other possible interpretations: Plato may intend the myth either as entirely false or as only symbolically accurate. The latter is the view that the myth, when cleansed of its specific scientific and metaphysical claims about the afterlife, expresses some important philosophical lesson. A myth that is "symbolically accurate" is one that, at its heart, entails an important philosophical truth, which Plato would himself be willing to endorse. I take up this possibility near the end of the next section.

\section{Risking the belief: a puzzling wager}

To this point, we have seen that, at $114 \mathrm{~d} 1-2$, Socrates is claiming that the myth ought not to be taken as a literal account of what happens when we die; it would be inappropriate, therefore, to take the myth dogmatically. Because, the myth is one imaginative rendering of our journey into the afterlife, a reasonable person ought not to maintain with any conviction that the myth has been an accurate, scientific account of what happens to the soul after the separation from the 
body. In the next breath, however, Socrates claims:

...[B]ut, seeing that the soul has been shown to be deathless, it is both fitting and good to risk believing this to be so-for the risk is good - that this is the case or something like it is the case about the soul and its dwellings.

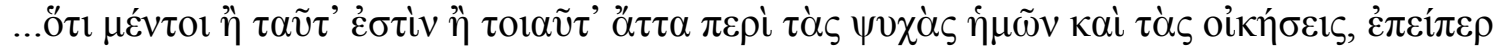

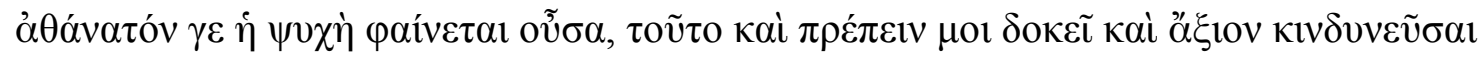

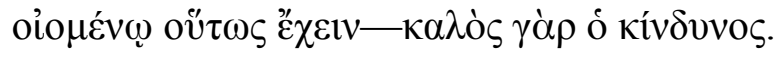

Why, if it is unreasonable to believe in the myth as an accurate account, does Socrates nevertheless recommend that it is fitting to risk a belief in his story or another like it (114d3-6)? Taken together the claims of $114 \mathrm{~d} 1-2$ and 114d3-6 are extremely puzzling. Socrates first claims that the myth ought not to be taken as an accurate account of what happens to the soul on its separation from the body. But in the very next line, he claims that it is fitting to venture to believe some such account, because the risk will be a good one.

Before moving on, let us say a bit more about this tension. Socrates' claim at 114d1-2 that the myth does not accurately report facts about the afterlife, paired with his recommendation at $114 \mathrm{~d} 3-6$ that a reasonable man ought nevertheless venture to believe the myth, seem to conflict with what I have been calling "the veridicity principle". ${ }^{154}$ This is the view that, for Plato, a person ought to believe a claim, $\mathrm{x}$, only insofar as he has a reason for thinking that $\mathrm{x}$ is, in fact, true. Generally speaking, Plato would seem not to be willing to give any credence to non-veridical reasons for belief. ${ }^{155}$ For him, it seems that a person ought to abstain from believing a claim, unless she has a veridical basis, a reason, argument, proof, or explanation as to why the claim in question is likely to be true. In the present context, however, we find him recommending the opposite: despite not believing that the myth is an accurate account of what happens when we die, we ought to venture to believe it.

This tension is made even more problematic by Socrates' expressed views about the influence of false beliefs on the soul. Socrates often argues that believing inaccuracies and falsehoods harms the soul. ${ }^{156}$ In the present discussion, he alludes to this view no less than three times. First, both the extended discussion of the affinity argument and the myth imply that 
believing false things will make the soul less prepared to undergo the journey into the next world. False beliefs, especially those about the value of bodily desires, seem to be what weighs the soul down, causing it to be trapped in the earthly realm (81b-e, 83d5). Souls that have mistakenly come to believe in the value of bodily pursuits - pleasure, comfort, wealth, etc. - are not ushered into the company of the gods. Second, in his aside about misology, Socrates makes the following rather explicit statement about false belief (91c1-5):

[I]f you think what I say is true, agree to it, and if not, oppose me with every argument you can muster, that I may not in my eagerness deceive myself and you alike and go away, like a bee, leaving my sting sticking in you.

In this passage, Socrates warns his young companions against believing untrue statements. They ought not to accept his account, he claims, unless they judge it to be true. He goes as far as to compare the badness of an untrue account to the sting of a bee; it stays with a person long after they have been stung. Third, and finally, at the end of the dialogue, Socrates makes what is perhaps the most explicit statement about the harms of false belief. Crito asks Socrates what they ought to do with his body when he is dead. Socrates responds that he does not care, but that Crito has failed to see that he will no longer inhabit his body. He ends by warning Crito against believing false things. "For you know well", he says, "dear Crito, to speak wrongly is faulty not

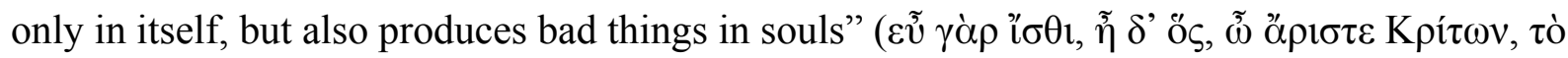

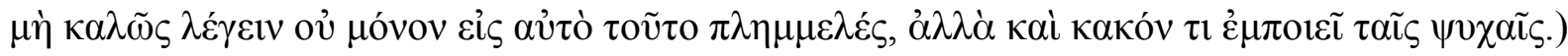
$(115 \mathrm{e} 5-7) \cdot{ }^{157}$

It will be useful, before moving on, to take a moment to say a bit more about why Socrates thinks that false belief is bad for the soul. What exactly is the problem with harboring false beliefs? Although I do not think I can fully resolve this issue in such a short space, it will be useful to notice that all of the above statements suggest that false belief is bad for the soul insofar as it contaminates one's ability to know what is true. Consider, first, that Socrates claims that false belief 'sticks' in a persons soul like a bee sting (91c1-5). This suggests that false belief is something that is bad because 'sticks' with a person and infuses his soul with falsehood. In a similar way, Socrates later claims that falsehood is not only faulty in its own right, "but also 


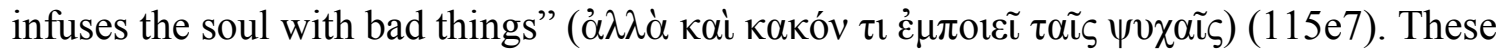
metaphors suggest that falsehood is something that we carry around in our souls and produces other bad results therein. In the extended discussion of the affinity argument, referenced briefly above, we see a further description of these effects. Socrates claims that a soul, which has given itself over to bodily desires, eventually comes to "[believe] that truth is what the body says it is" $(83 \mathrm{~d} 5) .{ }^{158}$ Socrates is here discussing a soul, who is possessed of false beliefs about what truly matters in life. His false beliefs eventually make it so that he no longer has the ability to see the truth. Convinced of the importance of bodily concerns, such a person misidentifies what is true and eventually loses all hope of knowing that what really matters is the state of his soul.

Although Socrates is here considering the badness of a particular kind of false belief - about the value of bodily pursuits - this is a lesson that might be taken as indicative of the harmfulness of falsehood more generally. Falsehood, when it is lodged in the soul, seems to change our ability to discern what is true.

Let us return to the problem at hand. Given Socrates' commitment to the view that believing false things harms the soul, we would expect him to think that we ought to strive to have only those beliefs that seem likely to be true. At the very least, we would expect him to think that a reasonable person ought to form beliefs based on the strength of her conviction that the belief in question is true, abstaining from belief if she has any reason to think an account does not accurately represent the way the world is. At $114 \mathrm{~d}$, however, we find a very different sort of view: it is fitting for a reasonable person to believe an account, despite not maintaining with conviction that such an account is an accurate portrayal of what happens to us when we die.

How, then, are we to resolve this tension? At the end of the last section, I mentioned that we might take a symbolic approach to the myth. On the symbolic reading, the myth is accurate only insofar as it expresses some important moral or philosophical lesson. Those who hold this view think that we can sanitize the myth of its scientific and metaphysical sounding details, as Plato did not himself accept these claims. Instead, he uses the myths to drive home other, more philosophical conclusions. David Sedley reads 114d1-5 in this way. He notes that much of the force of the myth might be preserved even if we reject it as a likely story about what happens to 
the soul on its departure from the body:

[T]he didactic function of the myth has relatively little to do with its literal truth or falsity. The lessons buried in it about cosmic justice and the proper character of teleological explanations are the same lessons whether or not the earth is structured in the way described. The same general message could, for example, just as well have been conveyed by letting the soul migrate not from habitation to habitation but principally, as elsewhere in Plato, between animals and species. And if the long-lived and happy aether dwellers should turn out not to exist, they would be no less effective illustrations of the need for would-be philosophical souls to narrow the gap between themselves and the divine. The lessons of the Phaedo myth, as no doubt of all Platonic myths, run immeasurably deeper than the mere facts which it purports to relate. $^{159}$

Sedley argues that the underlying moral lessons of the myth-about cosmic justice (which might be taken as a very abstract version of the ORP) and the need to do philosophy - could have been conveyed even if the myth had been different, even if Socrates had described the universe differently. ${ }^{160}$ Although Sedley is not explicitly worried about the tension I have described, his view might be taken as a promising resolution insofar as it marks out a distinction between the scientific and metaphysical descriptions of the universe set out in the myth and its moral message. Distinguishing between the descriptions themselves and the moral messages they entail might resolve our present tension in that Socrates, at 114d3-4, need not be seen as recommending a belief in a descriptive account of the afterlife, in which he seems to have little or no confidence. On this interpretation, Socrates is not, in one breath, claiming that a reasonable person will place no confidence in the myth, while claiming in another that we ought to venture to believe it. Instead, all that Socrates thinks we ought to venture to believe are the moral lessons that follow from his story.

Although it is attractive to think that we might disarm the tension introduced by the disclaimer so easily, there are, I think, a number of reasons to resist the symbolic interpretation.

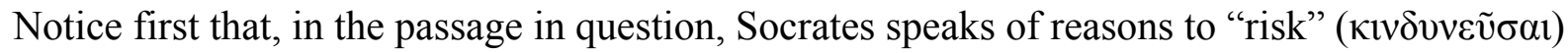

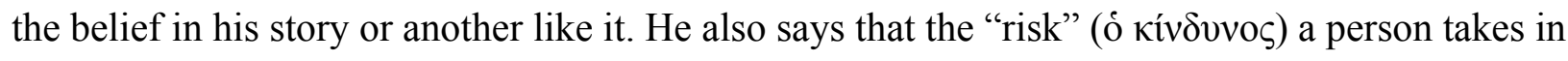
believing this is good or worthwhile. I take the language of "risk" to be highly relevant here, in that it suggests that whatever Socrates thinks we ought to venture to believe, it will be something risky, something unproven and potentially inaccurate. The symbolic solution holds that what we 
are supposed to risk a belief in are the moral lessons that follow from the myth. But it's not clear that there's anything risky about believing these underlying moral messages - that "would-be philosophical souls [must] narrow the gap between themselves and the divine". In fact, these seem to be the kinds of morals that Plato would regard as truths and not as anything especially risky to believe. It follows, I think, that Socrates ought not to be taken as merely recommending a belief in the moral truths that follow from the myth. He must, instead, be telling us to venture a belief in something that is a bit riskier.

In contrast to the symbolic solution, it seems that Socrates thinks it is fitting to venture a belief in some descriptive account of what the afterlife is actually like. The symbolic solution differentiates between the descriptions advanced in the myth - the scientific sounding details of what the afterlife is like - and the moral messages that follow from such an account. The symbolic solution further proposes that Plato would accept the moral messages that follow the myth, despite rejecting the scientific sounding details of what the afterlife is like. This seems incorrect, however, in that Socrates seems to endorse a belief in a detailed description of the afterlife; what he claims that we ought to convince ourselves of is a story like the one he has just told. Although we cannot be sure that such an account is accurate, it is nevertheless good, Socrates thinks, to venture to believe some story about what happens to us when we die.

There are many reasons to prefer this interpretation. First of all, Socrates says this much himself. Just after claiming that a reasonable man ought not to take the description of the afterlife to be an accurate account, he states "but it is both fitting and good to risk believing this to be so- - for the risk is good or noble - that this is the case or something like it is the case about the soul and its dwellings." In this passage, Socrates is not merely endorsing the moral lessons that follow from such a tale. Instead, he says that it is fitting to believe that "this is the case or something like it is the case about the soul and its dwellings." I take it that what Socrates thinks we ought to venture to believe is some description, a story like the one he told, about what happens to the soul, where the soul goes, and what it is continued existence is like.

Second, this reading is further supported by the fact that Socrates claims one ought "to

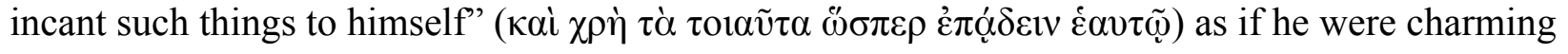


himself into believing them (114d4-5). ${ }^{161}$ Socrates thinks that we ought to convince ourselves of such a tale, charming ourselves, as it were, into believing in a description of what the afterlife is like. The difficulty and perseverance involved in convincing ourselves of these things, the fact that they will require repetition, suggests that what Socrates must be recommending is a belief in something that he would not accept on its own merits. Whatever it is that we are supposed to convince ourselves of, it will be something that requires us to persuade ourselves. Once again, it seems more likely that Socrates is recommending a belief in something that he does not take to be evident in its own right. For this reason, I conclude that Socrates thinks it fitting to convince ourselves of some descriptive story about what the afterlife is like - not merely the seemingly innocuous moral lessons that follow from such an account.

Third, and crucially, it is worth noting that the symbolic solution, if it were true, would do nothing to actually dispel the fear of death. Believing in the moral messages that follow from Socrates' account of the afterlife, that we ought to strive for wisdom or that we must become more like the divine, will not be powerful enough to dispel the fear that we may go to a place that is radically different from our present existence. In other words, believing in the moral messages that follow from the description of the afterlife and not some description itself will do very little to dispel the worry that we may await some unexpected or unfavorable fate. In contrast, if we convince ourselves of a description of what happens when we die, by repeating it as if it were a charm, this will bring us a certain amount of solace. Believing a descriptive account of what happens to the soul is, it seems, the way that we must dispel our fears about what the afterlife will be like.

In response to this last point, those who hold the symbolic view might object that I have merely misidentified the most important of the moral messages in the Phaedo myth. The myth does not simply show that 'we ought to strive for wisdom' or 'we must become more like the divine' - it reinforces the claim, pace my argument in section II, that 'a good afterlife awaits good people'. In other words, it may be that the moral of the myth which is most relevant in the present discussion is just some relatively abstract statement of the ORP. Sedley comes close to recommending this himself: he says that what the myth shows is that there is "cosmic justice" in the universe. Hackforth comes even closer. The myth is, on his view, a “symbol of [Plato's] own 
philosophic doctrine" of rewards:

[T] he whole complex of science, pseudo science and mythology of which the myth (in the wide sense) consists, is designed with marvelous skill to support the eschatological doctrine of rewards and punishments[.] ${ }^{162}$

This view, the objection goes, is that Socrates is at $114 \mathrm{~d}$ endorsing a belief in some abstract version of the ORP, i.e. 'good souls go on to a favorable existence'. This interpretation would not be inconsistent with Socrates' earlier statement that the myth is not an accurate account of what happens when we die. And so, this version of the symbolic view would dissolve the problem we have been considering. Moreover, although some of the lessons implied by the Phaedo myth are not strong enough to stave off the fear of death, this particular moral lesson may well be. If we come to believe that the souls of good men await a favorable afterlife - despite not believing any of the more specific claims in the myth about what the afterlife is like - this might be enough to ward off the fear of death.

In response to this reading, it is perhaps worth emphasizing that a belief in an abstract moral, even if the moral is 'good souls await a good afterlife', is simply not what Socrates is recommending in the above passage. What it would be fitting to believe is not some abstract lesson, like 'there is justice in the universe' or 'good souls await a good fate'. Instead, he seems to be recommending that we convince ourselves of something risky and difficult to believe: a detailed account like the one he told about what happens to the soul when we die.

As to the other suggestion, that some abstract version of the ORP, of the form 'good souls await a good fate', will be enough to dispel the fear of death, this is, I think, also not very convincing. We can repeat to ourselves over and over that 'there is justice in the universe' or 'something good will happen to good people in the afterlife', but such claims are going to be unconvincing. Believing in the myth only symbolically, accepting only the moral and philosophic messages that underlie them - that we ought to strive for wisdom, that we must become more like the divine, or even that there is some principle of universal reward and punishment-will not be enough to dispel the fear of death. Even if we come to believe, abstractly, that the universe is good and fair, there is still a very real sense in which we will 
worry that our souls await some fate that is very different from what we presently experience. In contrast, if we accustom ourselves to believe some detailed explanation of what happens to the soul on its departure from the body, by repeating it as if it were a charm, we will eventually become tranquil in the face of death. By believing some detailed explanation of what happens to the soul when we die, we will eventually begin to feel that we have nothing to fear.

We would be hard-pressed, I conclude, to take this part of the dialogue as evidence for the symbolic view that what Socrates recommends is merely a belief in the moral lessons that follow from the myth. Socrates must instead think it fitting to venture a belief in the details of the myth itself, as a descriptive account about what will occur when we die.

\section{Conclusion}

In part II, I argued that the the myth is an acknowledgement of an unargued premise in Socrates argument against the fear of death. In part III, I argued that Plato puts forward such a detailed myth, because convincing ourselves of some such an account will be our best hope of achieving tranquility in the face of death. We are now in a position to see that this is yet another case in which Socrates is himself aware of having given an unconvincing argument for one of his own views. He sets out in the dialogue to show that a philosopher has nothing to fear in the face of death, insofar as he has divorced himself from bodily concerns. This argument turns, we saw, on two premises: IS and ORP. For most of the dialogue, however, the interlocutors examine IS. It is not until the tail end of the discussion that Socrates reintroduces the ORP, giving the myth to acknowledge this other key assumption. However, I have argued, Socrates is aware at the end of his story that this key premise has not been firmly established; at the end of the dialogue, we are left to wonder what becomes of the souls of good men. Socrates deems it fitting to believe the myth, therefore, on pragmatic grounds - it will be beneficial to us to believe some detailed version of the myth insofar as this alone will bring us tranquility in the fear of death.

We are now in a position to return to the question raised at the beginning of this section. Given Socrates' commitment to the view that believing false things harms the soul, we would expect him to think that a reasonable person ought to form beliefs based on the strength of their 
conviction that the belief in question is true. If, however, Socrates is, indeed, aware of the fact that the myth is not a convincing argument for the ORP, but recommends that we believe it on pragmatic grounds, then we would appear to have evidence to the contrary. Why does Socrates recommend a belief in some account which is not likely to be correct?

In what remains of this paper, I consider a number of possible answers to this pressing question.

The yogic interpretation: a problem of knowledge

One possible interpretation of the myth, which I have yet to consider is the yogic view. This is the view that Plato's myths express 'truths' which are impossible to realize through reason alone. There is a sense in which a yogic reading of the myth may help to explain why Socrates recommends a belief in his tale on pragmatic grounds, despite thinking that it is likely to be inaccurate. Consider the view that, for Plato, humans have no reliable access to what the afterlife is like. If this is correct, then we have no access in our present state, as embodied humans, to what lies beyond death. We might even find some support for this claim early on in the dialogue. At 66a-67b, Socrates claims that we can never really have knowledge of reality, of what lies beyond ourselves and the visible world, until we are no longer embodied. If this is true, if we have limited access to what lies beyond death, it may be that Socrates feels that his tools, reasoning and argumentation, are underpowered in getting at the truth of this particular matter. If this version of the yogic view is correct, if indeed Plato thinks that we have very little evidence to go on in matters of the soul, then it may be that Socrates recommends the Phaedo myth, despite not thinking that it is accurate, because he thinks that this account is as good as any.

This view holds that, because we cannot be certain about what lies beyond death, because we are limited in our ability to develop a true account, the best way to dispel our fears will be to convince ourselves of some description, according to which we have a favorable fate. Because we have no way of verifying whether such an account is accurate, we simply have to take it on faith. This suggestion is, however, somewhat unsatisfactory in that Socrates does seem elsewhere in the dialogue to take the afterlife to be a subject that we can know about in our present state. The proofs for the immortality of the soul do, after all, make a number of claims about what 
happens to the soul after the death of the body: It is reincarnated. It recollects. It persists and does not dissolve. I conclude that, the yogic interpretation of the myth, although it may go some way in showing why Socrates would recommend an unlikely account on pragmatic grounds, is based on a somewhat unlikely assumption - that, for Plato, humans cannot use reason to approach matters of about the afterlife.

\section{For Socrates' sake?}

It may be instead that Socrates does not so much feel that reason is underpowered in determining what the next world must be like, as he feels the limits of the present discussion. It is worth remembering that Socrates is, at present, about to die. The dialogue itself takes place while he and his companions await the order for him to drink the poison. This is a fact of which we are frequently reminded in the narration. At the opening of the dialogue the ship has arrived home and Socrates' death appears imminent. Socrates is himself very aware of his impending death. At one point, he even goes as far as to suggest that this is effecting his ability to argue clearly (91a2-c4):

I am in danger at this moment of not having a philosophical attitude about this, but like those who are quite uneducated, I am eager to get the better of you in argument, for the uneducated, when they engage in argument about anything, give no thought to the truth about the subject of discussion but are only eager that those present will accept the position they have set forth. I differ from them only to this extent: I shall not be eager to get the agreement of those present that what I say is true, except incidentally, but I shall be very eager that I should myself be thoroughly convinced that things are so.

It is remarkable that Socrates admits to being in a harried state of mind. Despite the fact that he has argued throughout that he does not fear death, he does nevertheless show signs of distress at his fate. He even claims that he is not feeling as philosophically adept as he usually would; he cannot hope to muster good arguments in his present state of mind. ${ }^{163}$ Instead, he claims to be eager to believe what he has been saying about the soul. He even goes as far as to say that his motives in the present conversation are "selfish", that what he has said is far more for his own sake than for the sake of his listeners. In the same passage, he goes on to claim that, for his listeners, those present in the telling of the dialogue, he recommends that they decide for 
themselves whether what he says makes sense, claiming: "[G]ive little thought to Socrates and much more to the truth."

Although these remarks might be easily overlooked, Socrates' mindset is, I think, highly relevant in the present context. His arguments about the fear of death appear to be given under pressure and very much for his own sake. What I take this to show is that, even if Socrates might, under ordinary circumstances, think it is possible to muster arguments about the character of the afterlife, his present circumstances have led him to adopt a less-rigorous method than that which would ordinarily prefer. It may be, then, that Socrates simply feels unable to muster an argument in his present state. This is another potential explanation as to why he might turn to the myth. In order to convince himself that there is nothing to fear in death, he recommends repeating a tale about what happens to the soul. For us, however, we are encouraged to see his arguments as delivered for his own sake and to decide for ourselves whether to believe them. Although Socrates delivers this warning in the midst of his arguments about IS, it seems to apply equally well to the myth. We ought to decide for ourselves whether to follow Socrates in adopting such a belief.

In response to this suggestion, there is, however, also somewhat of a sticking point. That the myth is intended for Socrates' own sake does not explain why he later says that it is fitting, generally, to believe in the myth he has told. Although his earlier warning is explicit that the arguments he gives in response to Cebes' and Simmias' objections are for himself, Socrates' recommendation at $114 \mathrm{~d}$ appears to be issued to his general audience. "[I]t is both fitting and good", he claims, "to risk believing this to be so-for the risk is good-that this is the case or something like it is the case about the soul and its dwellings." Socrates tells all listening that it is appropriate to believe in his story about the afterlife. I conclude that the myth is intended, solely, for Socrates' own benefit. He may feel at a loss to muster a better account of the ORP, given his present situation, but this is not itself an explanation as to why he thinks it good or fitting to venture a belief in such an account.

\section{The myth is good even if it is false}

Why should Socrates recommend a belief in the myth on seemingly pragmatic grounds? The 
answer to this troubling question is, I suspect, that believing such an account will be beneficial, even if it turns out to be inaccurate. Earlier in this section, we saw that false beliefs are harmful to the soul, in that they pervert our ability to know the truth. We are now in a position to see that believing this particular account, regardless of its truth value, will be beneficial. Even if the myth about the afterlife is strictly false, it will be good to believe that the souls of the good go on to good fates whereas the souls of the bad do not. Believing a myth which supports the ORP will be beneficial in that it will motivate a person to do philosophy and pursue virtue. In fact, believing such an account of the afterlife will be a very powerful motivator. If it is true that the souls that fare best in the afterlife are the souls of those who are most accustomed to do philosophy, and if we are convinced of this fact, having repeated a story about the afterlife to ourselves to the point of believing it, then we will take great pains in the perfection of our own souls.

The myth, it seems, might be taken both as a means of staving off the fear of death and as a means of motivating the philosophical way of life. If, by contrast, we do not think that there is anything beyond death, if we think that either we cease to exist or we await an uncertain fate, not determined by our earthly character, then we might fall into a state in which we have no motivation to be good and virtuous. If nothing awaits us after death, if our embodied life is all there is, we may come to believe that what matters, really and truly, is nothing other than what the body recommends. ${ }^{164}$ In other words, unless we believe that some better fate awaits us, unless we posit a higher existence and see this as the reward for a life lived well, we will be at risk of believing that we have little or no reason to perfect our souls. It would appear, therefore, that the myth about the character of the afterlife is a way of motivating us to do philosophy and become better people.

This fact about the myth - that it will be good to believe even if it turns out to be false - is ultimately what resolves the tension with which I began this section. If I am correct that the myth (or some other story which illustrates the ORP) will be good for us to believe, if believing that the afterlife is ordered in such a way, that the good are rewarded and the bad are punished, encourages us to pursue philosophy and develop good souls, then it is easier to see why Socrates might endorse a view which would otherwise seem far-fetched and poorly 
defended. In the case of this particular belief, even if it turns out to be a false one, it will not be harmful to the soul in the way that other falsehoods might. Consider again the source of the tension in question: It seems that for Plato (and Socrates) we ought not to believe things which are likely to be false. Socrates seems, even in the present dialogue, to hold the view that believing false things will harm the soul. It is bad to believe what is false, I have argued, in that doing so will make the soul less prepared to determine what is good and true. Accepting falsehoods will distort our ability to discern true from false and good from bad. In short, if we accept falsehoods into our souls, if we come to believe false things while thinking them to be true, then we lose the ability to reason clearly about the truth. This is, I take it, why Socrates speaks of it false beliefs begetting other bad results in the soul (115e5-7): a person who believes falsehoods falls out of touch with reality and no longer has the means to find their way back. In the case of the myth, however, in the case of the story about the afterlife which Socrates recommends at $114 \mathrm{~d}$, the harm that one would endure in this sense, of believing a potentially false account, and thereby potentially distorting her ability to discern truth from falsehood, seems to be a far less problematic. In this case, accepting this unproven and far-fetched account, although it is unlikely to be true, will not so much distort our ability to reason as it will motivate us to do so in the first place. The myth is, it seems, a special sort of falsehood, one that encourages us to take better care of our souls. As such, even if it turns out to be false, the myth will provide us with the invaluable motivation to go looking for the truth of matters. The myth might be excused, therefore, in the sense that, even if it turns out to be false, it will encourage us to lead a life in the pursuit of the truth. 


\section{WORKS CITED}

Annas, J. 1982. "Plato's Myths of Judgement.” Phronesis 27: 119-43.

Apolloni, D. 1996. "Plato's Affinity Argument for the Immortality of the Soul." Journal of the History of Philosophy 34: 5-32.

Barnes, J. “Critical Notice of D. Gallop's Plato Phaedo.” Canadian Journal of Philosophy 8: 189-203.

Bluck, R. S. 1955. Phaedo. London: Routledge \& Paul.

Burger, R. 1984. The Phaedo: A Platonic Labyrinth. New Haven: Yale University Press.

Burnet, J. 1920. Early Greek Philosophy. London: A. \& C. Black.

Crombie, I. M. 1962. An Examination of Plato's Doctrines. New York: Humanities Press.

Dodds, E. R. 1959. Gorgias. Oxford: Clarendon Press.

Dorter, K. 1982. Plato's Phaedo: An Interpretation. Toronto: University of Toronto Press.

Eisner, R. 1982. "Socrates as Hero.” Philosophy and Literature 6: 106-18.

Elias, J. 1984. Plato's Defense of Poetry. Albany: SUNY Press.

Elton, M. 1997. "The Role of the Affinity Argument in the Phaedo." Phronesis 42: 313-6.

Findaly, J. N. 1978. "The Myths of Plato.” Dionysius 2: 19-34.

Ferrari, G. R. F. 1987. Listening to the Cicadas: a Study of Plato's Phaedrus. Cambridge: Cambridge University Press.

Friedlander P. 1958-69. Plato. 3 vols. Princeton: Princeton University Press.

Fowler, H. N. 1914 [1966]. Euthyphro, Apology, Crito, Phaedo, Phaedrus. London: Harvard University Press.

Gallop, D. (1975). Phaedo. Oxford: Clarendon Press.

Gotshalk, R. 2001. Loving and Dying: a Reading of Plato's Phaedo, Symposium, and Phaedrus. Lanham: University Press of America.

Gregory, M. 1968. "Myth and Transcendence in Plato." Thought 43: 273-96

Hackforth, R. 1955. Plato’s Phaedo. Cambridge; Cambridge University Press.

Hegel. 1894 [1995]. Lectures on the History of Philosophy. Trans. Haldane, E. and Simson, F. 1995. Lincoln: University of Nebraska Press.

Mattei, J. 1988. “The Theater of Myth in Plato.” In Platonic Writings / Platonic Readings, ed. 
Griswold, C. New York: Routledge: 66-83.

Levy, G. 1960. "Introduction.” In the Myths of Plato, eds. Levy G. and Stewart J. Carbondale: Southern illinois University Press.

McMinn, J. 1990. "Plato’s Mantic Myths in the Service of Socrates Maieutic Art.” Kernos 3; 219-34.

Miller, J. 1978. "Why Plato Wrote Myths.” Southwestern Philosophical Studies 3: 84-92.

Morgan, K. A. 2000. Myth and Philosophy from the Presocratics to Plato. Cambridge: Cambridge University Press.

Nussbaum, M.. 2001. The Fragility of Goodness: Luck and Ethics in Greek Tragedy and Philosophy. Cambridge: Cambridge University Press.

O'Brien, D. “The Last Argument of Plato's Phaedo.” Classical Quarterly 17: 198-231.

Partenie, C. 2004. Selected Myths. Oxford World's Classics. Oxford University Press.

Pender, E. 2012. "The Rivers of Tartarus: Plato's geography of dying and coming-back-to-life." In Plato and Myth: Studies on the Use and Status of Platonic Myths, eds. Catherine C., Destrée, P. and Gonzalez, F. Brill.

Pieper, J. 1964. Enthusiasm and Divine Madness. New York: Harcourt, Brace \& World.

Rowe, C. J. 1993. Phaedo. Cambridge: Cambridge University Press.

-2007. Plato and the art of philosophical writing. Cambridge, UK: Cambridge University Press.

Sinaiko, H. 1965. Love, Knowledge, and Discourse in Plato: Dialogue and Dialectic in Phaedrus, Republic, Parmenides. Chicago: University of Chicago Press.

Scott, D. 1995. Recollection and Experience: Plato's Theory of Learning and Its Successors. Cambridge: Cambridge University Press.

Sease, J. 1970. “The Myth in Plato's Theory of Ideas.” Southwestern Journal of Philosophy 1: 186-97.

Sedley, D. 1989. "Teleology and Myth in the Phaedo." Proceedings of the Boston Area Colloquium in Ancient Philosophy 5: 359-83.

Smith, J. 1985. "Plato's Myths as 'Likely Accounts', Worthy of Belief." Aperion 19: 24-42. .1986. "Plato's Use of Myth in the Education of Philosophic Man." Phoenix 40: 20-34. 
Stewart, D. 1965. "Man and Myth in Plato’s Universe.” Bucknell Review 13: 72-90.

Stewart, R. 1989. “The Epistemological Function of Platonic Myth.” Philosophy and Rhetoric 22: $260-80$.

Stormer, G. 1974. "Plato's Theory of Myth.” Personalist 55: 216-23

Tate J. 1929. “Plato and Allegorical Interpretation.” Classical Quarterly 23: 142-54.

Taylor, A. E. 1926. Plato, the Man and his Work. London: Methuen.

Ward, S. P. 2002. "Penology and Eschatology in Plato's Myths." Studies in the History of Philosophy, Vol. 65. Lewiston: Edwin Mellen.

Werner, D. 2012. Myth and philosophy in Plato's Phaedrus. Cambridge: Cambridge University Press.

Waterfield, R. 2002. Phaedrus. Oxford: Oxford University Press.

White, D. A. 1989. Myth and Metaphysics in Plato's Phaedo. Selinsgrove: Susquehanna University Press.

Zeller. 1876. Plato and the Older Academy. Eds. Alleyne, S. and Goodwin, A. London: Longmans, Green. 


\section{A NOTE ON CHAPTERS TWO AND THREE}

In Chapter 2 we saw that, near the end of the Phaedo, Socrates addresses the otherworldly rewards premise - an assumption that is crucial to the argument against the fear of death - in a myth. What is more, Socrates seems to be aware that the myth is insufficient proof that the souls of good men actually await an existence that is befitting their time spent on earth. In the disclaimer following the myth, he claims that a reasonable person will not endorse such an account as an accurate description of what happens to the soul on its departure from the body. $\mathrm{He}$ goes on, however, to endorse the myth insofar as it will be good to risk believing it. Once again, as was the case in the Meno, Socrates appears to be endorsing a poorly argued view on pragmatic grounds. This is problematic, however, in that it seems to violate the veracity principle. Plato seems committed, elsewhere, to the idea that one ought to believe only what he has a veridical basis for believing - some reason, argument, or explanation that the claim in question is likely to be true.

Chapter 2 has, however, made some progress in resolving this tension: I have argued that believing some version of the otherworldly rewards premise, even if it turns out to be a false account of what happens in the afterlife, will be of great benefit and little harm to those who believe it. If a person believes that his soul will go on to an existence befitting its time on earth, then he will take great care of his soul in the present life. He will have every reason to value the pursuit of truth over all other possible pursuits. In short, if a person believes some version of the ORP, this will motivates him to take up the philosophical life.

Furthermore, I have argued that risking a belief in the otherworldly rewards premise is permissible, although it has not been sufficiently proven, insofar as, even if it is false, it will not harm the soul in the way that other falsehoods might. In the last chapter, we saw that it is bad to believe what is false because false beliefs contaminate the soul's ability to know what is true. Not only does false belief beget other false beliefs in the soul, but it also eventually changes one's ability to recognize what is true. In the extended discussion of the affinity argument, Socrates claims that a soul, which has given itself over to bodily desires, eventually comes to "[believe] that truth is what the body says it is" (83d5). Such a person, because he sincerely 
believes what is false, loses both the ability and the motivation to discover what is true. He will lack the ability to know the truth insofar as consulting his other beliefs will do him no good in confirming what is true. This is just to say that he will have trouble determining what is true because the truth is unlikely to cohere with his other beliefs. Moreover, and most importantly, thinking that he already possesses the truth, the person who believes falsehoods will lack any and all motivation to correct himself. If a person sincerely believes what is false-if he thinks that he already has the truth in hand-this will make it so that he has no further reason to inquire.

We are now in a position to see that the claims we have been considering in chapters 1 and 2 - both the theory of recollection and the otherworldly rewards premise - are, in this respect, importantly different from other falsehoods. It is bad to believe false things, for Plato, because falsehoods beget other falsehoods and they prevent us from being able or motivated to discover the truth. The beliefs in question are different, however, in that, even if they turn out to be false or inaccurate, they provide us with a kind of fundamental motivation to continue inquiring. Believing the otherworldly rewards premise, that the soul awaits a fate that is befitting to its time spent on earth, will motivate us to do philosophy and take good care of our souls. Similarly, believing in the theory of recollection motivates a person to study philosophy by showing that it is possible to discover what we do not already know. The theory of recollection and the ORP are different, then, in that believing them without sufficient proof will not harm the soul in the way that other sorts of falsehoods might. Whereas other falsehoods prevent us from pursuing the truth, these theories, even if they turn out to be false, will nevertheless motivate us to study philosophy.

It is worth noticing at this point in my argument that, in both chapters 1 and 2 , the claims we have been considering are not necessarily false. In each case, Socrates has recommended that his interlocutor believe something that he thinks has been proven insufficiently. He has not, however, in either of the cases we have seen, put forward an account, which he thinks is false. In other words, to this point, we have been considering Plato's use of weak or undefended premises - not outright falsehoods. But what if there were such a case? What if Socrates were to endorse a view that he believes to be false? In the following chapter, I take up yet another disclaimer passage, from the Phaedrus. This passage is very similar to those we have seen in the 
other two chapters; there is, however, one startling difference. In the Phaedrus, where Socrates retrospects on his analysis of love, he claims that his two speeches contain an example of a knowledgeable speaker misleading his audience (262d). In other words, Socrates seems to be aware of having introduced something inaccurate or false in his examination of love.

To anticipate, the main focus of the following chapter, like those that have come before it, is to determine what exactly Socrates thinks has been misleading in his earlier speeches. Near the end of the chapter, however, I return to the question of why this occurs. We have already seen, in the Meno and Phaedo, that it is problematic that Socrates endorses a view that he is aware has been proven insufficiently. In the next chapter, we shall see an even more extreme version of this tension - it is all the more problematic that Socrates should ever endorse a view that he believes to be false. Why, indeed, should Socrates include an untrue account of love in his education of Phaedrus? Our project shall be to determine whether and to what extent our present solution - that there are certain claims in Plato, which even if they turn out to be false, are beneficial—might also help to justify Socrates' speeches in the Phaedrus. 


\section{CHAPTER THREE: THE PHAEDRUS}

Plato's Phaedrus contains three speeches about the nature of love. The first is a manuscript authored by Lysias, which Phaedrus carries with him and reads aloud (231a-234c). Lysias criticizes love, claiming that it drives men mad. It is better, he argues, for a youth to favor a non-lover. Enamored of this conclusion, Phaedrus convinces Socrates to deliver another speech on the same topic. In the second speech, which I refer to as "the ode", Socrates obliges, arguing that a lover can have very bad effects on his beloved and therefore ought not to be preferred to the non-lover. Feeling as though he has trespassed, however, Socrates stops abruptly halfway through the ode and decides to deliver another speech as recompense. (244a-257b). This third speech, called the "palinode", praises love through a fantastical story about the vital role it plays in our search for understanding: Socrates likens the soul to a winged, tripartite chariot team, which, after the death of the body flies into the the heavens (245c-249d). The best prepared souls, those with the strongest wings, join in the procession of the gods, traveling in circuits around the Forms. Those with weaker wings, however, struggle to see the Forms and are cast back to earth to be reincarnated as beasts. At the end of the story, Socrates explains the process by which souls strengthen their wings (249d-257b); when a soul falls in love, it recollects Beauty itself in another person, and the wings begin to grow. The wings, Socrates explains, are made weaker by the pull of bodily desires. They are made stronger, by contrast, if the soul is able to resist the desire for bodily pleasure, engaging with his lover in worthwhile intellectual pursuits instead. This is why, Socrates concludes, philosophical love is beneficial for all those involved-it prepares the soul for the afterlife.

Scholars have long treated Socrates' palinode as the "centerpiece" of the Phaedrus. ${ }^{165}$ Packed with wild imagery, enthused language, and poetic allusion, it is among the most rhetorically florid passages in all the dialogues. Harvey Yunis in his analysis of Socrates' "Great Speech", another name for the palinode, claims that it:

...owes its epithet to its sustained brilliance, expansiveness, imagination, and intensity, and also to the fact that within the dialogue it is presented as both a tour de force of rhetorical display and, in a challenge to the genre of rhetorical display, a deadly serious discourse on 
love and the pursuit of knowledge. ${ }^{166}$

The palinode is, indeed, a stunning display of rhetorical prowess. At the same time, however, Socrates seems entirely candid in his defense of philosophical love. He seems to think that this form of love is, indeed, a positive influence on all involved. It is also worth noticing that many elements of the tale - the theory of the Forms, recollection, and the tripartite soul—are thought to be highly representative of Middle Plato. For this reason, the palinode is often taken as a key text in tracing the development of Plato's own doctrines over time.

Because the palinode is both very beautiful and textually important, it comes as a great surprise that Socrates later reports that the two speeches about love demonstrate the way in which a knowledgeable speaker might mislead his audience. ${ }^{167}$ In the second half of the dialogue, the interlocutors abandon their examination of love and turn their attention to the rhetorical methods exemplified by the preceding exchange (259a). Here, Socrates becomes especially interested in what it takes to deceive an audience (262a) and calls our attention back to the earlier speeches for an example. He claims that the "two speeches do, it seems, contain an example of the way in which someone who knows the truth, by toying with words, might mislead his audience" (262d1-4). Just after one of the most noteworthy passages in the all the dialogues, Socrates suggests that there has been something misleading in what has come before. As careful readers we are left to ask: what exactly are the misleading bits of the two speeches? Might Plato even mean to cast doubt on the theory of the forms, recollection, or the tripartite soul? And, furthermore, why should Plato include something misleading in a discussion meant to convince Phaedrus of the virtues of love and philosophical discourse?

This Chapter examines the palinode through the lens of these later remarks. I argue that, where many have taken the palinode as an honest reflection of Plato's own most deeply-held doctrines, we ought to doubt such a straightforward interpretation. ${ }^{168}$ My arguments for this reading are in three parts. In the first part, I carefully examine the discussion of rhetoric from the second half of the dialogue. I take this exchange to show that Socrates recognizes that both of his earlier speeches — the ode and the palinode — are examples of misleading rhetoric. ${ }^{169}$ In the second part, I turn my attention to what exactly Socrates thinks might be misleading in each. The ode is 
clearly misleading in that it defends a wrongheaded account of love. It makes love out to be a negative force. With respect to the palinode, however, things are a bit murkier; the palinode seems to offer a better account in that it defends love, taking it to be a positive and beneficial force. I shall argue, however, that this speech turns on a number of careful equivocations. Although the palinode defends a true conclusion, it rests on a number of skillfully concealed mistakes. Finally, in the third part, I turn my attention to why Plato should include anything, which he recognizes as misleading, in a dialogue meant to induce a young person to do philosophy. If the palinode is inaccurate, misleading, or insincere what role can it play in the education of Phaedrus?

\section{The two speeches: Phaedrus 259-265}

Midway through the dialogue, in the space of a few lines, the interlocutors give up their examination of love and turn their attention to the rhetorical methods exemplified by the preceding speeches (259a). Here Socrates wonders whether there is a genuine art of speaking or whether it is a mere knack. He argues that if there truly is an art of speaking, then it must govern all forms of speech, whether it be political discourse or discourse about private affairs (261ce). In addition, he notes that this art would apply even to cases in which an orator misleads his audience (261e). In an effort to show that even misleading rhetoric will require skill, Socrates gives an argument, one that we shall see in detail below, that in order to mislead without being misled oneself, a person must have knowledge of the topics about which he speaks. At the end of this argument, however, something quite surprising occurs: Socrates calls our attention back to the two earlier speeches. Here, he claims (262d1-4):

And, with some luck, it seems, the two speeches contain an example of the way in which someone who knows the truth, by playing with words, might mislead his audience. ${ }^{170}$

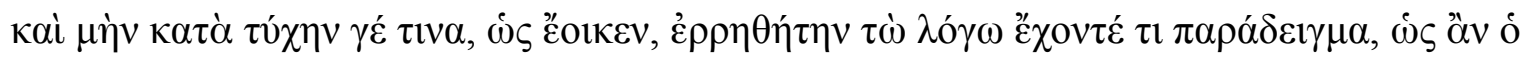

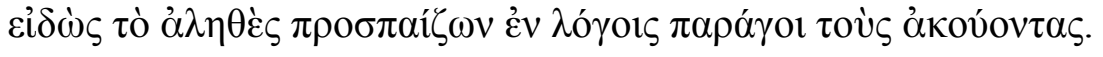

As I mentioned above, this passage raises a number of pressing questions. What exactly are the misleading bits of the two speeches? Might Plato even mean to cast doubt on any of his seemingly-characteristic doctrines? I will address these questions in the following section; in this 
section, however, I tackle a number of even more fundamental questions about how we ought to take the above passage. These questions are as follows. 1) To which bits of the dialogue do the "two speeches" ( $\tau \dot{\omega} \lambda \hat{\gamma} \gamma \omega)$ refer? 2) How are we to understand the two speeches as an "example" $(\pi \alpha \rho \alpha ́ \delta \varepsilon 1 \gamma \mu \alpha)$ of misleading rhetoric? Does Socrates mean that both speeches contain something misleading, or might there be a single example between them? 3) And, finally, why does Socrates say the two speeches serve as an example of the way in which a knowing speaker

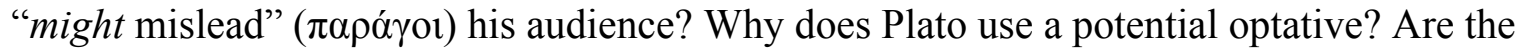
speeches only potentially misleading? Or does Socrates find some actual fault with them?

I turn now to the first of these ambiguities. Which are the "two speeches" ( $\tau \dot{\omega} \lambda \hat{\gamma} \gamma \omega)$ in question at $262 \mathrm{~d}$ ? This ambiguity arises in that Socrates calls our attention to two speeches that are meant to serve as an example of the way in which an orator misleads his audience, despite there being three speeches in the first half of the dialogue. ${ }^{171}$ It would seem that the "two speeches" may refer to (1) Lysias' speech and the ode, (2) Lysias' speech and Socrates' discourses taken as a whole, or (3) Socrates' discourses taken separately. ${ }^{172}$ Before we can even begin to investigate in what way these speeches might be misleading, we are left to ask which combination of the three speeches is meant to serve as an example in the first place. The question is: which of these combinations is the most likely pairing?

The above passage contains a number of subtle indications that Socrates means to pick out (3) his own two speeches. Consider first that he refers to the "two speeches" using the dual $\tau \dot{\omega} \lambda \hat{\gamma} \gamma \omega$. We can be reasonably sure that the speeches to which he refers form a "natural pair" - they exhibit the same kind of unity as a pair of eyes or shoes. ${ }^{173}$ From among the possible combinations of the three speeches, it would seem most natural to take the "two speeches" to be Socrates own, the ode and palinode. ${ }^{174}$ Furthermore, Socrates claims in the above passage that

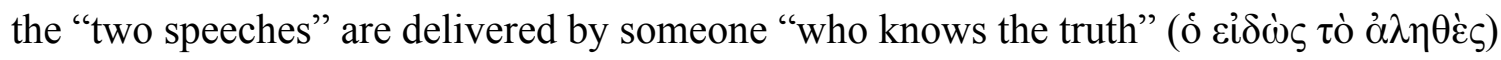
(262d2-3). Although there is some ambiguity as to whether knowing the truth refers, in this context, to knowing the definition of love or knowing whether love is beneficial, one thing is clear: this qualification would seem to rule out any combination which includes Lysias' speech. Socrates is quite clear that Lysias defends an incorrect view of love and that he does so 
completely without skill. In his analysis of this speech, Socrates notes that Lysias fails to issue a proper definition of love (263d-264a). Lysias does not describe what he means, but rather jumps ahead to his conclusion (264a4). He also fails to organize his speech in a logical manner (264). The speech appears "thrown together at random" and unprincipled (264b2-10). Of course, a knowledgeable speaker - one who knows the truth about love - would be able to effect a mistake more elegantly. All of this is just to say that, in this part of the dialogue, Lysias is certainly not cast as "one who knows the truth" about love. If his speech misleads, then, it would seem to do so in a way that is completely out of his control.

If this is correct, then we can reasonably eliminate Lysias' speech from consideration. The first two combinations-(1) Lysias' speech and the ode and (2) Lysias' speech and Socrates' discourses taken as a whole - no longer appear to be viable interpretations. I conclude that, it is very likely that the "two speeches", which serve as different examples of misleading by someone who knows the truth, must refer to (3) Socrates' own discourses taken separately. If this is correct, then the two speeches to which Socrates refers are none other than the ode and the palinode.

Of course, there is a further obscurity in the above passage in that the two speeches are supposed to provide an "example" ( $\pi \alpha \rho \alpha ́ \delta \varepsilon 1 \gamma \mu \alpha)$ of the way in which a knowledgeable person misleads. It is unclear just how how we are meant to construe this: does each of the two speeches serve as an example of misleading, or is there a single example between them? On the first interpretation, each speech would serve as an example in its own right. Both the ode and the palinode would demonstrate how a knowledgeable speaker misleads his audience. On the second interpretation, however, the two speeches would demonstrate, through a single example, the way in which someone who knows the truth might mislead his audience. On this view, the ode may be the sole case of misleading rhetoric in the dialogue - it is, after all, the only speech in which a person who knows the truth defends a conclusion he knows to be false. The palinode would be included as 'a part of the example' of misleading rhetoric simply because it it shows that the author of the two speeches, Socrates (or the local Muses), is in fact someone who knows the truth about love. The second interpretation is more conservative, therefore, in that it does not 
take the palinode as misleading in its own right.

I argue below in favor of the first interpretation. It is my view that both the ode and the palinode are demonstrations of misleading rhetoric. In what follows, I take it largely for granted that the ode misleads in that it puts forward a false account of love. (I will say a bit more about how the ode misleads in the next section.) My focus here is, instead, to dispel any objections as to whether Socrates takes the palinode to be misleading. To this end, I now turn to the discussion of rhetoric from the second half of the dialogue. Socrates' retrospective remarks show, I will argue, that the palinode is very likely intended as an example, in its own right, of the way in which a knowledgeable person might mislead his audience.

Let us begin with a brief summary of Socrates' arguments about artful misleading. There are a number of details in this part of the dialogue which will be useful in understanding his later remarks about the palinode. The interlocutors begin the discussion of rhetoric with a question about whether there is a genuine art of speaking or whether it is a mere knack. Socrates argues that, if there truly is an art of speaking, it must govern all forms of speech, political discourse or discourse about private affairs (261e1-3). In addition, he claims that if there were an art of speaking, it would apply even to acts of speech in which an orator misleads his audience (261e3). Here, Plato seems to have in mind a rhetorical technique, "antilogic" ( $\dot{\eta} \alpha \dot{\alpha} \tau \imath \lambda o \gamma \iota \kappa \eta)$, which was used by sophists and rhetoricians to defend both sides of a claim and, ultimately, derive a contradiction (261c8). Zeno was famous for giving "antilogical" arguments, proving that a single object, an arrow or a runner, could be at once stationary and in motion. In order to show that even antilogical speech, a mode of discourse which is intended to confuse or mislead, requires skill, Socrates gives the following argument (261e5-262c2):

I think it will become clear if we look at it in this way. Where is deception most likely to occur_-regarding things that differ much or things that differ little from one another?

-Regarding those that differ little.

At any rate, you are more likely to escape detection, as you shift from one thing to its opposite, if you proceed in small steps rather than in large ones.

-Without a doubt

Therefore, if you are to deceive someone else and to avoid deception yourself, you must know 
precisely the respects in which things are similar and dissimilar to one another.

-Yes, you must.

And is it really possible for someone who doesn't know what each thing truly is to detect a similarity—whether large or small—between something he doesn't know and anything else?

-It is impossible.

Clearly, therefore, the state of being deceived and holding beliefs contrary to what is the case comes upon people by reason of certain similarities.

-That is how it happens.

Could someone, then, who doesn't know what each thing is ever have the art to lead others little by little through similarities away from what is the case on each occasion to its opposite? Or could he escape this being done to himself?

-Never.

Therefore, my friend, the art of the speaker who doesn't know the truth and chases opinions instead is likely to be a ridiculous thing — not an art at all.

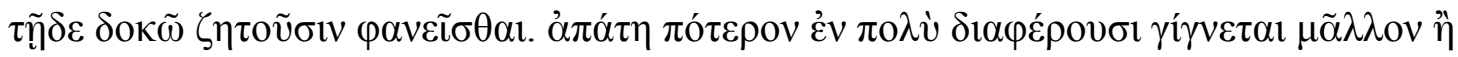
ỏ $\lambda$ ífov;

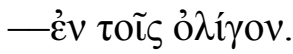

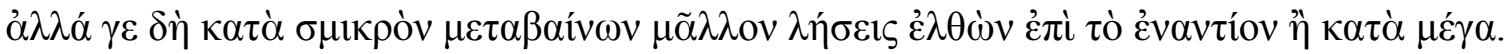

$-\pi \tilde{\omega} \zeta \delta^{\prime} \mathrm{ov}$

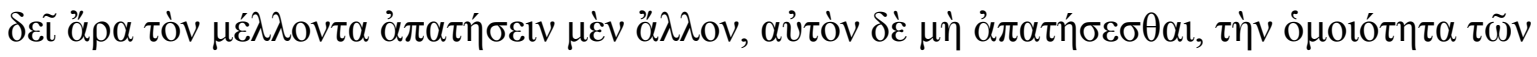

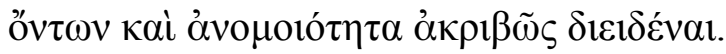

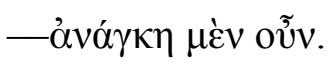

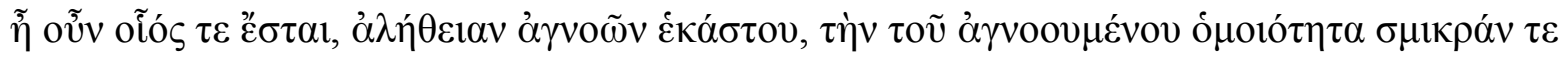

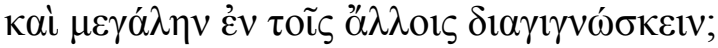

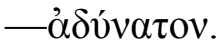

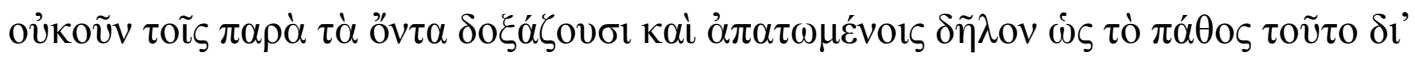

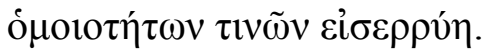

— -

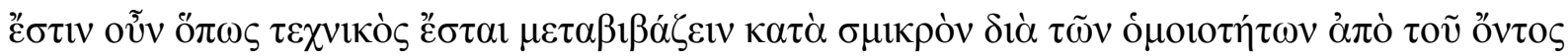

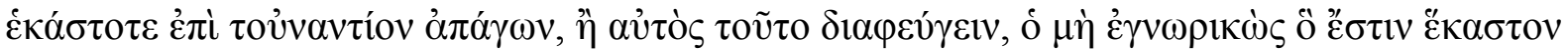
$\tau \tilde{\omega} v$ ő $v \tau \omega v$;

- ở $\mu$ í $\pi \mathrm{o} \tau \varepsilon$.

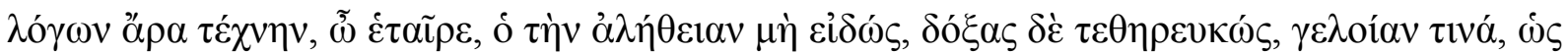

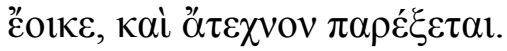


In this exchange, Socrates defends the view that antilogical speech, speech that effectively leads a person to believe that a single claim is both true and false, requires knowledge. He concludes that any speaker who wishes to mislead his audience, without being misled himself, must have knowledge of the topics in question. The reason for this, Socrates claims, is that false beliefs are formed as the result of mistaken similarities ( $\delta \imath^{\prime}$ ó $\mu$ oı $\left.\tau \eta ́ \tau \omega v\right) ~(262 b 4)$. One comes to hold a false belief insofar as he mistakes an entity (an object, concept, property, etc.) for a similar albeit different entity. A speaker who wishes to mislead his audience will, therefore, play on this fact about how false beliefs are formed, emphasizing the similarities between two different entities in order to convince his listener that they are in fact one and the same thing (262b5-6). This is just what Socrates has in mind when he says that a speaker "passes over" ( $\mu \varepsilon \tau \alpha \beta \alpha$ ív $\omega)$ from one thing to its opposite (262a2). A speaker elides or equivocates on the distinction between two different entities. Through each step of his argument, he makes these entities seem more alike than they actually are. Socrates adds that it is possible to effect such a mistake only when the audience is unaware or ignorant of the true nature of the entities in question (262a10). It follows that, a speaker, who is able to mislead without being misled himself, must have knowledge of the topics in question (262c1-2).

Before moving on, it will be good to take a moment to understand what Socrates has in

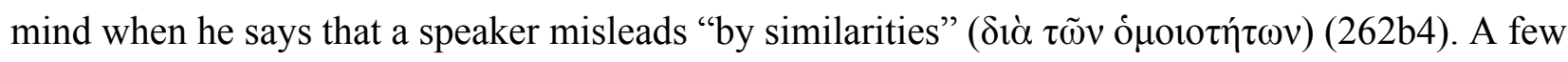
pages earlier, at 260b, Socrates gives a relevant example: he asks Phaedrus to imagine that he has composed a speech about the virtues of fighting on horseback (260b1-3). Socrates adds to this hypothetical that neither of them knows what a horse is. He also asks Phaedrus to consider that this speech, meant to praise horses, unwittingly mistakes them for asses, praising them for being creatures of value at home and in battle, good for carrying baggage and serving as a mount (260b4-c1). If Phaedrus were truly ignorant of the nature of horses and asses, the similarities between them might cause him to mistake an ass for a horse. Both agree that this would be a rather ridiculous result. This example, although it is not an example of intentional misleading, does provide a clear illustration of the way in which the similarities between two entities, whether it be horses and asses or good and evil actions, might contribute to the formation of a false belief. A conflation arises between two entities in that they share certain traits. One who is ignorant of the 
true nature of horses and asses, seeing their common traits and lacking the criteria to distinguish between them, will easily mistake one for the other. Because he lacks the ability to differentiate, the ignorant person will take these entities as interchangeable. Socrates adds that it will be quite difficult to mislead with respect to entities like iron and silver (or horses and asses, for that matter) insofar as the nature of these are firmly within the grasp of the average person (263a5). A conflation will be easier to effect, he thinks, in the case of entities like goodness and justice in that there is a great deal of disagreement about them.

Keeping in mind the above discussion of artful misleading, let us now turn our attention to Socrates' remarks about the palinode. Following the passage that has been the focus of this Chapter - that the two speeches demonstrate the way in which a knowledgeable person might mislead his audience-Socrates and Phaedrus begin to review each of the speeches in detail. This part of the Phaedrus, when it is read in light of the earlier discussion of artful misleading, seems to indicate that Socrates would include the palinode in the "example" of misleading discourse. For ease, I have printed his reflections about the palinode below (265b2-d3):

[W]e made four divisions of the divine madness, ascribing them to four gods, saying that prophecy was inspired by Apollo, the mystic madness by Dionysus, the poetic by the Muses, and the madness of love, inspired by Aphrodite and Eros, we said was the best. We described the passion of love in some sort of figurative manner, expressing some truth, perhaps, and perhaps being led away in another direction, and after composing a somewhat plausible discourse, we chanted a sportive and mythic hymn in meet and pious strain to the honor of your lord and mine, Phaedrus, love, the guardian of beautiful boys.

- Yes, and I found it very pleasant to hear.

Here let us take up this point and see how the discourse succeeded in passing from blame to praise.

-What do you mean?

It seems to me that the discourse was, as a whole, really sportive jest; but in these chance utterances were involved two principles, the essence of which it would be gratifying to learn, if art could teach it. ${ }^{175}$

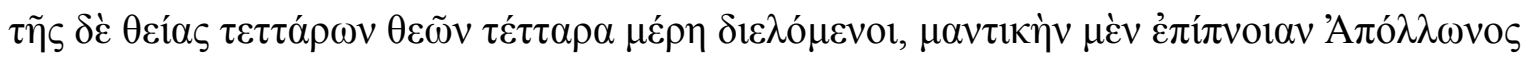

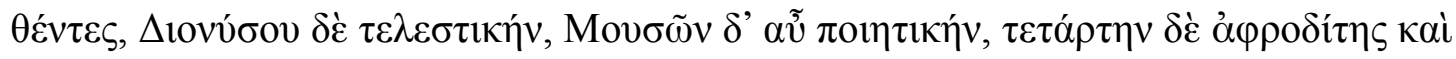




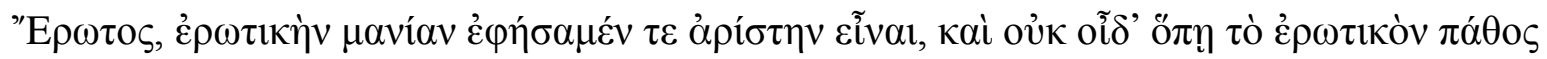

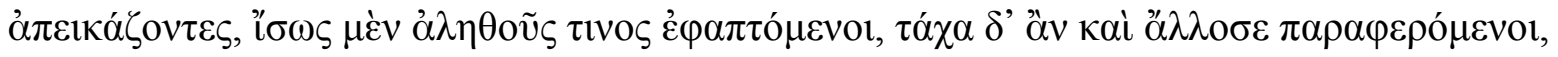

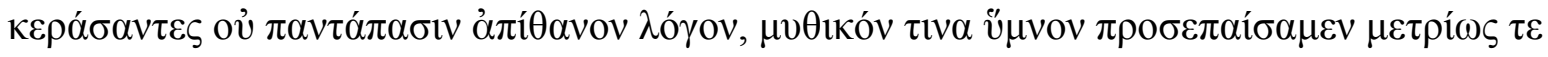

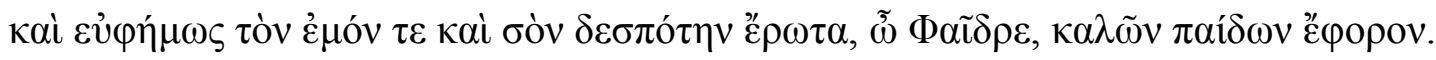

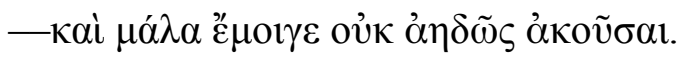

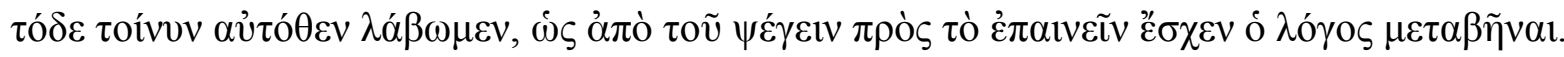

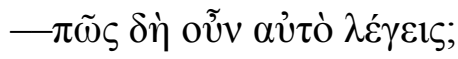

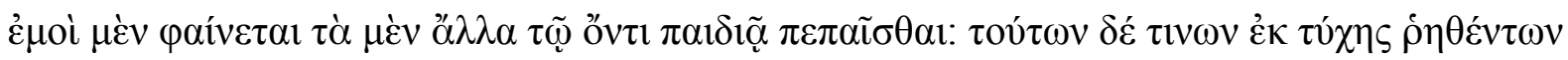

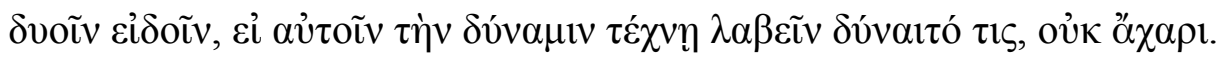

There are a number of useful observations to be made about his treatment of the palinode in this part of the dialogue. ${ }^{176}$ First, Socrates says that, although the speech expressed some truth, he and Phaedrus "may have been led astray" ( $\pi \alpha \rho \alpha \varphi \varepsilon \rho o ́ \mu \varepsilon v o l) ~(265 b 5)$. Presumably the palinode expresses some truth, in that it defends love. It is less clear, however, why Socrates thinks it also may have led them astray. Many commentators have taken this remark to refer to the imaginative, almost mythical tone of the speech. ${ }^{177}$ This reading garners further support from the fact that Socrates takes the palinode "to jest playfully" ( $\pi \alpha 1 \delta 1 \alpha \underline{\alpha} \pi \varepsilon \pi \alpha \tilde{\tau} \sigma \theta \alpha 1)$ (265c6). It might be concluded, based on this evidence, that Socrates means to call our attention to the speech's spirited tone or marvelous imagery.

Such readings are a natural starting-point, but fail, I think, to appreciate what Socrates says next. It is very telling that he thinks the palinode succeeds in passing ( $\mu \varepsilon \tau \alpha \beta \tilde{\eta} v \alpha \iota)$ from blame to praise (265c4). At first glance, this might seem like a completely innocuous description; presumably, he just means that the palinode succeeds in praising love whereas the first speech makes love out to be a destructive force. Yet a similar turn of phrase appears in the above discussion of artful misleading. There, Socrates refers to the way in which an antilogical speech misleads as "making a shift ( $\mu \varepsilon \tau \alpha \beta \alpha i v \omega v)$ by small steps from one thing to its opposite" (262a2). The repetition of $\mu \varepsilon \tau \alpha \beta \alpha i v \omega$ in the present passage is, I take it, no mere accident; Plato must see the palinode as fitting neatly into the discussion of antilogical speech from just a few pages before. It is very likely, therefore, that when Socrates says the palinode "makes a shift", he means that it resembles antilogical speech, playing on the similarities between otherwise 
dissimilar entities. As we saw above, the method Socrates has in mind is one by which a skillful orator makes an elision between otherwise dissimilar entities.

If this is correct, then, in its efforts to make love out to be a positive force, the palinode would seem to involve some kind of equivocation between dissimilar entities. ${ }^{178}$ In the next section, I shall say more about how and why the palinode effects this sort of intentional mistake. For the moment, however, I take these remarks as proof of a far simpler point: when Socrates speaks of the two speeches offering an "example" of misleading rhetoric (262d), it is very likely that he has in mind the palinode as an example in its own right. Socrates' appraisal of the speech in the second half of the dialogue is far less ambiguous: on multiple occasions, he claims that his recantation ought not to be taken in earnest. He first claims that he and Phaedrus "may have been led astray" by it ( $\pi \alpha \rho \alpha \varphi \varepsilon \rho o ́ \mu \varepsilon v o 1) ~(265 b 5)$, taking the palinode "to jest playfully" ( $\pi \alpha 1 \delta 1 \tilde{\alpha}$ $\pi \varepsilon \pi \alpha \tilde{I} \sigma \theta \alpha \imath)$ (265c6). Later, Socrates even goes as far as to say that the speech succeeds in passing $(\mu \varepsilon \tau \alpha \beta \tilde{\eta} v \alpha \imath)$ from blame to praise (265c4). The palinode would seem, therefore, to be an example of misleading rhetoric in its own right. ${ }^{179}$

We might finally turn our attention to the third ambiguity in the passage with which we began. It is somewhat confusing that, at $262 \mathrm{~d}$, Plato uses the potential optative: the two speeches serve as an example of the way in which a knowing orator might, by playing with words, mislead

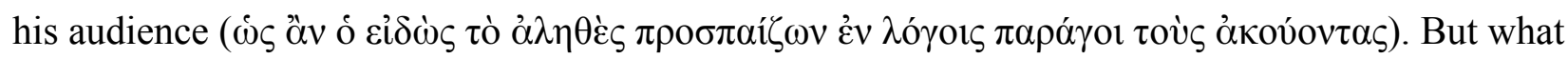
does it mean that the speeches are an example of how an orator "might" mislead? Once again, there are two possible interpretations. On the first interpretation, Socrates would recognize the two speeches as misleading, as they stand, in that each makes some mistake of which he is cognizant. On the second reading, however, Socrates would not recognize any particular flaw in the speeches as they stand; rather, he might be taken as indicating that the speeches have certain features which may, on some occasions, be considered misleading. He may, for example, think that the metaphorical imagery of the speech is misleading, if it is taken as an accurate account of love, philosophy, and the soul.

So which is it? Does Socrates recognize any particular mistakes in the two speeches? Or is he simply expressing the view that they have certain features which may, under certain conditions, 
be misleading? Drawing on evidence that we have already seen, there is, I think, a good reason to prefer the first reading. We can be relatively sure that Socrates is cognizant of some particular mistake in the two speeches. Above, I argued that Socrates speaks of some kind of equivocation in the palinode. He describes it, using the same language, which he used in describing the sort of equivocations central to antilogical arguments. It seems reasonable to conclude, therefore, that Socrates recognizes some particular mistake in the way that the palinode defends love. It would be odd to say that the palinode succeeds in the way of antilogical speech, in making an elision between dissimilar entities (265c4), if Socrates did not recognize any particular flaws in the speech.

If this is correct, however, if Socrates recognizes a flaw in the palinode, we might wonder, all the more, why he says that the two speeches serve as an example of the way in which an orator might mislead. Why not say that the two speeches are an example of the way in which an orator does mislead? Dominic Scott, in his analysis of this part of the dialogue takes these questions about Plato's use of the optative to be highly relevant. He argues:

In the case of the first speech, of course, we already have independent and explicit evidence that it was actually misleading. Where the second is concerned, however, Socrates might have a weaker point in mind: that it has the potential to mislead. (Similarly, in 265b6-8, Socrates does not say that the speech actually did mislead us about the erotic experience, just that it may have misled us in certain respects.) So I shall not try to force just from $262 \mathrm{c}-\mathrm{d}$ alone the implication that the palinode actually contains a deliberate mistake. Whether it does or not is something that can only be established on other grounds.

There are, I think, two points to be made in response to this worry. First, it ought to be noted that the reading I have presented here relies on a number of passages from the discussion of rhetoric, not just $262 \mathrm{~d}$. We have already seen, on other grounds, that Socrates very likely takes the palinode to be misleading in its own right. Second, we ought to be aware that Plato has a very good reason to speak cautiously about the effects of misleading rhetoric on his audience. In the discussion of artful misleading, we saw that whether or not something turns out to be misleading, whether or not it is successful, will be largely dependent on the audience in question. Socrates claims that an orator will only be able to effect a mistake, creating an elision between two dissimilar entities, insofar as his audience does not have knowledge of the topics in question (262a10). It is only possible to convince a person that two things are more or less dissimilar than they really are, if he 
is unfamiliar with the entities in question. If this is correct, if something's being misleading depends on the audience in question, then it is easy to see why Socrates should speak of the ode and the palinode as only potentially misleading. Even if Socrates recognizes a particular equivocation in the palinode, whether or not his speech turns out to be misleading will depend on who is listening - someone who knows the truth about love will escape unfooled, whereas someone like Phaedrus, who is ignorant of love's nature, will be taken in. It seems perfectly reasonable, therefore, that Socrates might both recognize particular equivocations in what he has said and think that the two speeches are only potentially misleading.

If the arguments of this section are correct, then Socrates' remarks in the second half of the Phaedrus suggest that Socrates sees the palinode as misleading in its own right. It is very likely that the palinode demonstrates a technique common to antilogical speech, in which an orator effects an intended mistake by equivocating between two or more dissimilar entities. Of course, I do not mean to oversell this result. Socrates suggests, in one breath, that the palinode rests on an equivocation, and in the next, the interlocutors turn to other topics. His remarks are so subtle and so fleeting that their force escapes Phaedrus entirely, who seems interested only in what the palinode does well (265d3). Nevertheless, a careful reading of this part of the dialogue has shown that, where many have taken the palinode as a sincere record of Plato's own most-deeply held philosophical doctrines or as "deadly serious" on the part of Socrates, we have a number of good reasons to doubt such a straightforward interpretation. ${ }^{180}$

\section{What exactly is misleading in the two speeches?}

To this point, we have seen that it is very likely that Socrates thinks each of his two speeches serves as an example of misleading rhetoric. But what exactly does he have in mind when he urges Phaedrus to look back at the two speeches from the first half of the dialogue for "an example of the way in which someone who knows the truth might mislead his audience" (262d1-4)? What precisely does he mean when he says that the palinode "makes a shift", following techniques common to antilogical speech (265c4)? In an effort to answer these questions, I now turn my attention back to each of the speeches in question. 


\section{The ode}

It is apparent, even on the first reading of the dialogue, that Socrates thinks the ode defends a false conclusion. He stops abruptly halfway through this address, before giving what would be "the other side" of the argument (where he would list the positive influence of the non-lover on a youth). What causes him to recant so suddenly is his realization that the ode offends love, presenting an argument that is incorrect (244a2-3). Socrates' meaning could not be plainer-he cannot continue to defend a conclusion that runs contrary to what he knows to be the truth (244a4). It is no wonder, then, why Socrates should later brand this speech "misleading"; it puts forward a conclusion, which he believes to be false.

Of course, wherever we find Socrates arguing against his convictions, it will be helpful to ask why he would do such a thing. Although this problem is less pressing in the case of the ode, there are at least three tentative observations to be made about what motivates Socrates to defend a false claim. First, it is especially relevant that Phaedrus challenges Socrates to deliver this speech in response to Lysias (235a-236e). A challenge of this sort often serves as an introduction to eristic discourse, in which Socrates engages with a known sophist, eschewing the common mandates of philosophical discussion in favor of a competitive way of speaking. ${ }^{181}$ Although Lysias, a well-known Sophist, is not present in the dialogue, there is nevertheless a sense in which he issues the challenge to Socrates. Phaedrus is an associate of Lysias and is so enamoured of him that he carries his written speech beneath his cloak. Phaedrus takes it as an offense that Socrates thinks the speech lacking and issues a challenge to Socrates on Lysias' behalf.

Second, Socrates' insincere arguments in the ode might be further explained by the fact that the speech demonstrates the technique of misleading by similarities. Above, I outlined the method, by which a speaker suggests a similarity between two or more entities in order to create an equivocation between them. In the ode, Plato puts this technique to work; Socrates creates a conflation between the desire for beauty and other excessive desires, in the service of defending a false account of love. The speech begins with a "definition" of sorts. Love, Socrates asserts, is an excessive desire, just like gluttony or drunkenness (238b). The only difference, he argues, is that the excess desire is not for food or drink but for beauty. With this "definition" in hand, one 
that plays on the similarity between the desire one feels in love and other common forms of excessive desire, Socrates proceeds to describe all the ways in which the lover, like a glutton or drunk, mistreats his beloved. Overcome by the desire for beauty and literally driven out of his mind (238e, 241a) a lover will pursue his beloved in great excess and, as a result, keep him away from a number of important goods (239b-240a). Jealous of his beloved's attention, a lover will wish to keep him away from intellectual improvements (239b1-c2). Moreover, he will wish for his beloved to have lost all his friends and family connections (239e1-240a2). By falsely defining love in this way, as an excessive desire, Socrates effects an intended mistake. He makes it seem as though the lover will be driven out of his mind, going to great lengths to fulfill his desire and will, as a result, harm the one he loves.

Third, and finally, it is worth noticing that Socrates does not hide his insincerity for long. Because the ode misrepresents love, falsely identifying it with an excessive desire, Socrates quickly decides to recant. This does, I think, take much of the sting out of the fact that he defends an untrue account. The ode puts forward a false account of love only momentarily; Socrates immediately retracts his arguments, delivering the palinode as compensation. I now turn to this speech, as it is less clear why and how Socrates thinks that the palinode misleads.

\section{The palinode}

As Socrates begins his recantation, he says, "I want to wash out the bitterness of what we've heard with a more tasteful speech" (243d4-5). Where the ode was a false account, the palinode will, it seems, tell the truth about love (244a4-5). ${ }^{182}$ Although I do not want to belabor this point, it is worth noticing that Socrates believes the conclusion of the palinode. He seems to think that love is, indeed, a positive force. It seems reasonable to think, therefore, that the palinode surpasses the earlier speeches in that it defends a true account of love. Yet, for this reason, it also seems odd to suggest that the palinode might be misleading. As we saw above, Socrates later refers to this speech as a part of the demonstration of misleading rhetoric, calls it little more than a "sportive jest", and says that it succeeds, in the manner of an antilogical speech, in "passing" from blame to praise $(265 \mathrm{c} 4)$. These disparate passages create a tension. If the palinode tells the truth about love, how does it also mislead? 
If what I have argued to this point is correct, there is a rather simple solution to this tension. We have seen that, despite making love out to be a beneficial force, the palinode passes from blame to praise in the manner of an antilogicial speech. It would seem, therefore, that the palinode defends love on the basis of an equivocation or elision. The palinode might be taken to be misleading, then, not with respect to its ultimate conclusion-it does not defend a false conclusion - but with respect to the method by which this conclusion is reached. In order to show that love is a positive force, the palinode equivocates between otherwise dissimilar entities.

This reading will become more convincing, I suspect, once we have seen the ways in which the palinode appears to "make a shift" from blame to praise. Let us now ask: how does Socrates pass from blaming love in the ode to praising it in the palinode? How does this speech exemplify the antilogical technique? In what remains of this section, I examine two possibilities, each of which seems to be a substantial equivocation on the part of Socrates. The first of these is that, in the palinode, Socrates takes philosophy to be a form of madness. The second possibility is that the palinode takes one form of love, philosophical love, to be indicative of the whole class. In this way, I argue, the palinode is very similar to the ode. Just as the ode focuses entirely on a bad form of love-love of beautiful bodies - the palinode focuses entirely on philosophical love, taking this one form of love to be indicative of the whole class. Love is beneficial, Socrates concludes, insofar as doing philosophy is good for the soul. This is mistaken, however, in that not all lovers will be philosophers. Let us turn now to the first of these possibilities.

\section{Philosophy and madness}

The palinode begins with the statement that, although the lover is overcome by a kind of madness, madness is not always a bad thing (244a2-3). In the ode, Socrates portrayed the lover as quite literally out of his mind with desire, unable to control himself and destructive to his beloved. Now, however, he means to show that the lover's madness is not always a destructive force. To this end, Socrates begins the speech by identifying three types of divine (and therefore beneficial) madness: prophecy, telestic madness, and poetry (244b-245b). He then posits a fourth type of madness (249e2). The fourth type, which is the focus of the rest of the speech, is philosophical, the process by which lovers who do philosophy are reminded of the form of 
beauty and prepared for their journey into the afterlife.

Gregory Vlastos was among the first to notice that the concept of a philosophic madness poses an interpretive problem. He writes that, in the palinode, love "is not only described, but defined, as mania by our ultra-rationalist, Plato, and is associated as mania in the closest terms with philosophy no less than the mystic cults." ${ }^{83}$ Vlastos finds the treatment of philosophy in the palinode quite puzzling; elsewhere in the dialogues, philosophy is consistently associated with the exercise of reason. In fact, this would seem to be a cornerstone of Platonic thought. It is strange, then, that Socrates should ever profess such a discordant view. To make matters worse, a bit later in the speech Socrates further describes this form of mania as the complete displacement of reason (one who is possessed by love is quite literally to aphron) (265e-266a). ${ }^{184}$ It looks like philosophy, an activity that Plato consistently characterizes as the exercise of reason is here characterized as the complete absence of it.

Dominic Scott, in a recent article, suggests that we read this part of the palinode "as an example of playfully misleading rhetoric". ${ }^{185}$ The speech misleads, he thinks, "precisely in treating philosophy as a bona fide form of madness." Like many interpreters, Scott is wary of attributing misleading arguments to Plato as anything but a last resort. Here, however, given the discussion of rhetoric that follows, he entertains this possibility as a viable solution. I argued above that the ode fits neatly into Socrates' description of misleading by similarities, in that it improperly defines love as an excessive desire. Scott thinks that the palinode does the same thing: it, too, serves as an illustration of misleading by similarity (he calls this the process of "assimilation"). In particular, Scott argues, the palinode effects a mistake by aligning philosophy with prophecy, possession, and poetry. After setting out the three types of divine madness, Socrates attempts to show that philosophical love is also a type of divine madness and that it is therefore just as beneficial (245b). Scott argues that Socrates achieves this result by showing that philosophical love, like other forms of divine madness, involves enthusiasm, in which a person is overcome by an outside force (249d3). In the palinode, when the philosopher recollects, his reason communes with the forms. In the moment of his communion, his reason becomes nearly divine (249c7-10). Because recollection appears to involve some kind of divine insight, then, Socrates concludes that philosophic love must also be a form of divine madness. 
It is a mistake, however, according to Scott, to extrapolate from the fact that the philosopher has a kind of insight into the nature of the forms to the conclusion that philosophy must therefore be a form of divine madness. He puts this point thus:

Prophets and poets become enthused by being literally invaded from without by a god. This is why the notions of inspiration and possession apply to them as well. But the enthusiasm of the philosopher is quite different. As we have seen, he is enthused in the same way as the gods themselves are. By contemplating the forms, the source of the gods' own divinity, his soul comes to be divine as well. But it is his own reason that is divine, and there is nothing in this concept of enthusiasm to suggest the intrusion of an outside force undermining the philosopher's intellectual agency (any more than there is in the case of the gods themselves). The problem is not that enthusiasm has two different species; [the problem] arises once one tries to make madness (and, with it, to aphron and paranoia) fall out of the concept of enthusiasm. Such a move only works when enthusiasm involves the displacement of reason by the divine, not reason's similarity to the divine, as in $249 \mathrm{c} 4-\mathrm{e} 4 .{ }^{186}$

Whereas the poet and the prophet are quite literally overcome by gods, serving as a "mouthpiece" of sorts, the philosopher is enthused without having his reason pushed out or displaced. When the philosopher recollects it is his reason that becomes nearly-divine. It is a mistake, therefore, to take having this kind of insight to imply having one's reason displaced. Yet the palinode does just this. Socrates assumes that the philosopher's communion with the forms implies that he is mad (249e1-3). It appears, therefore, that Socrates equivocates between philosophy, where one has nearly divine insight, and madness, where one's reason is actually pushed out and replaced by a divine force. In doing so, Socrates helps himself to the conclusion that he intends to reach: because philosophy is a form of divinely-inspired madness, it must, like other forms of divinely-inspired madness, be beneficial.

This interpretation fits very neatly with my analysis of the discussion of misleading rhetoric. In his analysis of the palinode, Socrates says that the speech succeeded in passing $(\mu \varepsilon \tau \alpha \beta \tilde{\eta} v \alpha \imath)$ from blame to praise (265c4). Scott's solution to the paradox of philosophic madness might be taken to explain the way in which the palinode makes this sort of equivocation, in that it seems to elide philosophical insight and madness. Socrates takes recollection (an important feature of his account of philosophic love) to involve divinely-inspired insight; he then elides this type of insight with three recognizable forms of divinely-inspired madness. This equivocation implies that the philosopher, like the poet or the prophet, will have his reason displaced, becoming a 
mouthpiece for the divine. This, in turn, enables Socrates to reach the conclusion that love must be beneficial. Because it is divine reason that invades the philosopher from without, it must therefore be something beneficial.

If this is correct, then it makes perfect sense that Socrates should later treat the palinode as misleading in its own right. In the service of showing love to be beneficial, the palinode equivocates between philosophical insight and madness. On this reading, the palinode misleads precisely in that it convinces Phaedrus that the philosopher's reason will be displaced in the search for understanding.

This reading fits neatly with what we have already seen - it may be that the palinode equivocates between philosophical insight and madness, and this is why he later treats it as misleading - nevertheless, I am reluctant to conclude either that there must be exactly one elision in the palinode or that this particular elision must be exactly what Socrates has in mind when he says that the palinode may have led them astray, passing in the manner of antilogical speech from blame to praise (265b-c). All of the evidence we have considered thus far is perfectly consistent with there being more than one equivocation in the palinode. In fact, in the discussion of artful misleading, where Socrates first introduces the method of misleading by similarity, he claims that an orator will often "make a shift" to his desired conclusion through a number of small steps (262a2). It is very likely, I conclude, that the palinode succeeds "in passing from blame to praise" through more than one equivocation. ${ }^{187}$ In the section that follows, I point to another prominent equivocation in the palinode.

\section{Love vs. philosophical love}

In this section, I shall argue that there is at least one other major equivocation in the palinode - whereas Socrates sets out to prove that love simpliciter (o $\varepsilon \rho \omega \varsigma$ ) is beneficial, he ends up proving instead that a subclass, philosophic love, is beneficial. Let us begin with a brief recap of what the palinode promises to prove. As we saw above, Socrates starts his recantation, claiming to offer the speech as compensation, both because he is ashamed at what others may think and because he is afraid of love himself $(243 \mathrm{~d} 3)$. Socrates claims that he will "wash out the bitterness 
of what we've heard with a more tasteful speech" (243d4-5). The palinode will, it seems, continue to examine the same topic as the ode; however, whereas the ode made love out to be a harmful force, the palinode will show that love is in fact beneficial. Although this may go without saying, the topic of the palinode - whether love is beneficial — is the very same topic as the last speech. Socrates will try to set the record straight with respect to the question of whether it is better to favor the lover or the non-lover. Furthermore, we ought to take note that, at the outset of the

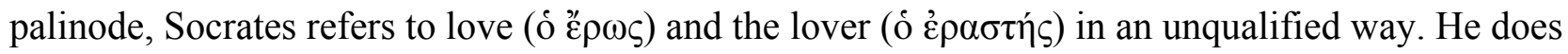
not divide love into different forms; instead, he seems to speak of love simpliciter.

For a time, it looks like the palinode will not deviate from the topic of love simpliciter. In an effort to show that love is beneficial to the lover, Socrates describes the different forms of divine madness and the benefits that each incurs. He concludes that all forms of divinely inspired madness ought not to be feared, insofar as each will be beneficial to the person inspired (245b1-3). In the next part of the speech, Socrates sets a new task, to show that both the lover and the beloved will be benefited by love: "Let him show in addition that love is not sent from heaven for the advantage of lover and beloved alike, and we will grant him the prize of victory" (245b4-6). This is notable in that, at this point in the speech, Socrates still speaks of both love and the lover in an unqualified manner. Love is here a simple, unqualified concept, carried over from the ode. Similarly, the lover would appear to be the same sort of lover that has been under consideration from the start - a lover of beautiful boys.

However, as the speech goes on the concept of love and the lover appear changed. ${ }^{188} \mathrm{~A}$ new kind of lover crops up, when Socrates is speaking of the different ways in which souls are rewarded and punished in the afterlife. Here, he casually introduces one who "has been a lover of

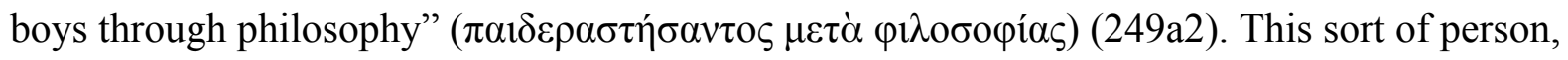
Socrates claims, will be the best off in the afterlife and will be freed completely of the cycle of reincarnation. Similarly, a bit later, Socrates claims to have shown that "one who loves the

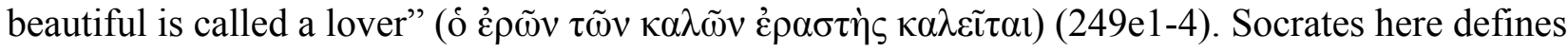
the lover as someone who loves the Beautiful (o $\dot{\varepsilon} \rho \tilde{\omega} v \tau \tilde{\omega} v \kappa \alpha \lambda \tilde{\omega} v)$. This is striking, however, in that it is somewhat divergent from the concept with which Socrates began: the lover of the ode was a lover of beautiful boys. It would seem that love of the palinode is a love of beauty itself. 
In the next part of the speech, Socrates continues to sort out the benefits that love brings to both parties involved. He first offers a description of what happens when a lover falls in love with a boy. Here, we find the rich description of the lover sprouting wings. This image seems to illustrate the passion one feels upon first falling in love. The shear vividness of the experience of sprouting wings, the sweat and pain of the image, pervade this part of the speech with a kind of physical longing. For this reason, we might be tempted to think that Socrates' topic is, once again, nothing other than a love of physical beauty. In other words, it may seem that the lover of this part of the dialogue is no different than the lover of the ode. However, as the story goes on, Socrates makes a number of remarks to suggest that his interest has shifted. Following on the heels of the image of the lover's wings, Socrates offers a classification of the sort of "lovers" he has in mind: these are the followers of Zeus, Ares, Hera, and Apollo (252c4-253c1). Each of these types, Socrates claims, is a follower of a different sort of god and will bring a different kind of benefit to his beloved (252e2-253b1). What is of particular interest, here, is that the sort of "lover" in question is one whose soul has followed the gods. In the speech to this point the only souls that have followed the gods are the philosophers; the philosophers are those souls with the wings strong enough to fly into the heavens. If this is correct, then it appears that Socrates has, in fact, recast the "lovers" in question as philosophers. This reading is further supported by the fact that, at the end of this passage, Socrates calls the "lovers" in question "those truly lovers" ( $\tau \tilde{\omega} v \omega \mathfrak{\omega} \varsigma \alpha \lambda \eta \theta \tilde{\omega} \varsigma \dot{\varepsilon} \rho \omega ́ v \tau \omega v)$

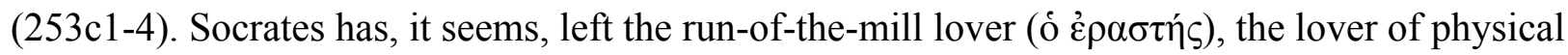
beauty, of the sort we find in the ode, far behind; he is interested instead in true lovers, the philosophers.

In what remains of the speech, Socrates continues with this new conception of love in mind. Near the end of the speech, he returns to the image of the charioteer, in order to show the way in which love ultimately benefits all involved. Socrates likens the lover's initial desire for sex and pleasure to a bad horse, which his reason, the charioteer, trains over time (253c7-254e8). The bad horse eventually buckles and learns to obey his driver; at this point, the lover learns to approach his beloved more respectfully. The beloved eventually admits the lover into his society, and, over time, they have conversations and become intimate (255b). Throughout this process the soul of the lover fills with desire for the boy. He becomes so full of love, that eventually some of it 
spills out into his beloved, who, experiences a kind of "backlove" (255d8). ${ }^{189}$ Once the beloved starts to feel this way, he is drawn to the lover through desire as well (265a1). It is at this point, when both lover and beloved are completely enamoured of one another, Socrates claims, that they are in a position to reap the very greatest rewards. When choosing whether to act on their desires, he claims (256a7-b6):

Now if the victory goes to the better elements in both their minds, which lead them to follow the assigned regimen of philosophy, their life here below is one of bliss and shared understanding. They are modest and fully in control of themselves now that they have enslaved the part that brought trouble into the soul and set free the part that gave it virtue. After death, when they have grown wings and become weightless, they have won the first of three rounds in these, the true Olympic Contests. There is no greater good than this that either human self-control or divine madness can offer a man.

If the lover and beloved, enthralled in the passion of love, refuse to give in to their bodily urges, if they maintain self-control, then they will have set themselves up for the greatest blessing of all. I assume that what Socrates has in mind in this passage is sexual desire; when the lover and the beloved realize that they are in love, they can act in one of two ways. Either they can express their love physically, engaging in intercourse, or they can maintain an intellectual relationship. It would appear that Plato recommends the latter as the way to reap the greatest rewards. By loving another person, passionately, and not acting on that passion, a person learns how to control his appetites. As a result, his soul becomes well prepared for the afterlife. This is why, Socrates ultimately claims that "love" is beneficial: living in the presence of beauty, feeling passion, and not acting on it, induces a soul to be incredibly self-controlled. When the soul of the "lover" dies, Socrates concludes, he will be better prepared than those who have never beheld beauty or those who have beheld beauty without being able to control themselves. The soul of the lover will, it seems, be the best controlled and, therefore, the most adept at steering his chariot into the next life.

But why has Socrates shifted from talking about lovers of beautiful boys to lovers of truth and beauty itself? There is, I think, a very good reason for this. In order to show that the love is, indeed, a great benefit to both the lover and his beloved, Socrates has had to delimit what he considers "love" and the class of people he considers "lovers". If Socrates had to consider other 
forms of love and other kinds of lovers, the game would be up; for, when love influences non-philosophical souls, who choose to indulge their desires, it can have profoundly bad effects. Love would seem to make the wild soul's appetites all the more wild. I conclude that, in order to reach the conclusion that love is beneficial, Plato has restricted the class of "lovers" to those who love beauty itself and are in control their appetites. For these people, for the philosophers (and perhaps even for the lovers of honor), love is a great benefit: it accustoms them to beholding beauty, so that when they encounter pure beauty in the next life, their souls are not startled or pulled wildly in different directions. Love is, for the philosophical types, a highly beneficial exercise in self-control. If I am correct, however, then, when Socrates draws the conclusion that love is beneficial, he is only entitled to this conclusion with respect to a particular kind of love and a particular kind of lover. Love is beneficial only insofar as it is purely intellectual in nature, and the lover is beneficial to his beloved only if he is in control of his appetites.

If I am correct, then, a shift occurs in the palinode between love simpliciter and philosophical love. Of course, we might wonder whether Socrates (Plato) was himself aware of having made this shift. In reply, it is telling that, at the end of the palinode, where Socrates reveals what benefits await the lover and the beloved, he only discusses lovers who are in control of their desires. There are, first, the lovers, who have trained their appetites to be in complete control (256b2). These lovers fare the best of all. But Socrates also includes another class of lovers, those who love honor, and, as a result, also fare better in the afterlife; because these lovers know it is bad to indulge their appetites, only failing to control themselves on occasion, they will also be drawn to the forms (256c-d). Notice, however, that Plato does not talk about other sorts of lovers, for example, those who see no shame whatsoever in indulging themselves. It would seem, then, that in the service of showing love to be beneficial, Socrates has left out a discussion of lovers who are attracted to physical beauty and act on their attraction without hesitation. Indeed, the only lovers under consideration in the palinode, those that benefit their beloveds, are well-controlled lovers of beauty itself.

Moreover, this particular equivocation - taking love simpliciter and philosophical love to be one and the same- fits neatly with the discussion in which Socrates later identifies the speech as misleading. In order to better explain this view, let us turn our attention once more to the 
discussion of misleading rhetoric. Following on his retrospective of the palinode, described in detail above, Socrates describes a well-known method of classification, often called "collection and division". Although much more might be said about this method, suffice it to say that collection and division supply an orator with a schematic overview of the similarities and differences between topics. For this reason, Socrates places collection and division at the heart of the art of speechmaking. Even those who wish to mislead an audience must, it seems, appeal to this process in order to deliver a convincing speech. For ease, I have recorded the passage in which this process is introduced:

It seems to me that [the palinode] was, as a whole, really sportive jest; but in these chance utterances were involved two principles, the essence of which it would be gratifying to learn, if art could teach it.

-What principles?

That of perceiving and bringing together in one idea the scattered particulars, that one may make clear by definition the particular thing which he wishes to explain; just as now, in speaking of Love, we said what he is and defined it, whether well or ill. Certainly by this means the discourse acquired clearness and consistency.

-And what is the other principle, Socrates?

That of dividing things again by classes, where the natural joints are, and not trying to break any part, after the manner of a bad carver. As our two discourses just now assumed one common principle, unreason, and then, just as the body, which is one, is naturally divisible into two, right and left, with parts called by the same names, so our two discourses conceived of madness as naturally one principle within us, and one discourse, cutting off the left-hand part, continued to divide this until it found among its parts a sort of left-handed love, which it very justly reviled, but the other discourse, leading us to the right-hand part of madness, found a love having the same name as the first, but divine, which it held up to view and praised as the author of our greatest blessings (265d-e).

In this passage, parts of which we have already analyzed, Socrates announces that he is not wholly satisfied with the palinode; nevertheless, he claims that it demonstrates the two core principles of speechmaking, collection and division. The principle of collection is the act of "perceiving and bringing together in one idea the scattered particulars, that one may make clear by definition the particular thing which he wishes to explain" (265d). By grouping disparate albeit similar particulars together under a single class, one determines those traits or characteristics which all the members of the class share. Socrates then introduces the principle of division, which he describes as "dividing things again by classes, where the natural joints are, 
and not trying to break any part, after the manner of a bad carver" (265e). By dividing a larger class into subclasses, an orator gains a finer understanding of the differences between each of its members.

Notice that in this passage, Socrates describes both the ode and the palinode in the context of how they collected and divided love. Having collected both good and bad forms of love under the same class, madness, "one discourse, cutting off the left-hand part, continued to divide this until it found among its parts a sort of left-handed love, which it very justly reviled, but the other discourse, leading us to the right-hand part of madness, found a love having the same name as the first, but divine, which it held up to view and praised as the author of our greatest blessings" (265d-e). This passage would seem to indicate that each speech is somewhat incomplete in that each only addresses one form of love. The ode, carving off the bad kind of love, showed love, generally, to be a negative force. But this is misleading in that not all love is bad. In the palinode, Socrates addresses a positive form of love. However, this speech makes a similar mistake. Socrates takes philosophical love, only one part of the class of love, to be indicative of the whole. Love is, Socrates argues, a positive force, because doing philosophy is good for the soul. But, as we have already seen in the ode, there is another kind of love-love of beautiful bodies, a distinctively non-philosophical form of love-which, insofar as it creates unrest in the soul, is not beneficial for those involved.

If I am correct, then the mistake of the palinode is the same mistake of the ode: it takes one form of love to be indicative of the whole class. Once again, it would appear that Socrates has made a shift in an effort to pass from blame to praise. In this case, he has created an elision between love simpliciter and philosophical love. It turns out that, in the palinode, Socrates has not shown that love, of the sort we saw in the ode, is beneficial. In fact, he has shown that when this kind of love influences people who are prone to give in to desire easily, all those involved are harmed. Love encourages a person to further lose control of their desires, and, as a result, makes him less prepared for the afterlife. It is only when love influences those who are inclined to remain in control of their appetites that it is beneficial. This intellectual kind of love, Socrates claims, is a great benefit to both the lover and the beloved, because it fills them with desire for beauty, while, at the same time, bolstering their self-control. 


\section{An objection: what justifies misleading?}

If the arguments of this Chapter are correct, then the palinode, although it makes love out to be a beneficial force, rests on at least two prominent equivocations. Socrates takes philosophical insight to be interchangeable with madness, and love simpliciter to be interchangeable with philosophical love. In Chapters 1 and 2, we saw two cases in which Socrates is aware of having presented an unconvincing argument in defense os a beneficial view. In each of these chapters, we saw it was problematic that Socrates should ever feel justified in relying on unconvincing arguments. In the present discussion this worry is even more pressing. The above analysis, if it is correct, shows that in an effort to defend a true conclusion, the palinode makes at least two misleading claims, passing in the manner of antilogical arguments from blame to praise. Yet this sort of tactic, misleading by similarities, would seem patently inconsistent with the general reverence for truth that we find expressed throughout the dialogues. Why, after all, in the process of educating Phaedrus, should Socrates feel the need to mislead him?

We might express this worry more generally as follows: it seems deeply problematic that Socrates might resort to using false claims - even as a part of a more general effort to persuade an interlocutor of some important truth. Gregory Vlastos, in the conclusion of his influential study of Socratic irony, issues a similar challenge against any interpretation which has taken the dialogues to contain knowing fallacious arguments. He puts this challenge thus:

None of the scholars who have seriously believed that Socrates employed insincere beliefs or consciously fallacious inferences in these or other arguments has ever tried to explain how such infidelity to the quest for truth could be reconciled with Plato's concept of Socratic philosophizing. ${ }^{190}$

It seems inconsistent with Socrates' (and Plato's) views about the pursuit of truth to suggest that he might ever knowingly mislead his interlocutors. In light of this tension, Vlastos concludes that it is far simpler to assume that Plato was simply unaware of the deep flaws in reasoning that we sometimes find in Socrates' arguments. Although Vlastos' solution is generally an acceptable one, such an explanation is unconvincing in the present discussion. We have seen that Plato is very much aware of the fact that the palinode misleads. When penning Socrates' reflections on this 
speech, he indicates that it passes in the manner of antilogical speech from blame to praise-it would seem that Plato is very much aware that the palinode rests on one or more equivocations. The question is: how are we to square this with the goals of Socratic-Platonic philosophy more generally? And why should Plato feel justified in representing Socrates in this way?

In what remains of this Chapter, I advance two possible justifications for Socrates' insincerity in the palinode. The first justification, which I have already begun to explore, is that Socrates' speeches are intended to persuade Phaedrus to pursue of a better sort of life. The palinode encourages Phaedrus to disassociate himself from men like Lysias and to pursue a life of philosophy instead. The second justification is that Socrates' speeches serve as a demonstration of the art of misleading rhetoric, which will be instructive for readers of Plato.

\section{Defending philosophy}

In Chapters 1 and 2, we saw that Socrates sometimes puts forward unconvincing arguments followed by pragmatic reasons for belief. These take the form: it will be good to believe $\mathrm{x}$, so you should believe x. In these cases, I argued that what Socrates recommends - the theory of recollection and the ORP - although they have been proven insufficiently will be beneficial even if they turn out to be false. Whereas other sorts of falsehoods make it so that a person has no reason to investigate the truth, the theory of recollection and the otherworldly rewards premise motivate a person to seek the truth in the long term. This is why, I have argued, these are not harmful falsehoods: they motivate a person to question his beliefs through the continued pursuit of truth.

Although the present disclaimer is structurally quite different from the passages we have already seen, in that Socrates does not seem to endorse the palinode on explicitly pragmatic grounds, a very similar justification may be at work. Each of the equivocations of the palinode, even if they lead Phaedrus to believe falsehoods, will ultimately be beneficial to believe. Recall that, at the start of the dialogue, Phaedrus is wholeheartedly convinced by Lysias' argument against the lover. More importantly, he appears to have fallen completely under the influence of the rhetoricians. By the end of the palinode, however, Phaedrus has begun to express an interest in philosophy $(278 b 4,279 \mathrm{c} 5) \cdot{ }^{191}$ At the end of the dialogue he believes that it is better to give his 
favor to the lover of truth and beauty itself. He has given up his infatuation with Lysias and rhetoric and decided instead to begin caring for his soul by pursuing philosophy. The palinode has thereby changed the course of Phaedrus' life. It causes him, at least for a time, to abandon the company of rhetoricians and undertake a more beneficial path.

Let us now turn to each of the equivocations in question. Both of these are, I argue, useful in convincing Phaedrus of the importance of pursuing philosophy. In this way, the elisions of the palinode, if they result in false beliefs, will not cause Phaedrus to believe falsehoods that are harmful in the way that other falsehoods are.

I begin with the claim that philosophical love is a form of madness. Why would Socrates of all people, a great defender of reason, feel justified in defining philosophical insight as a kind of madness? The answer may be, at least in part, the result of Socrates' view that one ought to tailor a speech to the interests of his interlocutor. Consider the following argument (271d1-272b6):

Since the nature of speech is in fact to direct the soul, whoever intends to be a rhetorician must know how many kinds of soul there are... These distinctions established, there are, in turn, so-and-so many kinds of speech, each of such-and-such a sort. People of such-and-such a character are easy to persuade by speeches of such-and-such a sort... When he has learned all this - when in addition he has grasped the right occasions for speaking and for holding back... then, and only then, will he have finally mastered the art well and completely.

In this part of the dialogue, Socrates claims that a successful rhetorician will be one who knows how to tailor his speech to the soul of his audience. Certain kinds of speeches, certain kinds of reasons will be more palatable to particular audiences. Now, consider that Phaedrus seems intuitively interested in the view that love is a form of madness, or enthusiasm. That love is madness is a central tenet of Lysias' speech, which Phaedrus carries around to memorize. Moreover, it is worth noticing that, in the Symposium, Phaedrus puts forward the view that love is a kind of insight, in which a person is quite literally enthused ( $\left.\varepsilon^{\prime} v \theta \varepsilon \circ \varsigma\right)$ by the god of Love (179a7, 179b1, 180b4). ${ }^{192 \mid 193}$ On his view, Love takes over the mind of the lover; it is a form of beneficial possession. Given that Phaedrus seems to hold this belief, that love is a form of divine insight, it is no wonder that Socrates might take this as a starting point for his defense of philosophy. By making philosophical love out to be a form of divinely inspired madness, in 
which a person is quite literally enthused from without by truth, Socrates appears to be playing off a belief that Phaedrus already holds. If this is correct, Socrates would appear to be tailoring the palinode to Phaedrus' interests, building his argument on a premise Phaedrus already believes.

In the palinode, Socrates puts the view that a good orator will tailor his arguments to the soul of his interlocutor: seeing that Phaedrus will be sympathetic to the view that philosophical love is a form of divine madness, Socrates elides the two concepts. The palinode will convince Phaedrus that a life of philosophy is better than a life of rhetoric. But Socrates' speech will succeed only if he can get Phaedrus interested enough in philosophy to continue studying it. Moreover, it is also worth noticing that the claim that philosophy is a kind of divinely-inspired insight will be more appealing to some than conceiving of it purely as cool-headed reason. Those who are prone to more romantic pursuits, to poetry, art, and in this case rhetoric, will be far harder to reach with a defense of philosophy that makes it out to be a stuffy enterprise, devoid of inspiration. Conceiving of philosophy as a form of divinely-inspired insight is simply more attractive to the romantic soul.

But why is this elision not harmful? Why is believing that philosophical insight is a form of divine madness not a bad thing? If I am correct in the above analysis, if Socrates means to appeal to Phaedrus' romantic sensibility, getting him on board with the philosophical way of life, then it becomes easier to see why the elision between philosophy and divine insight is not harmful in the way that other falsehoods may be. Just like the other claims we have seen in this study, the claim that philosophy is a form of madness will be one that motivates Phaedrus to study philosophy in the long term. As a result, Phaedrus, even if he harbours a false belief about the nature of philosophical insight, will stand a better chance of one day knowing the truth, than if he continues to believe in the value of empty rhetorical pursuits. Pursuing rhetorical skills will do little for the state of his soul; he will lack the motivation to correct any of his false beliefs. If, however, Phaedrus decides to pursue philosophy as a result of thinking that it is a form of madness, he will be motivated to question his beliefs. And, if he keeps at it long enough, he might even, one day, overturn the very belief which caused him to undertake this new way of life, the belief that philosophy is a form of divinely-inspired madness. 
Let us now consider the second elision. Why, in the palinode, does Socrates take one subclass of love, philosophical love, to be indicative of the entire class? Why, if his intention is to educate Phaedrus about the true nature of love, does he make the same sort of mistake that we saw in the ode? This is perhaps the more complicated of the two elisions. How might Phaedrus stand to benefit from believing that love, generally, is just philosophical love? With respect to this question, it may be useful to return to a justification we saw in the case of the first elision. Socrates expresses the view that the skillful orator will know how to tailor his arguments to the soul of his interlocutor. This is useful to notice in connection with the second elision, in that Phaedrus is certainly a person who is prone to be loved. He is a beautiful and attentive youth; moreover, he seems interested in older men. At the start of the dialogue he seems quite interested in Lysias, even carrying his speech beneath his cloak. Because Phaedrus is going to become the beloved of someone, because he seems prone to enter into a relationship with an older man, it will benefit him to seek out a good sort of companion.

How does this explain the elision between love and philosophical love? Consider the outcome of believing that what love is, what it means to love, is to do philosophy. Although this belief is false, in that it ignores the fact that there are left-handed kinds of love, love of physical beauty, it will perhaps lead Phaedrus to choose the proper sort of relationship. Phaedrus, when he chooses a lover, will likely choose a philosopher over one who does not care for the education of his soul. Although the palinode mistakes love, in general, of which there are good and bad forms, for philosophical love, the reason for this seems, once again, to motivate Phaedrus to study philosophy. Phaedrus is going to become the beloved of some man; he may as well choose to enter into a relationship with a philosopher.

This is, however, a somewhat tenuous explanation. After all, Socrates could have simply explained to Phaedrus that there are good and bad forms of love, and that he should choose the better form. Indeed, it seems problematic, especially in the case of the second elision, that Socrates does not simply choose to tell the truth. ${ }^{194}$ Why mislead Phaedrus about the nature of love in an effort to educate him on this very topic? The answer lies, I suspect, in the fact that the palinode serves another sort didactic purpose, demonstrating to readers of the dialogues that 
there are cases in which misleading rhetoric can be put to good use.

\section{A demonstration of the art of misleading}

Above I argued that the ode offers a somewhat technical demonstration of how to mislead by similarities. It makes love out to be an excessive desire, and proceeds to show why this has harmful effects. I also argued that the palinode appears to do the same, creating at least two elisions between otherwise dissimilar entities. If this is correct, then the palinode might be taken as a demonstration, at a very technical level, of the way in which an orator makes these sorts of careful equivocations. This explanation is especially useful in understanding the second elision. Readers of the dialogue will certainly get more out of the elision between love and philosophical love - as a demonstration of true rhetorical skill - than Phaedrus himself seems to. It is extremely useful for readers, who revisit the two speeches, to discover that there are different ways in which a speech might mislead: both in the service of a useless and untrue conclusion and in the service of a beneficial and true one. The ode misleads in that it makes all forms of love out to be negative. The reason Socrates undertakes this first speech is, like the rhetoricians, to show his rhetorical prowess. The palinode, by contrast, puts misleading rhetoric to a good use. The palinode misleads, through at least two careful elisions, if not more, all in the service of showing that philosophy is the more beneficial way of life. This is a rather surprising result - there are, it seems, cases in which misleading arguments can be put to good use.

Believing that philosophy is madness, and that love is nothing other than philosophical love, insofar as each of these claims motivates Phaedrus to undertake a life of philosophy, are cases in which misleading rhetoric serves a good end. Each of these claims, if followed to their logical conclusions, support a life of philosophy. As such, even if Phaedrus comes to hold false beliefs as a result of the palinode, these beliefs are of the sort that give him a fighting chance of one day knowing the truth. This is just to say that believing these claims will not harm Phaedrus' soul, in the long run. He will ultimately be in a far better position, than if Socrates were not able to convince him of the benefits of philosophy. Even if Phaedrus accepts the most far-fetched claims of the palinode - even if he routinely mistakes philosophy for madness, or love, generally, for 
philosophical insight — he will be in a far better position than the one in which he began. For, if Phaedrus were to maintain his current course, keeping company with sophists and misologists, it is very likely that over his lifetime he will come to hold many other false beliefs. Moreover, if he falls into the trap of thinking that there is no truth to be found, if he comes to believe that all claims are equally true and false, this belief will strip him of all motivation to discover the truth. As a result, he will lose all hope of ever correcting his false beliefs. This is a very bad condition to be in, not just to maintain some false beliefs, as the palinode has made him do, but to maintain false beliefs of the sort that strip a person of any and all motivation to ever correct them. By contrast, Socrates has convinced Phaedrus of the need to always pursue the truth. This does Phaedrus a great service in that one who is open to the pursuit of truth is always questioning his own beliefs. In his present state, Phaedrus will be able to further perfect his soul. It is even possible that, over time, Phaedrus will rid himself of the inaccurate views which Socrates has advanced in the palinode. And so, although Socrates has convinced Phaedrus of a number of inaccuracies, he has provided him with something far greater: the motivation to pursue the truth. 


\section{WORKS CITED}

Barnes, A. 1997. Seeing Through Self-Deception. Cambridge: Cambridge UP 4-17.

Bartsch, S. and Bartscherer, T. 2005. Erotikon: Essays on Eros Ancient and Modern. Chicago, University of Chicago Press.

Cobb, W. S. 1993. The Symposium and, the Phaedrus ; Plato's erotic dialogues. Albany, State University of New York Press.

De Vries, G. J. 1969. A Commentary on the Phaedrus of Plato. Amsterdam: Adolf M. Hakkert. Ferrari, G. R. F. 1987. From Argument to Example. Listening to the Cicadas; A Study of Plato's Phaedrus. Cambridge: Cambridge UP 41-245.

Fowler, H. N. 1966. Euthyphro, Apology, Crito, Phaedo, Phaedrus. London, W. Heinemann.

Guthrie, W. K. C. 1975. A History of Greek Philosophy: Plato the Man and His Dialogues

Earlier Period. Cambridge: Cambridge UP.

Hackforth, R. 1952. Plato's Phaedrus. Cambridge: Cambridge UP.

Klosko, G. 1987. Plato and the Morality of Fallacy. The American Journal of Philology, 108(4), $612-26$.

Liddell, H. G. and Scott, R. 1972. Greek-English Lexicon. Oxford: Clarendon Press.

Murray, J. S. 1988. Disputation Deception and Dialectic: Plato on the True Rhetoric. Philosophy \& Rhetoric 21(4) 279-289.

Mahon, J.E. 2007. A Definition of Deceiving. International Journal of Applied Philosophy 21

(2):181-194.

Moss, J. 2012.

Nehamas, A. 1999. The Phaedrus. Virtues of authenticity: Essays on Plato and Socrates.

Princeton: Princeton UP 329-358.

Nussbaum, M. C. 1986. The Fragility of Goodness: Luck and Ethics in Greek Tragedy and Philosophy. Cambridge: Cambridge UP.

Plato 1997. Euthydemus. Trans. Sprague, R. in: Cooper, J. M. and Hutchinson, D. S. eds. Plato: Complete Works. Indianapolis: Hackett Pub.

Plato 1997. Phaedrus. Trans. Nehamas, A. and Woodruff, P. in: Cooper, J. M. and Hutchinson, D. S. eds. Plato: Complete Works. Indianapolis: Hackett Pub. 
Price, A. W. 1989. love and Friendship in Plato and Aristotle. Oxford University Press.

Rowe, C. J. 1986. Phaedrus. Warminster Wiltshire England; Atlantic Highlands: Aris \& Phillips; Humanities Press.

Scott, D. 2011. Philosophy and Madness in the Phaedrus. Oxford Studies in Ancient Philosophy XLI 169-200.

Smyth, H. W. and Messing, G.M. 1984. Greek Grammar. Cambridge: Harvard UP.

Vlastos, G. 1981. Platonic Studies. Princeton: Princeton UP 3-42.

—1991. Socrates, ironist and moral philosopher. Ithaca, N.Y.: Cornell UP.

Werner, D. 2003

2007. Plato's Phaedrus and the Problem of Unity. Oxford Studies in Ancient Philosophy $32: 91-137$.

Yunis, H. 2011. Plato's Phaedrus. Cambridge University Press. 


\section{CONCLUSION}

\section{Beneficial false belief}

Each of the above cases, from the Meno, Phaedo, and Phaedrus, is one in which Socrates maintains a thesis without a veridical basis for doing so. In each, Socrates issues an argument or claim for his view, which he recognizes as weak, unconvincing, or false. He then disclaims his argument and endorses the view on seemingly pragmatic grounds: one ought to believe his thesis, because it will be good or beneficial to believe. We have seen, however, that this is quite perplexing - for Plato, one ought to accept only those claims which he has some reason to think are true. This study has advanced a number of arguments in response to this problem, as to why Socrates might be justified in employing such non-veridical reasons. Let us turn briefly to the arguments of each chapter. There are, I have argued, a certain limited class of claims, which, insofar as they justify and motivate philosophical inquiry, will be good or appropriate to believe, even if they turn out to be false or inaccurate.

In the first chapter, on the Meno, I argued that Socrates endorses the theory of recollection, despite thinking that the demonstration argument is an insufficient proof of its truth. This reading focused largely on an analysis of the disclaimer at $86 \mathrm{~b}$, where Socrates claims to be unwilling to "altogether confidently affirm" something he has said in support of the theory of recollection. I argued that he is wary to 'put his trust in' or 'stake his case for' the theory of recollection on the demonstration argument. It is very likely, given the many weaknesses in the argument that Socrates does not think that he has shown the slave boy recollecting anything. Moreover, I argued that, despite thinking the demonstration argument is insufficient proof of recollection, he endorses the theory anyway, on what appear to be pragmatic grounds. Socrates claims that the theory of recollection will be good to believe, in that one will be better, braver, and less idle if he believes it. Presumably, this just means that, if Meno believes in the theory of recollection, he will be far better off than if he believes the eristic claim that we cannot search for or discover what we do not already know. He will become less intellectually stagnant, insofar as he believes that it is possible to inquire into the nature of unknown entities.

Near the end of this chapter, I also argued that Socrates gives a pragmatic defense of the 
theory of recollection, largely, as a justification for the philosophical way of life. The eristic challenge - that we cannot search out or discover what we do not already know — is an outright attack on Socrates' philosophical method. If we cannot search for or discover what we do not know at present, then it makes no sense to devote one's life to the pursuit of truth and knowledge. If Meno is correct about the possibility of inquiry, then philosophy would seem to be a complete and utter waste of time. If, however, an account like the theory of recollection is correct, then, inquiry is entirely possible. An account, like the theory of recollection, which explains how we come to have knowledge, by uncovering whatever it is that lies undiscovered in the soul, provides for the possibility of searching out and discovering what we do not know at present.

Of course, this is not an entirely sufficient explanation. Why should Socrates recommend a belief in a view for which he has given only a very weak argument, one that, as we saw, is full of logical and methodological holes? Vlastos, in the conclusion of his influential essay, formulates this challenge as follows:

None of the scholars who have seriously believed that Socrates employed insincere beliefs or consciously fallacious inferences in these or other arguments has ever tried to explain how such infidelity to the quest for truth could be reconciled with Plato's concept of Socratic philosophizing. ${ }^{195}$

Why, indeed, should Plato of all people include unconvincing arguments and pragmatic reasons in the dialogues? It seems inconsistent with his commitment to the pursuit of truth that he should ever portray Socrates giving bad arguments, making false claims, or giving non-veridical reasons for belief. It seems extremely un-Platonic that Socrates should endorse any view for which he has not given a sufficient proof. This problem is complicated in the Meno by the fact that Socrates seems to present an unconvincing argument for, of all things, the philosophical way of life. Why not convince Meno of the possibility of inquiry through careful dialectical argumentation? This would, after all, seem to be more in line with Plato's thinking about when it is appropriate to form a belief.

In the next chapter, on the Phaedo, I began to argue for a solution to this problem. In 
large part, my arguments were focused on another disclaimer passage, which bears a striking resemblance to the disclaimer in the Meno. In the Phaedo, Socrates delivers a myth in order to address the little-discussed otherworldly rewards premise. Once again, however, following the myth, at 114d, Socrates claims that a reasonable person would not 'put his trust in' or 'stake a case on' the description of the afterlife he has just presented. He does not seem to think that it is reasonable to accept such a story. It follows, I argued, that such story is insufficient proof, of the sort a reasonable person would demand, for the view that we are rewarded in the afterlife according to our earthly merits. Nevertheless, Socrates endorses this claim on pragmatic grounds; believing in a myth of the sort he has told will motivate his listeners to care for their souls by pursuing philosophy. Once again, Socrates endorses an important philosophical claim on a non-veridical basis. He claims that it will be good to believe some story in support of the otherworldly rewards premise, and that it is therefore appropriate to believe it.

This chapter provides us with another case in which Socrates defends a poorly argued claim on non-veridical grounds. In addition, as I mentioned above, in this chapter I advanced a reason for these non-veridical reasons for belief. There are, I argued, a certain class of claims, which it may be appropriate to believe, even if they might turn out to be false. The reason that it is appropriate to believe such claims is that, even if they are false, they do not harm the soul in the way that other false claims do. We saw that, in the Phaedo, false belief is harmful to the soul for two reasons. First, accepting false beliefs leads a person to believe other false things. His entire system of beliefs suffers from accepting falsehoods. Second, believing false things deprives a person of his motivation to go looking for the truth. Thinking that he has the truth in hand, a person will not have any reason to correct himself. What we have seen, however, is that the theory of recollection and the otherworldly rewards premise, even if they turn out to be false, are not like other falsehoods in these respects. They are unlikely to beget other potentially false beliefs in the soul. Nor are they likely to cause a person to lose motivation to seek the truth. Instead, both are claims which, even if they turn out to be false, provide a person with the motivation to pursue philosophical inquiry. The theory of recollection encourages a person to think that inquiry is possible and worthwhile - and that he can discover all that he does not already know. Similarly, the otherworldly rewards premise leads a person to do philosophy: it is 
only through the perfection of his soul, by studying philosophy, that a person secures the greatest rewards in the afterlife. In other words, whereas most falsehoods make is so that a person accepts other falsehoods and has no reason to inquire further-thinking that he already knows the truth - each of these views is special in that it opens one up to the need to perfect one's beliefs through a lifetime of questioning.

In the third chapter, we saw a similar, although slightly more complex case from the Phaedrus. Following the palinode, in which Socrates defends love, he once again seems to disclaim something of what has come before. The difference is: here he claims that something in his two speeches about love has been misleading. Socrates is not simply expressing a lack of confidence in one of his arguments or proofs. Instead, he seems to be admitting to have put forward one or more claims which he believes to be false. In my analysis of the palinode, I identified a number of possible false claims: the elision between philosophy and madness, the immortal soul and mortal soul, and love and philosophical love. If I am correct in this analysis, then, the Phaedrus disclaimer is quite a bit stronger than the disclaimers of the first two chapters. And, it is all the more problematic. Why, after all, should Socrates be justified-not only in giving arguments he recognizes as weak - but in actually misleading his interlocutors? How does this evidence square with the notion that Socratic-Platonic philosophy aims always at the truth? In answer this question, I suggested that, in keeping with the other disclaimers we have seen, the misleading claims of the palinode might also be understood as special sorts of claims, which are beneficial even if they are false. Socrates equivocates between philosophy and madness, the soul in its immortal state and its mortal state, and between love generally and philosophical love, all in the service of convincing Phaedrus to study philosophy. At the end of the dialogue, even if Phaedrus believes each of these claims, he will be in a far better position than the position in which he began. Rather than think that rhetoric is the proper course of study, he will have come to believe that philosophy is a far more valuable way of life. As a result, he stands a chance of, one day, coming to have knowledge of the truth. In short, this would appear to be yet another case of non-veridical reasoning in the dialogues. Although Socrates does not come out and say that he endorses the claims of the palinode for pragmatic reasons, it seems very likely that his reason for putting forward these claims is in the service of convincing Phaedrus of a better way 
of life.

\section{A note on subversive interpretation}

If I am correct in my analysis of these dialogues, then there are times when it is inappropriate to take the arguments of the dialogues at face value. In fact, in the three cases presented herein, to force an interpretation of these arguments, making them out to be valid and sound, would be to misinterpret Plato.

We ought, however, to be careful not to take this study as advancing a somewhat different view, one that I have not discussed at any length. In the last century, a number of influential scholars have argued that, with respect to his political philosophy in particular, Plato was anything but concerned with truth-telling. Leo Strauss, in the City and Man, championed an interpretive approach, according to which a careful reader of the dialogues is supposed to pay attention to the "silence and action of Socrates which is not identical with his speech". ${ }^{196}$ Strauss was an advocate of a style of interpretation, which took as a fundamental assumption the fact that the dialogues themselves contain important exclusions and deliberate falsehoods. Accordingly, he held that it was the job of the careful reader to employ his understanding of those deliberately excluded facts - facts about the characters, history, political strife, etc. - in order to discern Plato's own undisclosed views, which could, at times, be radically different from the views expressed in the dialogues.

This study has given rise to a number of conclusions that are reminiscent of the Straussian approach, in the sense that the view I have defended, if it is correct, supports a method of close reading, with an eye to whether or not particular passages are intended as good arguments. Like the Straussian approach, then, my view suggests that there are times at which it is inappropriate to take the arguments in the dialogues completely at face value. Nevertheless, the approach I have suggested in this study is different from the Straussian approach in at least two ways. First, I have focused exclusively on cases in which we have some reason to believe, based on what is recorded in texts themselves, that Plato has advanced a claim or argument that he recognizes as unconvincing or misleading. This is just to say that this study focuses exclusively on disclaimer passages — on instances in which Socrates draws his interlocutors' 
attention back to some weakness or falsehood in the arguments he has presented. In this way, this study avoids one potential weakness in the Straussian approach, insofar as we can be sure that we are not inventing the need to read these texts subversively. Each of the cases I consider is one in which Plato is himself aware of having advanced imperfect arguments or false claims. Second, whereas the Straussian approach suggests that there are a number of deliberate falsehoods included in the dialogues, as a result of Plato's own social and political view, the cases I am considering are not so much deliberate falsehoods, as they are bad or unconvincing arguments for, what Socrates seems to think, are true conclusions. Each of the cases I have been considering, is one in which Socrates seems, ultimately, to believe the conclusions towards which he is driving. In the Meno, for instance, I have argued that Socrates endorses the theory of recollection, despite thinking that he's given a bad argument for it. Similarly, in the Phaedo, Socrates is eager to believe the myth in support of the otherworldly rewards premise, despite thinking that such a story is unreasonable to believe. In both, what is at issue is not so much whether Socrates believes the view in question, so much as it is whether he thinks he has given a good argument for it. Although the Phaedrus case is somewhat different-Socrates there defends a number of false claims, ones that he does not seem to believe - this case, too, is ultimately one in which Socrates believes the conclusion towards which he is driving. He may advance a number of elisions in the palinode, but he seems to believe the conclusion of the speech nevertheless, that one ought to perfect his soul through the pursuit of philosophy. In contrast to the Straussian approach, all the cases I have put forward in this study share in the fact whatever contains unconvincing or misleading arguments they contain are put forward in the service of a conclusion which Socrates ultimately believes - that philosophy is the best sort of life.

\section{Disclaimers and pragmatic reasons: why do it?}

At the end of this study, a number of important questions remain. Chief among them is a question of motive or warrant - why should Plato not have simply stuck to giving good arguments on the part of Socrates? Plato could, presumably, have given a better proof of each of the claims in question. For example, in the Meno, it is noticeable that Socrates gives a shoddy demonstration of the theory of recollection, when in the Phaedo, he gives a much more thorough 
argument. So the question is, why not attempt a better sort of argument in the Meno? Or, if Plato had yet to work out his views about the theory of recollection, why not simply have Socrates admit his own ignorance? Why not simply tell Meno that the theory of recollection, if it is true, constitutes a counterexample to the eristic argument, and therefore provides for the possibility of inquiry - but that the theory of recollection is something of which he, Socrates, has yet to prove sufficiently? His own ignorance is, after all, something which Socrates has no trouble admitting in other places in the dialogues. Similarly, Plato could have Socrates say nothing at all. He could put forward a shoddy argument, and, insofar as his interlocutor accepts it, pass without any effort onto another topic. The question is, why have Socrates give an incomplete, unconvincing, or flawed argument, if only to disclaim it a few lines later?

A closely related puzzle concerns Plato's use of pragmatic reasons. Although this study has made some progress in showing how pragmatic reasoning is consistent with Platonic thought - insofar as the claims Socrates endorses with pragmatic reasons seem to be of a particularly harmless sort-I have nevertheless advanced no explanation as to what might motivate Plato to resort to them. Again, the question seems to be, why not simply give veridical reasons? If arguments which address the truth of a given claim are in fact the gold standard, if indeed the pursuit of the truth is what is most important in philosophical investigations, then why resort to anything but veridical arguments? Another helpful way of formulating these questions is to ask them in tandem: if Plato's pragmatic reasons are, indeed, sufficient for belief, why does he go to the trouble of presenting arguments for the truth of the conclusion in question? If Plato accepts the pragmatic reasoning, of the form "it is good to believe $\mathrm{x}$, therefore you should believe x", why ever give arguments for the truth of a claim? Why not simply present his pragmatic reasons, insist that this justifies belief, and move on?

Of course, there are many possible answers to the question of motivation, all of which are highly speculative. It is impossible to say with any certainty why exactly Plato might choose to flag Socrates' unconvincing arguments or argue on grounds other than the truth of the claims in question. Still, it might be useful, as a matter of conclusion, to consider a number of the more philosophically fruitful possibilities. In what follows, I present, two possible answers as to how these bad arguments paired with pragmatic reasons function in the dialogues. 


\section{A didactic function}

Scholars often note that the dialogues serve a didactic function, not just in the sense that they portray Socrates educating the men of Athens, but also in that they seem to serve as educational texts for the reader. This view may help to explain the reason for which Socrates sometimes flags his less successful arguments, following up with pragmatic reasons for belief. Let us first consider the effect of the disclaimers on a reader. When we encounter one of these disclaimers, the effect is to question what has come before. Because Socrates claims that there has been something unconvincing or misleading in what has come before, the careful reader is forced to return to the arguments in question, reevaluating their strength. The didactic function of the disclaimers, then, is to draw the reader back into a discussion of the arguments in question.

But what of the pragmatic reasons? What is their role? It may be that these also have a didactic function. Throughout this study, we have noted that the claims in question, the theory of recollection, the otherworldly rewards premise, and the defense of philosophical love in the palinode provide motivation for the philosophical way of life in the face of eristic and sophistic challenges. In this way, these claims seem to motivate the interlocutors to study philosophy. There is, I think, a very similar effect on the reader. Consider the case of the Meno; the careful reader, like Meno, will be in a state of puzzlement after the introduction of the eristic challenge. If, however, he realizes that the demonstration argument is less than satisfactory, he will remain puzzled. Is inquiry possible? Does it even make sense to pursue the truth? These problems stand in the way of our returning to the philosophical questions themselves. Even the careful reader, if he is taken with the eristic challenge, may not think it possible to discover what we do not already know. For him, then, the pragmatic argument is necessary, in that it motivates him in the face of the eristic challenge, to continue the investigation. All of the pragmatic reasons might be understood in this way, as motivating the both Socrates' interlocutors and Plato's readers to continue looking into the deep and important philosophical questions at hand.

\section{Stop gaps}

This answer takes its inspiration from the fact that the two phenomena I've been considering 
seem to appear in unison. Socrates does not simply flag problems in his arguments and move on. Instead, in the cases in question he flags a problem in his argument, and follows this with a pragmatic reason to believe the claim in question. Even in the Phaedrus, where the pragmatic reason is most implicit, we are told that it will be good to believe the palinode so that we might appease the god of Love. We might wonder, therefore, what is the function of this particular structure-why the unconvincing argument followed by a pragmatic argument?

It may be that Socrates uses pragmatic reasons as stop gaps. Consider that the ultimate goal of philosophy is to have knowledge of the truth. Certainly, nothing we have seen suggests that pragmatic reasons, of the form " $\mathrm{x}$ is good to believe, therefore it is appropriate to believe $\mathrm{x}$ ", are sufficient for knowledge. Instead, Socrates seems only to be claiming that it is appropriate to adopt a belief in the claims in question insofar as they will motivate a person to search for the truth. It is very likely that Plato still maintains the view that the way to have knowledge of the truth is through the use of veridical arguments - those that determine the truth of matters through careful deductive reasoning. Nevertheless, for practical reasons, because philosophy is difficult and time consuming, Plato may not have the time or the wherewithal to completely work out such an argument. His interlocutors are often young, like Phaedrus, who is perhaps not yet ready for a more thorough explanation of the value of love. Some, like Meno, although they are not young are philosophically resistant. At every turn Meno resists Socrates attempts to pursue virtue; Socrates must, therefore, take immediate measures to keep him motivated. In the Phaedo, the conflict is not so much with the interlocutors as it is with time itself. Socrates, on the day of his death, does not have the time or the wherewithal to completely rehearse an argument for the otherworldly rewards premise. On this occasion a myth will have to do.

Of course, pragmatic reasons are not themselves sufficient for knowledge. Perhaps the best indication we have of this view is that, although Plato sometimes puts forward pragmatic reasons as stop gaps, running short on time or facing a resistant interlocutor, he nevertheless always tries to show what a veridical argument would look like. In other words, Plato's the pragmatic reasons are a last resort, providing us with the motivation to continue, and signaling that an argument for the conclusion in question needs to be better worked out. For the sake of progress, Socrates claims that it is appropriate to believe those conclusions that are good for us to 
believe - especially those, like the theory of recollection, which support the philosophical way of life.

In conclusion, it appears that Platonic pragmatism is very likely motivated by real-world concerns about teaching philosophy. It is a way in which Plato encourages his students to continue in the pursuit of truth, despite not having all the answers worked out. Because philosophy is hard, because it is time-consuming and difficult, we will not always be able to produce arguments for our views on the spot. But this doesn't stop us from having to make choices about what to believe. In cases where we are faced with a choice between different views, between, say, Meno's paradox and the theory of recollection, Plato believes that it is perfectly appropriate to choose to believe the view which is most beneficial, especially if it is a view which defends the very value of philosophical inquiry. 